University of Rhode Island

DigitalCommons@URI

Open Access Dissertations

2005

\title{
APPLICABILITY OF THE TRANSTHEORETICAL MODEL IN WEIGHT \\ MANAGEMENT IN AN ADOLESCENT POPULATION IN TAIWAN
}

Yating Yeh

University of Rhode Island

Follow this and additional works at: https://digitalcommons.uri.edu/oa_diss

\section{Recommended Citation}

Yeh, Yating, "APPLICABILITY OF THE TRANSTHEORETICAL MODEL IN WEIGHT MANAGEMENT IN AN ADOLESCENT POPULATION IN TAIWAN" (2005). Open Access Dissertations. Paper 1054.

https://digitalcommons.uri.edu/oa_diss/1054

This Dissertation is brought to you for free and open access by DigitalCommons@URI. It has been accepted for inclusion in Open Access Dissertations by an authorized administrator of DigitalCommons@URI. For more information, please contact digitalcommons-group@uri.edu. 
APPLICABILITY OF THE TRANSTHEORETICAL MODEL IN WEIGHT MANAGEMENT IN AN ADOLESCENT POPULATION IN TAIWAN

BY

YATING YEH

A DISSERTATION SUBMITTED IN PARTIAL FULFILLMENT OF THE REQUIREMENTS FOR THE DEGREE OF

DOCTOR OF PHILOSOPHY

IN

PSYCHOLOGY

UNIVERSITY OF RHODE ISLAND

2005 


\begin{abstract}
Westernized dietary preferences and life-styles are thought to have a significant impact on the increasing prevalence of obesity in Asian populations. The increased numbers of overweight and obese adolescents is becoming an emerging health issue in Asia. Meanwhile, previous studies have indicated that adolescents' self-perceived weight is poorly related to the medical definition of overweight and considerable numbers of clinically normal-weight persons are trying to or wish to control weight. Due to the considerable prevalence of desire for weight control among adolescents who are not overweight /obese, it is important for researchers to look at the issue of weight management in non-clinical populations.
\end{abstract}

The main goal of the investigation was to examine the applicability of the concepts of decisional balance and self-efficacy in weight management behavior in an adolescent population in Taiwan. The first step was to develop and evaluate a 14-item Chinese version of Decisional Balance Inventory; and a 15-item Weight Efficacy Questionnaire using a sample of 491 adolescents in a high school in Taiwan. Using split-half, cross-validation procedures, a two-factor decisional balance model fit the data best ( $\mathrm{CFI}=.971, \mathrm{RMSEA}=.042)$ with good internal consistency for both Pros $(.85)$ and Cons (.72). Using split-half, cross-validation procedures, a hierarchical four-factor self-efficacy model fit the data well $(\mathrm{CFI}=.940, \mathrm{RMSEA}=.059)$ with adequate internal consistenc) for all scales: negative emotion (.80), availability and positive activities (.80), social pressure (.68), and physical discomfort (.80). External validity of the scales was assessed with MANOVA, ANOVAs, and follow-up Tukey tests examining the relationships between decisional balance and Stage, and the relationships between selfefficacy and Stage. Results from multiple-sample confirmatory factor analyses suggested that gender subgroups could be treated as arising from the same population. Results also indicated that the tau equivalent model, instead of parallel model, was the preferred model for decisional balance and selfefficacy across the two BMI groups. Results supported the reliabilities and validities of the Decisional Balance Inventory and Weight Efficacy Questionnaire, and suggested that these measures are similar to the measures for US adolescents. These measures may be useful for developing and tailoring interventions to adolescents' level of readiness for weight management. 


\section{Acknowledgement}

I wish to thank Dr. Joseph Rossi, supervisor of the dissertation, for his support in the project. I also thank Dr. Colleen Redding, Dr. Bob Laforge, and Dr. Susan Rossi for providing valuable suggestions.

Finally, I express my gratitude and appreciation to Dr. Orlando Merino, Sandra Pearlman, David Terry; Jan Terry, Dr. Yuanyu Ting, Amitabh Avasthi, Anurag Awasthi, and my family; for instilling their unstinted confidence and support during this project. 


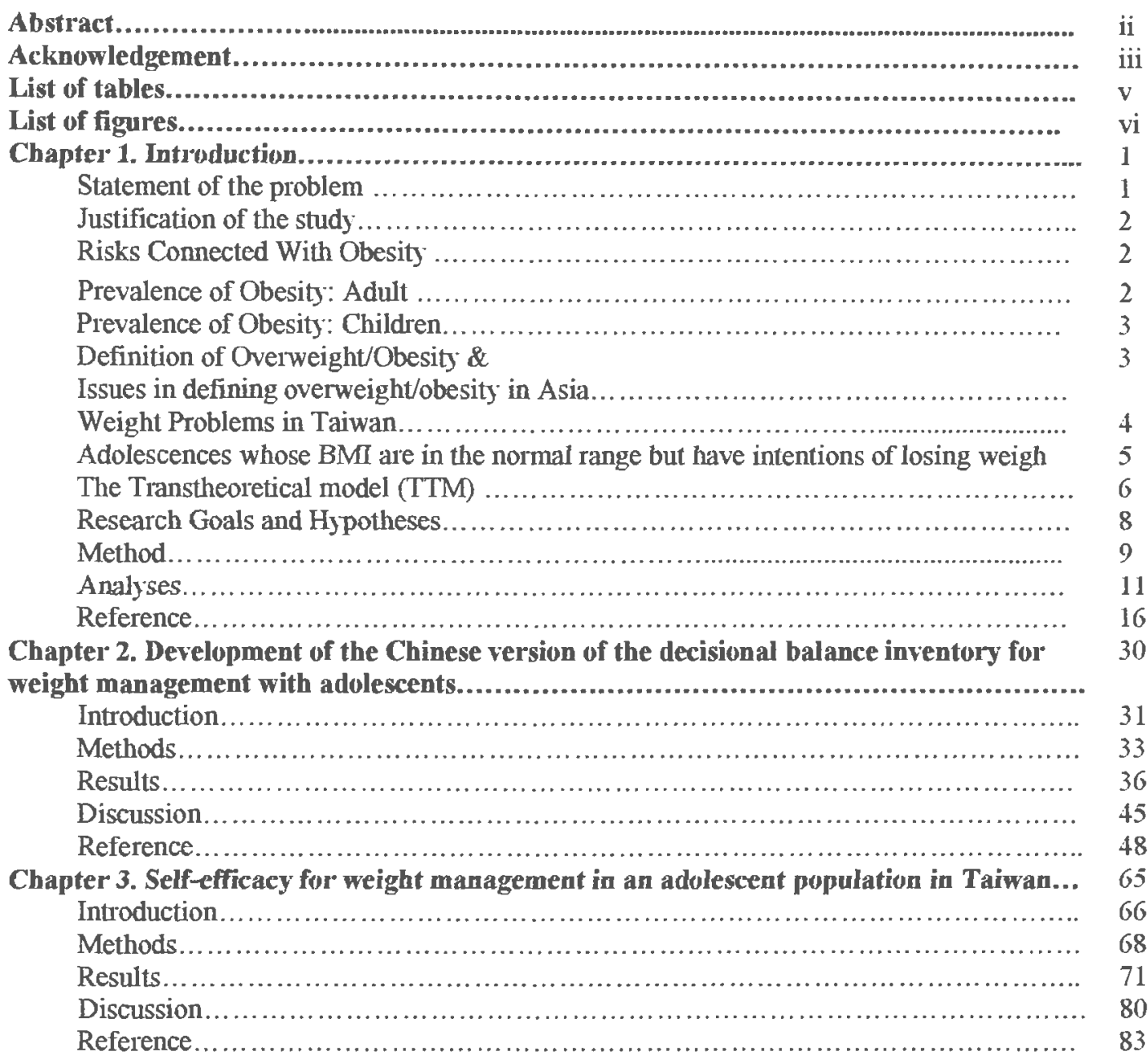

Chapter 4. Prediction of stage of change in weight management from decisional balance and self-efficacy.................................................................................... 10

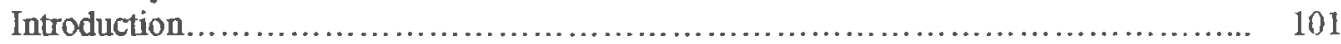

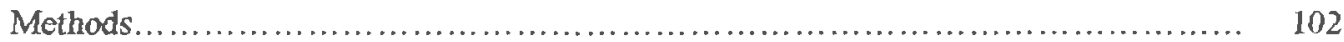

Results....................................................................... 105

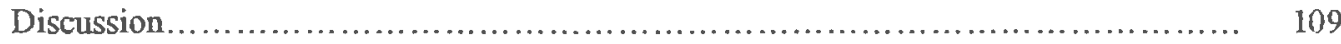

Reference ...................................................................... 111

Chapter 5. Conclusions, limitations and future directions................................. 120

Summaries of research results ................................................... $\quad 120$

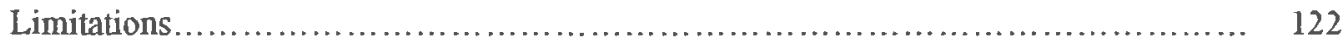

Future direction............................................................... 122

Appendices

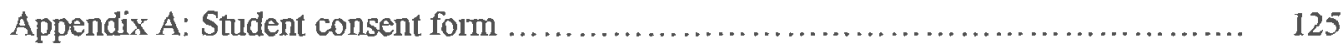

Appendix B: Student consent form Chinese version............................. 126

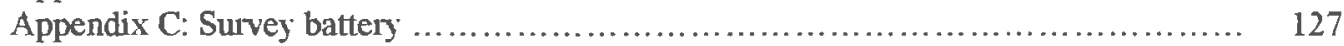

Appendix D: Survey battery Chinese version.................................. 130

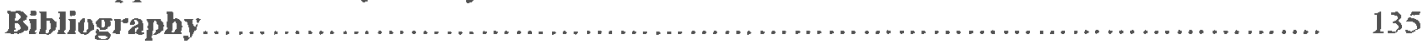




\section{List of tables}

Table 1.1. Original sample: BMI distribution by school year and gender.................... 24

Table 1.2. Overall sample used in analyses: BMI distribution by school year and gender..... 25

Table 1.3. Parents' Education level................................................. 26

Table 1.4. Overall sample used in analyses: BMI distribution by intention of weight

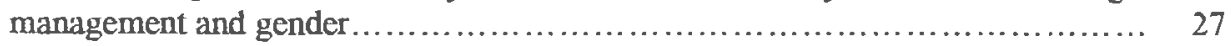

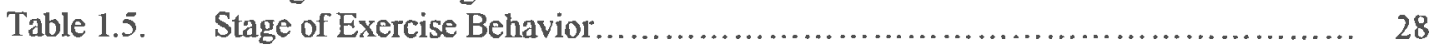

Table 1.6. Days of exercise within previous month................................... 29

Table 2.1. Summary statistics for Decisional Balance Inventory (by item): sample 1.......... 53

Table 2.2. Items by scale and varimax pattern for the Decisional Balance Inventory.......... 54

Table 2.3. Means, standard derivations, and coefficient alphas for Decisional Balance $\quad 55$

Inventory Chinese version

Table 2.4. Summary statistics for Decisional Balance Inventory (by item): sample 2....... 56

Table 2.5. Decisional Balance Inventory Chinese edition: Summary of model fit indices.... 57

Table 2.6. Summary statistics for overall participants................................... 58

Table 2.7. Summary Statistics by Stage of Change $\quad$...................................... 59

Table 2.8. Summary of Multiple Sample Model Results.............................. 60

Table 3.1. Summary statistics of Weight Efficacy Questionnaire (by item): Sample 1........ 87

Table 3.2. Items by scale and varimax pattern for the Weight Efficacy Questionnaire 88 $(\mathrm{N}=244)$

Table 3.3. Means, standard derivations, and coefficient alphas for Weight Efficacy $\quad 89$

Questionnaire Chinese version

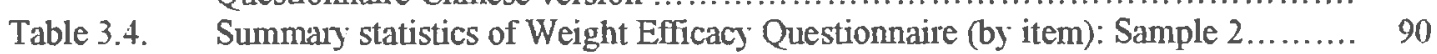

Table 3.5. Weight Efficacy Questionnaire: Summary of model fit indices ................. 91

Table 3.6. Summary Statistics: : Self-efficacy (by BMI status) .......................... 92

Table 3.7. Summary Statistics: : Self-efficacy (by gender and Stage) $\quad$..................... 93

Table 3.8. Summary Statistics: : Self-efficacy (by BMI status and Stage).................. 94

Table 3.9. Weight Efficacy Questionnaire: Summary of Multiple Sample Model Results..... 95

Table 4.1. Summary Statistics: self-efficacy and decisional balance ....................... 113

Table 4.2. Correlation: Self-efficacy and decisional balance $(\mathbb{N}=491) \ldots \ldots \ldots \ldots \ldots \ldots \ldots . . \ldots \ldots$

Table 4.3. Pooled Within Canonical Structure........................................ 115

Table 4.4. Group Centroids (Class Means on Canonical Variables) ....................... 116

Table 4.5. Classification of Stage of Change .......................................... 117 


\section{List of figures}

Figure 2.1. Two correlated factor model for decisional balance....................... 61

Figure 2.2: $\quad$ Overall participants: Standardizes T score pattern for decisional balance........ 62

Figure 2.3. Participants with normal BMI: Standardizes T score pattern for decisional balance................................................................ 63

Figure 2.4. Participants who were overweight or obese: Standardizes T score pattern for decisional balance....................................................... 64

Figure 3.1. Four correlated factor model for self-efficacy ............................. 96

Figure 3.2. Hierarchical model for self-efficacy ..................................... 97

Figure 3.3. Overall participants: pattern for self-efficacy .................................. 98

Figure 3.4. Participants with normal BMI: pattern for self-efficacy ...................... 99

Figure 3.5. Participants who were overweight or obese: pattern for self-efficacy........... 100

Figure 4.1. Group Centroids: first function .......................................... 118

Figure 4.2. Group Centroids: second function ...................................... 119 


\section{Chapter 1. Introduction}

\section{Statement of the Problem}

It is estimated that each year nearly 300,000 adults in the United States die of causes related to obesity (Allison, Fontaine, Manson, Stevens, \& VanItallie, 1999), confirming the widely acknowledged link between obesity and increased morbidity and mortality (Allison \& Saunders, 2000; Bray; 1985 ; Feinleib, 1985; Gidding. 1995, Hoffmans, Kromhout, de Lezenne, \& Coulander, 1988; Kissebah, Freedman, \& Peiris, 1989; Manson, Willett, Stampfer et al., 1995; Simopolous, \& Van Itallie, 1984). Obesity is also identified as a substantial predictor of long-term morbidity and premature mortality (Alexander, Sherman \& Clark, 1991; Rocchini, Katch, Schork \& Kelch, 1987; Srinivasan, Bao, Wattigney, \& Berenson, 1996), and is related to numerous health concerns in the United States (Allison \& Saunders, 2000). With the population of obese or overweight persons growing rapidly, the diseases associated with these conditions constitute a serious public health issue.

This increase is not limited to major industrialized countries, but is also becoming an emerging health issue throughout the developing world (Rössner, 2002). Findings on diseases related to obesity; as well as statistics showing increased incidence of obesity in the adolescent population in Asia, strongly suggest the importance of weight control in that demographic, and underscores the immediate need for effective intervention by health professionals. In the long run, prevention of obesity will have significant pay-offs in terms of the cost from weight problems.

Due to the considerable prevalence of desire for weight control among normal-weight adolescents (Brugman et al, 1997; Kaneko, Kiriike, Ikenaga, Miyawaki, \& Yamagami, 1999; Neumark-Sztainer, Rock, Thornquist, Cheskin, Neuhouser, \& Barnett, 2000; Nowak, Speare, \& Crawford, 1996; Strauss, 1999; Steen, Wadden, Foster, \& Andersen, 1996), it is also important for researchers to look at the issue of weight management in non-clinical populations (i.e., people whose Body Mass Index, BMI, is in the normal range but who intend to lose weight).

Weight management is a multi-dimensional issue because an individual's weight is linked to medical, psychological, sociocultural, and economical factors. Therefore, it is essential that health professionals use the sound framework of behavioral science theories to investigate weight problems in Asia. The Transthoeretical Model (TTM; Prochaska, DiClemente, \& Norcross, 1992), an empirically 
supported theor; could serve as the framework for investigating the issue. The main aim of this investigation is to examine the applicability of TTM to weight management behavior in an adolescent population in Taiwan.

\section{Justification of the Study}

Risks Connected With Obesity

Obesity is associated with increased risk for various disorders such as coronary heart disease. adult and pediatric hypertension, serum lipid, diabetes mellitus, noninsulin-dependent diabetes mellitus, adult-onset (type II) diabetes, gall bladder disease, dyslipidemia, atherosclerotic disease, cardiovascular disease, sleep apnea, musculoskeletal disorders, islipidemias, gallstones, osteoarthritis, lower back pain, infertility, and some forms of cancers (Abbott, Wilson, Kannel, \& Castelli, 1988; Alexander, Sherman \& Clark, 1991; Barrett-Connor, 1985; Criqui, Barrett-Connor, Holdbrook, Austin, \& Turner, 1980; Gidding, 1995; Hubert, 1986; Kannel, \& Wilson, 1995; Pi-Sunyer, 1991; Rocchini, Katch, Schork \& Kelch, 1987; Rössner, 2002; Srinivasan, Bao, Wattigney, \& Berebson, 1996). It also has devastating psychosocial consequences (Dietz, 2002).

Prevalence of Obesity: Adult

Statistics on obesity reveal a shocking picture of the degree to which the problem is widespread. Based on World Health Organization (WHO) data, nearly a half billion of the world's population is now considered to be overweight or obese. Moreover, there is a considerable global increase in this demographic. The increased number of overweight and obese people is not limited to major industrialized countries, but is also becoming an emerging health issue throughout the developing world (Rössner, 2002). Obesity is rapidly replacing malnutrition as a serious health problem in developing countries. In China, for instance, between 1989 and 1992, the number of overweight individuals increased from $9 \%$ to $15 \%$.

Recent data from the United States indicate that the prevalence of obesity is approximately $35 \%$ (Mokdad, Ford, Bowman, Dietz, Vinicor, Bales, \& Marks, 2003). In addition, obesity is also common and on the rise in Europe. The International Obesity. Task Force (IOTF) conducted studies in individual European nations showing the presence of obesity in 10 to $20 \%$ of the male population and 
10 to $25 \%$ of the female population. That is an increase of approximately 10 to $40 \%$ in the past 10 years.

Prevalence of Obesity: Children

Obesity in children is growing and becoming a more pervasive health problem worldwide (Troiano, Flegal, Kuczmarski, Campbell, \& Johnson, 1995). The National Health and Nutrition Examination Survey (NHANES) conducted in the US in 1999-2000 reported the prevalence of overweight children to be $15.5 \%$ among 12 through 19 -year-olds, $15.3 \%$ among 6 through 11 -year-olds, and $10.4 \%$ among 2 through 5 -year-olds. This is an increase from with $10.5 \%, 11.3 \%$, and $7.2 \%$, respectively; in 1988-1994 (NHANES III). In addition, the number of overweight children is growing rapidly in many countries in Europe (Ebbeling, Pawlak, \& Ludwig, 2002; Guillaume, \& Lissau, 2002; Wang, Monteiro, \& Popkin, 2002). The number of overweight children in the 7 to 11 year age group in the UK rose from $8 \%$ to $20 \%$ between 1984 and 1998 (Lobstein, James, \& Cole, 2003). In Spain, the percentage of overweight children aged 6-7 years increased from $23 \%$ to $35 \%$ in the period June 1985 to June 1995 (Moreno, Sarría, \& Popkin, 2002).

Definition of Oyerweight/Obesity \& Issues in defining overweight/obesity in Asia

Obesity is defined as a status of excessive fat accumulation in the body to the level that health and well-being are adversely affected (World Health Organization, 2000). A popular index to describe the individual's weight status is the Body Mass Index (BMI), which is defined as body weight (kg) divided by squared body height $\left(\mathrm{m}^{2}\right)$. By the operational definition, obesity is defined as BMI $\geq 30 \mathrm{~kg} /$ $\mathrm{m}^{2}$; while overweight is described as $\mathrm{BMI} \geq 25 \mathrm{~kg} / \mathrm{m}^{2}$ (World Health Organization, 1998),

However, the appropriateness of adopting BMI greater than 25 for defining overweight and BMI greater than 30 for obesity for the Asian population has been questioned.

There are a least two reasons to believe why the "Western" BMI cut off might be inappropriate when applied to Asians. First, it has been shown that a different BMI/ percent body fat (BF\%) relationship among ethnic groups might result in different cut-off points for obesity, since obesity is defined as a condition where there is excess body fat (WHO, 2000). Empirical research and metaanalysis have shown that there is an inconsistent relationship between BMI and percent body fat (BF\%) across various ethnic groups (Chang, Wu, Chang, Yao, Yang, Wu, \& Lu, 2003; Deurenberg, 
Deurenberg-Yap, \& Guricci, 2002; Deurenberg, Yap, Staveren 1998). Research suggests that BMI cutoff and percent body fat should be ethnic-group-specific. It is generally indicated that Asians have a lower BMI but a higher BF\% than Caucasians of the same age and sex (Deurenberg-Yap. Schmidt, van Staveren, \& Deurenberg, 2000; Guricci, Hartriyanti, Hautvast, \& Deurenberg, 1998; Wang. Thomton, Russell, Burastero, Shen, Tanenbaum, Heymsfield, Pierson, 1996). For instance, research suggests that Taiwanese have a higher BF\% than Caucasians in any given BMI (Chang, Wu, Chang, Yao, Yang, Wu, $\&$ Lu, 2003). Secondly; from the viewpoint of the risk factors for morbidity and mortality; it might be more practical to have ethnic-group specific BMI cutoff. The reason is that the prevalence of obesity would be low in Asia-Pacific region when based on WHO obesity cutoffs (World Health Organization, 1998). However, the prevalence of cardiovascular diseases and diabetes mellitus were similar for AsiaPacific region and Western countries (Deurenberg- Yap, Tan, Chew, Deurenberg, \& van Staveren, 1999; Lu, Yang, Wu, Wu, \& Chang, 1998). For instance, research suggests that the prevalence of hypertension, diabetes, and hyperuricemia is higher for Taiwanese than for white Americans across most BMI values. Moreover; as the BMI increases, Taiwanese are at a higher risk for hypertriglyceridemia and hypertension, as compared to white Americans (Pan, Flegal, Chang, Yeh, Yeh, Lee, 2004). The Japan Association for the Study of Obesity (JASSO) has been reported to be considering lowering the cutoff for obesity to BMI greater than 25 (Inue, 2002). Research conducted in China suggested that the cutoff for defining overweight should be lowered to between $24.0-27.9$ and greater than 28 for obesity ( $\mathrm{Wu}, 2002$ ). With regards to children, different cut-off points have been used in Taiwan. For instance, for a 16 year-old female group, the cut-offs of BMI for overweight and obesity are 22.7 and 25.3, respectively (Department of Health in Taiwan, 2002).

\section{Weight Problems in Taiwan}

A cross-sectional survey among junior high school students in Taipei in 1994 indicates the percentage of overweight children remained stable from 1980 to 1994 in both genders; however, the incidence and tendency of obesity increased considerably, especially among boys and older girls (Chu, 2001). Another survey in the first grade of primary schools in Taichung City; Taiwan, shows that the prevalence of overweight was 11.07 percent in boys and 11.64 percent in girls, while the occurrences of obesity was 14.19 percent in boys and 12.89 percent in girls ( $\mathrm{Lai}, \mathrm{Ng}, \mathrm{Lin}, \& \mathrm{Chen}, 2001$ ). In a 2002 
nationwide survey of 86,967 children and adolescents in Taiwan and Fuchien Areas, the prevalence of obesity was $18.5 \%$ in males and $15.0 \%$ in females. In comparison to results from 1997 , the prevalence of childhood and adolescent obesity for both sexes was higher in 2002 . The 2002 survey implies an increasing prevalence of obesity during childhood and adolescence for both genders in recent years (Huang. Wu, \& Yang, 2003).

Adolescences whose BMI are in the normal range but have intentions of losing weight

Cultural and psychosocial factors have been considered as important determinants of overconcern of weight and body in Western society (Paquette \& Raine, 2004; Rodin, 1993). These cultural and psychosocial contributors may include ideal of attractiveness, attributes of being thin (Brownel1, 1991), body image and other factors (Paquette \& Raine, 2004; Rodin, 1993).

Previous studies have indicated that the adolescent population's self-perceived weight is poorly related to the medical definition of overweight, and considerable numbers of clinically normalweight persons are trying to or wish to control weight. For example, in the NHANES III sample, $52 \%$ of girls who perceived themselves as overweight were actually of normal weight, while $25 \%$ of boys who believed themselves to be overweight were of normal weight (Strauss, 1999). Similarly, the 1999 National Youth Risk Behavior Survey showed that $43 \%$ of students were trying to lose weight; however, only $25 \%$ of U.S. high school students were either overweight ( $11 \%$ ) or at risk for becoming overweight (14\%) (Lowry, Galuska, Fulton, Wechsler, \& Kann, 2002). A survey conducted in adolescents from four regions of the United States further showed that $44 \%$ of adolescent girls and $37 \%$ of adolescent boys reported current weight-control behaviors (Neumark-Sztainer, Rock, Thornquist, Cheskin, Neuhouser, \& Barnett, 2000). Another survey done in the U.S. showed that $33 \%$ of normalweight girls were dieting (Steen, Wadden, Foster, \& Andersen, 1996).

Research done in North Queensland, Australia indicated that only $41 \%$ of the girls and $54 \%$ of the boys were content with their weight; $52 \%$ of the girls and $27 \%$ of the boys wanted to lose weight (Nowak, Speare, \& Crawford, 1996). Meanwhile, 35\% of the girls and 22\% of the boys were trying to lose weight (Nowak, Speare, \& Crawford, 1996).

In Europe, the similar phenomenon was also observed. For example, a survey among 1359 secondary school children in the Netherlands demonstrated that $13 \%$ of girls and $5 \%$ of boys were 
dieting at the time of the health assessment. Among the students who were dieting, $50 \%$ were at risk of being overweight; but the other $50 \%$ were within the normal weight range (Brugman et al., 1997).

The intention of losing weight in non-clinical adolescent populations was observed in Asia as well. One investigation done in the Osaka Prefecture, Japan, showed that $48 \%$ of $10-y$ ear-old females and $84 \%$ of 17-year-old females self-categorized themselves as 'fat' or 'too fat' (Kaneko, Kiriike, Ikenaga, Miyawaki, \& Yamagami, 1999).

The widespread trend of intention of losing weight in non-clinical adolescent populations may not only refect the self-percetions of adolescents, but also refect the cultural ideas of thinness.

The Transthoeretical Model (TTM)

Regardless of clinical or non-clinical populations, weight management should be treated as a multi-dimensional issue due to the fact that obesity is linked with medical, psychological, social, economic and related problems. Therefore, it is important for healthcare professionals, most notably health psychologists, to investigate weight control and management or prevention under the framework of behavioral-science theories based on empirical evidence. Based on research following sound theories, the healthcare professional would be able to develop effective interventions for populations with weight-related problems. The Transthoeretical Model (TTM; Prochaska, DiClemente, \& Norcross, 1992), an empirically supported theory; is one such theory that can serve as the framework for investigating the issue of weight management. The TTM has been applied to numerous aspects of diet and health related problems in various populations including: dietary fat consumption, weight control, diabetes self-management, fruit and vegetable consumption, and calcium intake (Emmons, Marcus, Linnan, Rossi, \& Abrams, 1994; Greene, Fey-Yensan, Padula, Rossi, Rossi, \& Clark, in press; Greene \& Rossi, 1998; Greene, Rossi, Rossi, Velicer, Fava, \& Prochaska, 1999; Hargreaves et at, 1999; Rossi, 1995; Rossi, Rossi, Rossi-DelPrete, Prochaska, Banspach, \& Carleton, 1994; Prochaska, Norcross, Fowler, Follick, \& Abrams, 1992; Rossi, Rossi, Velicer, \& Prochaska, 1995; Vallis et al., 2003). Consequently, the TTM will be used as the framework of the current research.

Stages of change, decisional balance, self-efficacy and processes of change are the main components of the TTM. The current investigation will only focus on stages of change, decisional balance and self-efficacy because of limited research resource. A brief overview introduces the concepts 
of TTM. Stage of Change (SC), the central construct of the TTM, represents a sign of motivational readiness to change. SC makes it possible to understand when particular types of change occur. Five stages of change have been defined for most problem behaviors, including precontemplation, contemplation, preparation, action, and maintenance, with a theoretical sixth stage, termination, proposed for some behaviors, such as smoking cessation (Rossi \& Rossi, 1999).

The decision-making component of the TTM is based on a model first conceptualized by Janis and Mann (1977). Eight specific categories of decision-making were proposed in the Janis and Mann (1977) model; however, only two general dimensions, the pros and cons of behavior change, have been supported consistently by factor analytic studies (Prochaska, Velicer, Rossi et al., 1994). The pros describe positive aspects of changing behavior, including facilitators of change. The cons describe negative aspects of changing behavior and may be thought of as disadvantages to change. In general, the pros of healthy behavior increase as a function of SC whereas the cons decrease. In progressing from precontemplation to action, the pros of a healthy change tend to increase by about one standard deviation; whereas, the cons of change tend to decrease by about one-half of a standard deviation (Prochaska, Velicer, Rossi et al., 1994). These results have led to the development of strong and weak principles of behavior change (Prochaska, 1994).

The self-efficacy dimension of the model was originally based on Bandura's (1977) concept of self-efficacy; but has since undergone considerable elaboration within the context of the TTM. Another similar concept is situational temptations that reflect the intensity of urges to engage in a specific habit when in the midst of difficult situations. Self-efficacy has been found to monotonically increase across the five stages, whereas temptation monotonically decreases (DiClemente et al., 1991; Prochaska, Velicer, Guadagnoli, Rossi, \& DiClemente, 1991).

Processes of change are activities and experiences that people engage in through the stages. Results have suggested ten processes of change (Prochaska, Velicer, DiClemente, \& Fava, 1988). The ten processes could also be categorized into two main processes, Experiential and Behavioral processes. The five Experiential processes of change are consciousness raising, dramatic relief, environmental reevaluation, social liberation and self revaluation. The five Behavioral processes of change are stimulus control, helping relationship, counter conditioning, and reinforcement management. 
The TTM has been applied in many health-related behaviors and areas over the world (e.g., America, Netherlands, Australia, Germany, Japan, France, Bulgaria, Israel, Spain, Canada, Slovakia, United Kingdom, and Singapore). In the field of weight control, TTM has been mostly applied to clinical obese/overweight adult populations (Clark et al., 1991; Prochaska, Norcross. Fowler, Follick \& Abrams, 1992; Rossi, Rossi, Rossi-DelPrete, Prochaska, Banspach \& Carleton, 1994), and in some cases to college student populations (O’Connell \& Velicer, 1998).

\section{Research Goals and Hypotheses}

It is hypothesized that TTM is applicable to Taiwanese adolescent weight management behaviors. Furthermore, it is expected that the results will provide future research investigators and health professionals with information to assist in the development of interventions tailored for Asian adolescent populations. To achieve this purpose, several analytic steps were conducted.

Step 1: The goal of step 1 was to develop Chinese-language versions of the TTM weight control instruments for an adolescent population in Taiwan. The specific objectives for Step 1 were to explore the underlying dimensionality of the decisional balance and self-efficacy Questionnaires. It was hypothesized that two components would best represent the decisional balance data and that five components would best represent the self-efficacy data.

Step 2: This step focused on confirming the validity of TTM weight management measures developed in Step 1. The specific objectives for Step 2 included: (1) to verify the two-factor model for decisional balance for weight control behaviors; and (2) to confirm the five-factor hierarchical model for self-efficacy to manage weight.

Step 3: The purpose of this step was to examine the external validity of the TTM constructs in weight management. The specific objectives were: (1) to examine the relationship between decisional balance and stage of change using Multivariate Analyses of Variance (MANOVA); and (2) to test the connection between self-efficacy and stage of change applying MANOVA.

Step 4: The goals of this step were to examine the level of factorial invariance of the measures (Decisional Balance Inventory, Weight Efficacy Questionnaire) across two sets of demographic variables: (1) high school students with different BMI status, and (2) gender. 
Step 5: The goal of this step was to evaluate the ability of decisional balance and self efficacy to correctly classify high school students into their reported stage of change. A discriminant function analysis was conducted using the decisional balance and self efficacy to predict the five stages of change

\section{Method}

Participants

During the 2005 school year, 780 senior high students from a high school in Taiwan were recruited into a cross-sectional study examining weight management behaviors. Of the 780 students, $492(63.16 \%)$ were first-year senior high students, and 287 (36.84\%) were second-year students; 388 (49.87\%) were male and $390(50.13 \%)$ were female students. The majority of participants' parents had junior, senior, or vocational high school degrees (Table 1.3).

Based on criteria recommended by the Department of Health in Taiwan, the BMI cutoffs for underweight, normal, overweight and obesity among first-year male students were $<18.2,18.2-23,1$, $23.1,25.5$, respectively; while for first-year female students were $<18,18.0-22.7,22.7,25.3$, respectively. The BMI cutoffs for underweight, normal, overweight and obesity among second-year male students were $<18.6,18.6-23.4,23.4,25.6$, respectively; while for first-year female students were $<18.2,18.2-22.7,22.7,25.3$, respectively. The BMI distribution by school year and gender are shown in Table 1.1.

Based on the response on the item asked "how do you feel about your current weight", participants were distinguished as 'with intention of losing weight', 'stay the same weight' and 'with intention of gaining weight'. In this study; the non-clinical population with intention of losing weight and overweight/obese students are the focus. Therefore, students who were underweight and those whose BMI were in normal range with intention of maintaining, or gaining weight were excluded. That was, only students who were either overweight, obese or in the normal range but with the intention of losing weight were included in the analyses. Thus, of the original 780 students, 491 students met the criteria and were used for the analyses in the investigation. The BMI distributions of students used in the analyses were shown in Table 1.2. The BMI distributions of participants by weight management intention and gender were shown in Table 1.4. The sample consisted of 202 males (41.1\%) and 289 
females $(58.9 \%) ; 310$ were first year students $(63.1 \%)$ and 181 were second year students $(36.9 \%)$. The distributions of stages of exercise behavior of students and days of exercise were shown in Table 1.5 and 1.6.

Procedure

The sample was recruited from classes at a senior high school in Taiwan. Participation was anonymous, voluntary, took about 40 minutes, and involved no incentives to the subjects for their participation. Participants were fully provided with complete information regarding the purpose, benefits, and possible risks of the study. They completed questionnaires in the classrooms. The survey was conducted as a paper-and-pencil measure in the participants' classrooms. Procedures of the study were approved by the Institutional Review Board at the University of Rhode Island.

Instruments

The Weight Management questionnaire packages were presented in the following order: demographics information, Stages of Change Measures, Decisional Balance Questionnaire (DBQ), and Weight Efficacy Life-Style Questionnaire (WELSQ). The first language of survey participants is Mandarin Chinese. Thus, all assessments were conducted in Chinese.

The original English-language questionnaires were translated into Chinese and then backtranslated into English by a panel of bilingual psychologists. During the processes of back translation, the equivalence of Chinese and English version was ensured. The questionnaires were then applied to groups of students to verify their understanding of the questions. The necessary modifications were applied to ensure the understandabililty of the instruments.

Stages of Change Measures/ Stage of Weight Management

The stages of change algorithm contains a brief series of questions to measure weight loss intentions and behaviors. Individuals are classified into one of five discrete stage categories. Precontemplation includes those who have no intention of losing or controlling weight in the next six months. Whereas, Contemplation includes those who are not trying to lose or manage weight, but seriously thinking about doing so in the next six months. Preparation includes those who are not trying to lose or manage weight but are seriously thinking about doing so in the next 30 days. The Action Stage includes those who are actively trying to lose or control weight or who have successfully done so 
but for less than six months. The Maintenance stage includes those who have successfully maintained their weight loss for at least six months.

It has been showed that the stages construct is reliable across many other problem behaviors (Marcus, Rossi, Selby, Niaura, \& Abrams, 1992; Prochaska, DiClemente, \& Norcorss, 1992; Prochaska, Norcross, Fowler, Follick, \& Abrams, 1992; Prochaska et al., 1994; Rossi et al., 1995).

Decisional Balance Inventory (DBI)

The Decisional Balance Inventory (DBI) is composed of 20 items and was applied to examine two hypothesized dimensions (i.e., Pros and Cons) of decision making for weight management (O'Connell \& Velicer, 1988). The Pros are positive aspects of changing behavior, including facilitators of change. Examples of Pros include: "I could wear attractive clothing if I lost weight," "My health would improve if I lost weight." The Cons represent negative aspects of changing behavior. An example of a Con is "Trying to lose weight could end up being expensive when everything is taken into account."- Research showed that coefficient Alpha was .91 for the pros scale and .84 for the cons scale (O'Connell \& Velicer, 1988; Rossi et al, 1995).

Weight Efficacy Life-Style Questionnaire (WELSQ)

The Weight Efficacy Life-Style Questionnaire (WELSQ) consists of 20 items to evaluate five dimensions (i.e., Availability, Negative Emotions, Physical Discomfort, Positive Activities, and Social Pressure) of self-efficacy for weight management (Clark, Abrams, Niaura, Eaton, \& Rossi, 1991). Using a 10-point Likert-type format, respondents are asked to rate their self-assurance in resisting overeating in various tempting situations. Alphas were .76 and .83 for the Availability scale, .87 and .88 for the Negative Emotions scale, .82 and .84 for the Physical Discomfort scale, .70 and .79 for the Positive Activities scale, and .90 and .89 for the Social Pressure scale (Clark et al., 1991; Rossi et al., 1995).

\section{Analyses}

Analysis Step 0: Preliminary Analyses

Stage of Weight Management

Chi-square tests were applied to examine the independence across stage of weight control and school year, stage of weight control and gender, stage of weight management and BMI status, stage of 
weight management and stage of exercise. The results showed that there was not an association between stage of weight management and school year; $\chi_{(4)}^{2}=4.365, p=.359$. The stage of weight management for male did not differ from the stage of weight management of female students; $\chi^{2}(4)=4.239, p=.375$. The stage of weight management for normal BMI differed from the stage of weight control of overweight/obesity BMI groups; $\chi_{(4)}^{2}=12.563, \mathrm{p}=.014$. The result indicated that there was an association between stage of exercise behavior and stage of weight management; $\chi^{2}{ }_{(16)}=154.804, p<$ .0001 .

\section{BMI Status}

The results showed that there was not an association between BMI status and school year; $\chi^{2}(1$, $=0.027, \mathrm{p}=.870$. The BMI status for male differed from the BMI status of female students; $\chi_{(1)}^{2}=$ 57.683, $\mathrm{p}<.0001$.

\section{Stage of Exercise Behavior}

Chi-square tests were applied to examine the independence across stage of exercise behavior and school year, stage of exercise behavior and gender, stage of exercise behavior and BMI status, stage of exercise behavior and stage of weight control. The results showed that there was not an association between stage of exercise behavior and school year; $\chi_{(4)}^{2}=5.309, \mathrm{p}=.257$. The stage of exercise behavior for male differed from the stage of exercise behavior of female students; $\chi^{2}{ }_{(4)}=47.705, \mathrm{p}<$ .0001 . The results showed that there was not an association between stage of exercise behavior and BMI status: $\chi_{(4)}^{2}=9.109, \mathrm{p}=.058$.

T test was applied to examine the school year difference in time of doing exercise. The results indicate that there was a statistically significant difference between first-year and second-year senior high students in length of doing exercise; $\mathrm{t}(414)=2.23, \mathrm{p}=.027$. In other words, first-year students spent statistically significantly much more time on exercise (mean $=6.013$ days) than second-year students (mean $=4.651$ days). Results from t-test showed that there was not a statistically significant difference between BMI groups in terms of exercise behaviors; $\mathrm{t}(485)=1.76, \mathrm{p}=.079$.

Gender difference in time of doing exercise was also examined by $t$ test. The results indicate that there was a statistically significant difference between male and female students in length of doing 
exercise: $\mathrm{t}(319)=6.60, \mathrm{p}<.0001$. In other words, male students spent statistically significantly much more time on exercise $($ mean $=7.975$ days $)$ than female students (mean $=3.782$ days $)$.

Analysis Stepl: Exploratory Measurement Analysis

The 491 students used for analyses in this investigation were split in half randomly. Exploratory analyses were conducted on the first half of the data in Step 1 and confirmatory analyses on the second half of the data in Step 2. Two hundred forty four students were included in Step 1. Of sample One, 154 (63.1\%) were first year students, and 90 (36.9\%) were second year students; 96 were male (39.3\%) and 148 female $(60.7 \%)$. Of sample Two, $156(63.2 \%)$ were first year students, and 91 (36.8\%) were second year students; 106 were male (42.9\%) and 141 female $(57.1 \%)$

Principal components analyses (PCA) using the SAS 9.0 computer program were conducted to determine the psychometric factor and measurement structure of the decisional balance and situational temptation questionnaires. Horn's (1965) parallel analysis, the minimum average partial (MAP) technique (Velicer; 1976), the scree test, and theoretical considerations based on the TTM were used as the guidelines to decide the numbers of components that would best represent the data. Varimax rotation of the factor pattern was employed. The standards used to decide whether or not an item was to be retained on a specific factor was that the item loading had to be at least .50 on the target component but not be more than .30 on any other component.

Psychometricians have demonstrated the utility of conducting structural equation modeling in instruments based on a strong fundamental theoretical model in the exploratory measurement development stage (Bollen, 1989; Long, 1983; Marcus, Rossi, Selby; Niaura, \& Abrams, 1992). Different indices were applied to evaluate the fit between the proposed model and the data in order to ascertain the factor structure. These indicators of fit included absolute fit (e.g., $\chi^{2}$, GFI, RMSEA) and relative indices (e.g., CFI). Modeling procedures and fit indices are described in more detail below. Analysis: Step 2: Confirmatory Analyses

The second step involved an examination of the cross-validation of the measurement structures from Step 1 with the second half of the sample using confirmatory factor analysis procedures. To prevent confirmation bias, and as an advanced analysis of the adequacy of the models derived from 
sample 1, several alternative models illustrating different conceptualizations of the structures of the WELSQ and DBQ were compared to best interpret the data.

Several indices were used to examine various aspects of fit for the structural models. At a macro-level, significance tests are expected to show that a hypothesized model provides a good fit to the data, with small chi-square values relative to the degrees of freedom (normalized $\chi^{2}$ index). Small chi-square values and a non-significant $\mathrm{p}$ value indicate that there is little difference between the hypothesized model and the data. However; even good fitting models often fail this test since the statistical power of the test is often very high due to large sample sizes, so that even small departures from perfect model fit result in statistically significant $p$ values. Furthermore, it has been shown that the $\chi^{2}$ test of model fit is not especially robust to non-normality and other violations of assumptions that might be expected, especially when item-level data serve as the manifest indicators of the models. Standardized residuals between a hypothesized model and the pattern of variances and covariances are expected to be relatively small for a reasonable model. This is evaluated by examining the root mean square enror of approximation (RMSEA). It is suggested that RMSEA should be smaller than 0.08 to be consider a good fit (Byrne, 2001).

The comparative fit index (CFI) will also be examined, and it should be relatively large $(>.90)$ if a model is providing a better approximation of the data than a model that hypothesized no covariances among variables. At a micro level, the significance of specific hypothesized paths, and the percentage of explained variance for all dependent constructs was examined. Significant and meaningful predictors are identified by significant path coefficients to the dependent constructs, and at least a moderate degree of explained variance is expected. Chi-square difference tests were conducted to compare nested models represented in the current study. By subtracting the chi-square and degrees of freedom values for relevant nested models from a fuller model and assessing the significance of the incremental difference, the importance of competing models can be evaluated. If the difference in models is significant, this indicates that the fuller model is preferred to help explain the data.

Analysis Step 3: External Validity Analyses

Several criteria were employed to examine the external validity of the Stage of Change algorithm. The standards were as follows: (a) the pattern of self-efficacy by stage of change; and (b) 
the pattern of the decisional balance by stage of change. Appropriate analyses included multivariate and univariate analyses of variance, univariate follow-up procedures, determination of effect sizes and confidence intervals.

Analysis Step 4: Factor Invarjance Analyses

Two sub-steps were conducted to examine the level of factorial invariance of the measures across two sets of demographic variables achieve the goals. In sub-step one, multiple sample model analyses were applied to examine the factor invariance between students whose BMI were in the normal range with intention of losing weight, and those who were overweight and obese. In sub-step two, male and female students were compared with multiple sample model analysis.

Analysis Step 5: Discriminant Function Analyses

A discriminant function analysis was conducted using the decisional balance and self efficacy to predict the five stages of change. The ability of decisional balance and self efficacy scales to correctly classify study participants into their reported stage of change was also investigated. 


\section{References}

Abbott, R.D., Wilson, P.W., Kannel, W.B., \& Castelli, W.P. (1988). High density cholesterol, total cholesterol, screening and myocardial infarction. The Framingham Study. Atherosclerosis, 8, 20717.

Alexander, M... Sherman, J.B. \& Clark, L. (1991). Obesity in Mexican-American preschool childrena population group at risk. Public Health Nursing, 8, 53-58.

Allison, D.B., \& Saunders, S.E. (2000). Obesity in North America: an overview. The Medical Clinics of Vorth America, 84, 305-332.

Allison, D.B., Fontaine, K.R., Manson, J.E., Stevens, J., \& VanItallie, T.B. (1999). Annual deaths attributable to obesity in the United States. Journal of the American Medical Association, 282, $1530-1538$

Bandura, A. (1997). Self-efficacy: The exercise of control. New York: W.H. Freeman.

Barrett-Connor, E.L. (1985). Obesity; atherosclerosis and coronary artery disease. Annuals of Internal Medicine, 103, 1010-1019.

Bollen, K. A. (1989). Structural equations with latent varjables. NY: Wiley: A leading, readable text on structural modeling.

Bray, G.A.(1985). Complications of obesity: Annuals of Internal Medicine, 103, 1052-1062.

Brownell, K.D. (1991) Dieting and the search for the perfect body: where physiology and culture collide Behaviour Therapy, 22, 1-12.

Brugman, E. Meulmeester, J.F., Spee-van der Wekke, A, Beuker, R,J., Zaadstra, B.M., Radder, J.J., \& Verloove-Vanhorick, P.S. (1997) Dieting, weight and health in adolescents in the Netherlands International Journal of Obesity, 21, 54-70.

Byrne, B.N. (2001). Structural Equation Modeling with AMOS. Rahwah, NJ: Lawrence Erlbaum Associates.

Criqui, M.H., Barrett-Connor, E., Holdbrook, M.J., Austin, M., \& Turner, J.D. (1980). Clustering of cardiovascular disease risk factors. Preventive Medicine, 9, 525-533. 
Chang, C-J., Wu, C-H., Chang, C-S., Yao, W-J., Yang, Y-C., Wu, J-S., \& Lu, F-H. (2003). Low body mass index but high percent body fat in Taiwanese subjects: implications of obesity cutoffs. International journal of Obesity, 27, 253-259.

Clark, M.M., Abrams, D.B., Niaura, R.S., Eaton, C.A., \& Rossi, J.S. (1991). Self-efficacy in weight management. Journal of Consulting and Clinical Psychology, 59, 739-744.

Chu NF.(2001). Prevalence and trends of obesity among school children in Taiwan-the Taipei Children Heart Study. International Journal of Obesity, 25, 170-176.

Deurenberg-Yap, M., Schmidt, G., van Staveren, W.A., \& Deurenberg, P. (2000). The paradox of low body mass index and high body fat percentage among Chinese, Malays and Indians in Singapore. International Journal of Obesity, 24, 1011-1017.

Deurenberg. P., Deurenberg-Yap. M., Guricci, S. (2002). “Asians are different from Caucasian and from each other in their body mass index/ body fat per cent." Obesity Reviews, 3, 141-146.

Deurenberg- Yap, M., Tan, B.Y., Chew, S.K., Deurenberg, P., \& van Staveren, W.A. (1999). Manifestation of cardiovascular risk factors at low levels of body mass index and waist-hip ratio in Singaporean-Chinese. Asia Pacific Journal of Clinical Nutrition, 8, 177-183.

Deurenberg, P., Yap, M., van Staveren, W.A. (1998). Body mass index and percent body fat: a metaanalysis among different ethnic groups. International Journal of Obesity, 22, 1164-1171.

DiClemente, C.C., Prochaska, J.O., Fairhurst, S.K., Velicer, W.F., Velasquez, M.M., \& Rossi, J.S. (1991). The process of smoking cessation: An analysis of precontemplation, contemplation and preparation stages of change. Journal of Consulting and Clinical Psychology, 59, 295-304.

Dietz. W.H. (2002). Medical consequences of obesity in children and adolescents. In: Fairburn, C.G. Brownell, K.D.(eds). Eating Disorders and Obesity: A comprehensive Handbook. Guilford Press: New York, 2002, pp 473-476.

Ebbeling, C.B., Pawlak, D.B., \& Ludwig, D.S. (2002). Childhood obesity: public health crisis, common sense cure. Lancet, $360,473-482$.

Emmons, K.M., Marcus, B.H., Linnan, L., Rossi, J.S., \& Abrams, D.B. (1994). Mechanisms in multiple risk factor interventions: Smoking, physical activity, and dietary fat intake among manufacturing workers. Preventive Medicine, 23, 481-489. 
Feinleib, M. (1985). Epidemiology of obesity in relation to health hazards. Anmuals of Internal Medicine, 103, 1019-1024.

Gidding. S.S. (1995). A perspective on obesity. The American Journal of the Meducal Sciences, 310. S68-71.

Greene, G.W., Fey-Yensan, N., Padula, C., Rossi, S., Rossi, J.S., \& Clark, P.G. (in press). Differences in psychosocial variables by stage of change for fruits and vegetables in older adults. Journal of the American Dietetic Association.

Greene, G., \& Rossi, S., (1998). Stages of change for dietary fat reduction over 18 months. Journal of the American Dietetic Association, 98, 529-534.

Greene, G.W., Rossi, S.R., Rossi, J.S., Velicer, W.F., Fava, J.L., \& Prochaska, J.O. (1999). Dietary applications of the stages of change model. Journal of the American Dietetic Association, 99, 673678.

Guillaume, M, \& Lissau, I. Epidemiology. In: Burniat W, Cole T, Lissau I, Poskitt EME (eds). Child and Adolescent Obesity: Causes and Consequences, Prevention and Management. Cambridge University Press: Cambridge, 2002, 28-49.

Guricci, S., Hartriyanti, Y., Hautvast, JGAJ, Deurenberg, P. (1998). Relationship between body fat and body mass index: differences between Indonesians and Dutch Caucasians. Europe Journal of Clinical Nutrition, 52, 779-783.

Hargreaves, M.K., Schlundt, D.G., Buchowski, M.S., Hardy, R.E., Rossi, S.R., \& Rossi, J.S. (1999). Stages of change and the intake of dietary fat in African-American women: Improving stage assignment using the Eating Styles Questionnaire. Journal of the American Dietetic Association, 99. 1392-1399.

Hoffmans MDAF, Kromhout D, de Lezenne Coulander C. (1988). The impact of body mass index of 78,612 18-year old Dutch men on 32-year mortality from all causes. Journal of Clinical Epidemiology, 41,749-756.

Horn. J. L. (1965). A rationale and test for the number of factors in factor analysis. Psychometrika, 32 , 179-185. 
Huang, Y.C., Wu, J.Y., \& Yang, M.J.(2003)Weight-for-height reference and the prevalence of obesity for school children and adolescents in Taiwan and Fuchien Areas. Journal of Chinese Medical Association, 66, 599-606.

Hubert, H. B. (1986). The importance of obesity in the development of coronary risk factors and disease: the epidemiologic evidence. Annul Review Public Health, 7, 493-502.

Inue S. Criteria for obesity in Japan and Asia-Oceania and causes of obesity in Japan. ILSI Symposium and Workshop on Forging Effective Strategies for Prevention and Management of Overweight and Obesity in Asia. Singapore: 22-24 April 2002.

Janis, I. \& L. Mann, L. (1977) Decision Making: A Psychological Analysis of Conflict, Choice and Conmuitment. New York: Free Press.

Kaneko, K., Kiriike, N., Ikenaga, K., Miyawaki, D, \& Yamagami, S (1999). Weight and shape concerns and dieting behaviours among pre-adolescents and adolescents in Japan Psychiatry and Clinical Neurosciences. Psychiatry and Clinical Neurosciences, 53, 365.

Kannel, W.B. \& Wilson PWF (1995). An update on coronary risk factors. The Medical Clinics of North America, 79, 951-971.

Kissebah, A.H., Freedman, D.S., \& Peiris, A.N. (1989). Health risks of obesity. The Medical Clinics of North America, 73, 111-138,

Lai, S.W., Ng, K.C., Lin, H.F., \& Chen, H.L. (2001). Association between obesity and hyperlipidemia among children. Yale Journal of Biological Medicine, 74, 205-210.

Lobstein, T, James, WPT., \& Cole. T. (2003). Increasing levels of excess weight among children in England. International Journal of Obesity, 27, 1136-1138.

Long. J. Scott. (1983). Covariance Structure Models: An Introduction to LISREL. Beverly Hills: Sage Publications. ISBN: 0-8039-2045-8 (pbk.).

Lowry, R., Galuska, D.A, Fulton, J.E., Wechsler, H., \& Kann, L. (2002). Weight management goals and practices among US high school students: Associations with physical activity, diet, and smoking. Journal of Adolescent Health, 31, 133-144. 
Lu, F.H., Yang, Y.C., Wu,J.S.,Wu,C.H., \& Chang, C.J.(1998). A population-based study of the prevalence and associated factors of diabetes mellitus in southern Taiwan. Diabetic Medicine: $a$ Journal of the British Diabetic Association, 15, 564-572.

Manson, J., Willett, W.C., Stampfer, M.J., et al. (1995). Body weight and mortality among women. New England Journal of Medicine, 333, 677-685.

Marcus, B.H., Rossi, J.S., Selby, V.C., Niaura, R.S., \& Abrams, D.B. (1992). The stages and processes of exercise adoption and maintenance in a worksite sample. Health Psychology, 11, 386-395.

Mokdad, A.H., Ford, E.S., Bowman, B.A., Dietz, W.H., Vinicor, F., Bales, V.S., \& Marks, J. (2003). Prevalence of obesity, diabetes, and obesity-related health risk factors, 2001. Journal of American Medical Association, 289, 76-79.

Moreno, L.A., Sarría. A.,\& Popkin, B.M. (2002).The nutrition transition in Spain: a European Mediterranean country. Europe Journal of Clinical Nutrition, 56, 1-12.

Neumark-Sztainer, D., Rock, C.L.,Thornquist, M.D., Cheskin, L.J., Neuhouser, M.L., \& Barnett, M.J.(2000). Weight-Control Behaviors among Adults and Adolescents: Associations with Dietary Intake. Preventive Medicine, 30, 301-391.

Nowak, M., Speare, R\& Crawford, D.(1996). Gender differences in adolescent weight and shaperelated beliefs and behaviour. Journal of Pediatrics and Child Health, 32, 148-152.

O'Connell, D., \& Velicer, W. F. (1988). A decisional balance measure and the stages of change model for weight loss. International Journal of the Addictions, $23,729-750$.

Pan, W.H., Flegal, K.M., Chang, H.Y., Yeh, W.T., Yeh, C.J., \& Lee, W.C. (2004). Body mass index and obesity-related metabolic disorders in Taiwanese and US whites and blacks: implications for definitions of overweight and obesity for Asians. American Journal of Clinical Nutrition, 79, 3139.

Paquette, M.C. \& Raine, K. (2004). Sociocultural context of women's body image. Social Science \& Medicine, 59, 1047-1058.

Pi-Sunyer, F.X. (1991). Health implications of obesity. American Journal Clinical Nutrition, 53, $1595 \mathrm{~S}-1603 \mathrm{~S}$ 
Prochaska, J.O. (1994). Strong and weak principles for progressing from precontemplation to action on the basis of twelve problem behaviors. Health Psychology, 13, 47-51.

Prochaska, J.O., DiClemente, C.C., \& Norcross, J.C. (1992). In Search of how people change, American Psychologist, 1102-1114.

Prochaska, J.O., Norcross, J.C., Fowler, J.L., Follick, M.J., \& Abrams, D.B. (1992). Attendance and outcome in a work site weight control program: Processes and stages of change as process and predictor variables. Addictive Behoviors, $17,35-45$.

Prochaska, J.O., Velicer, W.F., Guadagnoli, E., Rossi, J.S., \& DiClemente, C.C. (1991). Patterns of change: Dynamic typology appliod to smoking cessation. Multivariate Behavioral Research, 26, 83-107.

Prochaska, J.O., Velicer, W.F., Rossi, J.S., Goldstein, M.G., Marcus, B.H., Rakowski, W., Fiore, C., Harlow, L.L., Redding, C.A., Rosenbloom, D., \& Rossi, S.R. (1994). Stages of change and decisional balance for 12 problem behaviors. Health Psychology, 13, 39-46.

Prochaska, J.O., Velicer; W.F., DiClemente, C.C., \& Fava, J. (1988). Measuring processes of change: applications to the cessation of smoking. Journal of Consulting and Clinical Psychology, $56(4): 520-528$.

Rocchini, A.P., Katch, V., Schork, A., \& Kelch, R.P (1987). Insulin and blood pressure during weight loss in obese adolescents. Hypertension, 10, 267-273.

Rodin, J.(1993).Cultural and psychosocial determinants of weight concerns. Annals of Internal Medicine, $119,643-645$.

Rossi. J.S. (1995). Why do people fail to maintain weight loss? In D.B. Allison \& F.X. Pi-Sunyer (Eds.), Obesity treatment: Establishing goals, improving outcomes, and reviewing the research agenda (pp. 97-102). New York: Plenum.

Rossi, S.R., \& Rossi, J.S. (1999). Concepts and theoretical models. In N. Jairath (Ed.), Coronary heart disease and risk factor management: A nursing perspective (pp. 47-69). Orlando, FL: W.B. Saunders. 
Rossi, J.S., Rossi, S.R., Velicer, W.F., \& Prochaska, J.O. (1995). Motivational readiness to control weight. In D.B. Allison (Ed.), Handbook of assessment methods for eating behaviors and weightrelated problems: Measures, theory, and research (pp. 387-430). Thousand Oaks, CA: Sage.

Rossi, S.R., Rossi, J.S., Rossi-DelPrete, L.M., Prochaska, J.O., Banspach, S.W., \& Carleton, R.A. (1994). A processes of change model for weight control for participants in community-based weight loss programs. International Journal of the Addictions, 29, 161-177.

Rössner, S. (2002). Obesity: the disease of the twenty-first century. International Journal of Obesity, $26, \mathrm{~S} 2-\mathrm{S} 4$.

Simopolous, A.P. \& Van Itallie, T.B. (1984). Body weight, health and longevity. Annuals of Internal Medicine, 100, 285-295.

Srinivasan, S.R., Bao, W., Wattigney; W.A., \& Berenson, G.S. (1996). Adolescent overweight is associated with adult overweight and related multiple cardiovascular risk factors: the Bogalusa Heart Study. Metabolism, 45, 235-240.

Strauss, R. S. (1999). Childhood obesity. Current Problems in Pediatrics, 29, 1-29.

Steen, S.N., Wadden, T.A., Foster, G.D., \& Andersen, R.E. (1996). Are obese adolescent boys ignoring an important health risk? The International Journal of Eating Disorders, 20, 281-286.

Troiano, R.P., Flegal, K.M., Kuczmarski, R.J., Campbell, S.M., \& Johnson, C.L. (1995). Overweight prevalence and trends for children and adolescents. The National Health and Nutrition' Examination Surveys, 1963 to 1991. Archives of Pediatrics \& Adolescent Medicine, 149, 10851091.

Vallis, M., Ruggiero, L., Greene, G., Jones, H., Zinman, B., Rossi, S., Edwards, L., Rossi, J.S., \& Prochaska, J.O. (2003). Stages of change for healthy eating in diabetes: Relation to demographic, eating-related, health care utilization, and psychosocial factors. Diabetes Care, 26, 1468-1474.

Velicer, W. F. (1976). Determining the number of components from the matrix of partial correlations. Psychometrika, 41, 321-327.

Wang, J., Thornton, J.C., Russell, M., Burastero, S., Shen, J., Tanenbaum, S., Heymsfield, S., \& Pierson, R. N.(1996). Comparison for BMI and body fat percent among Puerto Ricans, Blacks, Whites and Asians living in the New York City area. Obesity Research, 4, 377-384. 
Wang, Y., Monteiro, C., \& Popkin, B.M. (2002). Trends of obesity and underweight in older children and adolescents in the United States, Brazil, China, and Russia. Anterican Journal of Clinical Nutrition, 75, 971-977.

World Health Organization. Obesity: preventing and managing the global epidemic: Report of a WHO consultation on obesity; Geneva, 3-5 June, 1997. WHO: Geneva, 1998.

World Health Organization. Obesity: Preventing and Managing the Global Epidemic. WHO Obesity Technical Report Series no. 894. WHO: Geneva, 2000.

$\mathrm{Wu}, \mathrm{Y} . \mathrm{F}$. The appropriate cutoff points of BMI and waist circumference for identifying obesity and overweight in Chinese adults: a pooling analysis of a cross-sectional sample of 240,000 adults and a follow-up cohort of 76,227 adults. ILSI Symposium and Workshop on Forging Effective Strategies for Prevention and Management of Overweight and Obesity in Asia. Singapore: 22-24 April 2002. 
Table 1.1. Original sample: BMI distribution by school year and gender

\begin{tabular}{|c|c|c|}
\hline Participants & Frequency & Percentage \\
\hline First-Year Male Senior High School Students & & \\
\hline Underweight & 41 & $16.60 \%$ \\
\hline Normal BMI & 139 & $56.28 \%$ \\
\hline Overweight & 32 & $12.96 \%$ \\
\hline Obesity & 35 & $14.17 \%$ \\
\hline Second-Year Male Senior High School Students & & \\
\hline Underweight & 28 & $19.86 \%$ \\
\hline Normal & 73 & $51.77 \%$ \\
\hline Overweight & 18 & $12.77 \%$ \\
\hline Obesity & 22 & $15.60 \%$ \\
\hline Underweight & & \\
\hline Normal & 51 & $20.90 \%$ \\
\hline Overweight & 155 & $63.52 \%$ \\
\hline Obesity & 23 & $9.43 \%$ \\
\hline Underweight & 15 & $6.15 \%$ \\
\hline Normal & & \\
\hline Overweight & 30 & $20.69 \%$ \\
\hline Obesity & 95 & $65.52 \%$ \\
\hline & 11 & $7.59 \%$ \\
\hline Second-Year Female Senior High School Students & 9 & $6.21 \%$ \\
\hline
\end{tabular}


Table 1.2. Overall sample used in analyses: BMI distribution by school year and gender

\begin{tabular}{|c|c|c|}
\hline Participants & Frequency & Percentage \\
\hline First-Year Male Senior High School Students & & \\
\hline Normal with intention of losing weight & 61 & $47.66 \%$ \\
\hline Overweight & 32 & $25.00 \%$ \\
\hline Obesity & 35 & $27.34 \%$ \\
\hline Second-Year Male Senior High School Students & & \\
\hline Normal with intention of losing weight & 34 & $45.95 \%$ \\
\hline Overweight & 18 & $24.32 \%$ \\
\hline Obesity & 22 & $29.73 \%$ \\
\hline First-Year Female Senior High School Students & & \\
\hline Normal with intention of losing weight & 144 & $79.12 \%$ \\
\hline Overweight & 23 & $12.64 \%$ \\
\hline Obesity & 15 & $8.24 \%$ \\
\hline Second-Year Female Senior High School Students & & \\
\hline Normal with intention of losing weight & 87 & $81.31 \%$ \\
\hline Overweight & 11 & $10.28 \%$ \\
\hline Obesity & 9 & $8.41 \%$ \\
\hline
\end{tabular}


Table 1.3. Parents' Education level

\begin{tabular}{|l|l|l|l|l|}
\hline Education-Overall Participants (N=780) & \multicolumn{3}{|l|}{ Father (Missing=4) } & \multicolumn{2}{l|}{ Mother (Missing=4) } \\
\hline & Frequency & Percent & Frequency & Percent \\
\hline Never attain school & 0 & 0 & 5 & 0.64 \\
\hline Elementary school & 57 & 7.35 & 96 & 12.37 \\
\hline Junior high school & 225 & 28.99 & 219 & 28.22 \\
\hline $\begin{array}{l}\text { Senior high school/ } \\
\text { Vocational high school }\end{array}$ & 352 & 45.36 & 358 & 46.13 \\
\hline College & 127 & 16.37 & 96 & 12.37 \\
\hline Graduate school & 15 & 1.93 & 2 & 0.26 \\
\hline Participants used in analyses (N=491) & Father (Missing=3) & Mother (Missing=1) \\
\hline & Frequency & Percent & Frequenc) & Percent \\
\hline Never attain school & 0 & 0 & 3 & 0.61 \\
\hline Elementary school & 37 & 7.58 & 65 & 13.27 \\
\hline Junior high school & 150 & 30.74 & 149 & 30.41 \\
\hline $\begin{array}{l}\text { Senior high school/ } \\
\text { Vocational high school }\end{array}$ & 213 & 43.65 & 214 & 43.67 \\
\hline College & 79 & 16.19 & 58 & 11.84 \\
\hline Graduate school & 9 & 1.84 & 1 & 0.2 \\
\hline
\end{tabular}


Table 1.4. Overall sample used in analyses: BMI distribution by intention of weight management and gender

\begin{tabular}{|c|c|c|c|c|c|c|}
\hline & \multicolumn{3}{|c|}{ First year } & \multicolumn{3}{|c|}{ Second year } \\
\hline Male & $\begin{array}{c}\text { normal } \\
\text { BMI }\end{array}$ & $\begin{array}{l}\text { over- } \\
\text { weight }\end{array}$ & obesity & $\begin{array}{l}\text { normal } \\
\text { BMI }\end{array}$ & $\begin{array}{l}\text { over- } \\
\text { weight }\end{array}$ & obesity \\
\hline would like to lose a lot of weight & 8 & 11 & 24 & 7 & 4 & 17 \\
\hline would like to lose a little weight & 53 & 18 & 11 & 27 & 14 & $\overline{5}$ \\
\hline $\begin{array}{l}\text { would like to stay the same } \\
\text { weight }\end{array}$ & 50 & 3 & 0 & 20 & 0 & 0 \\
\hline would like to gain a little weight & 27 & 0 & 0 & 17 & 0 & $\overline{0}$ \\
\hline would like to gain a lot of weight & 1 & 0 & 0 & 2 & 0 & 0 \\
\hline & \multicolumn{3}{|c|}{ First year } & \multicolumn{3}{|c|}{ Second year } \\
\hline Female & $\begin{array}{l}\text { normal } \\
\text { BMI }\end{array}$ & $\begin{array}{c}\text { over- } \\
\text { weight }\end{array}$ & obesity & $\begin{array}{l}\text { normal } \\
\text { BMI }\end{array}$ & $\begin{array}{l}\text { over- } \\
\text { weight }\end{array}$ & obesity \\
\hline would like to lose a lot of weight & 40 & 16 & 14 & 24 & 7 & 8 \\
\hline would like to lose a little weight & 104 & 7 & 1 & 63 & 3 & 1 \\
\hline $\begin{array}{l}\text { would like to stay the same } \\
\text { weight }\end{array}$ & 9 & 0 & 0 & 8 & 0 & 0 \\
\hline would like to gain a little weight & 2 & 0 & 0 & 0 & 1 & 0 \\
\hline would like to gain a lot of weight & 0 & 0 & 0 & 0 & 0 & 0 \\
\hline
\end{tabular}


Table 1.5. Stage of Exercise Behavior

\begin{tabular}{|c|l|l|}
\hline Overall participants $(\mathrm{N}=780)$ & Frequency & \multicolumn{1}{|c|}{ Percent } \\
\hline Precontemplation & 164 & 21.03 \\
\hline Contemplation & 254 & 32.56 \\
\hline Preparation & 120 & 15.38 \\
\hline Action & 125 & 16.03 \\
\hline Maintenance & 117 & 15 \\
\hline Participants used in analyses (N=491) & Frequenc) & Percent \\
\hline Precontemplation & 81 & 16.5 \\
\hline Contemplation & 184 & 37.47 \\
\hline Preparation & 86 & 17.52 \\
\hline Action & 88 & 17.92 \\
\hline Maintenance & 52 & 10.59 \\
\hline & & \\
\hline & & \\
\hline & & \\
\hline & & \\
\hline
\end{tabular}


Table 1,6. Days of exercise within previous month

\begin{tabular}{|l|l|l|l|l|l|}
\hline & $\mathrm{N}$ & Mean & SD & Skewness & Kurtosis \\
\hline Overall participants & 733 & 6.19 & 7.59 & 1.41 & 1.29 \\
\hline Participants used in analyses & 487 & 5.51 & 6.76 & 1.42 & 1.55 \\
\hline Normal BMI (missing=2) & 163 & 6.27 & 7.26 & 1.25 & 1.03 \\
\hline Overweight/Obesity (missing=2) & 324 & 5.13 & 6.47 & 1.51 & 1.88 \\
\hline First year (missing=2) & 308 & 6.01 & 7.05 & 1.39 & 1.52 \\
\hline Second year (missing=2) & 179 & 4.65 & 6.15 & 1.42 & 1.16 \\
\hline Male (Missing=1) & 201 & 7.98 & 7.89 & 0.87 & -0.08 \\
\hline Female (Missing=3) & 286 & 3.78 & 5.19 & 1.87 & 4.00 \\
\hline
\end{tabular}




\title{
Chapter 2. Development of the Chinese version of the decisional balance inventory for weight
}

\section{management with adolescents}

\begin{abstract}
Westernized dietary preferences and lifestyles are likely to have a significant impact on the increasing prevalence of obesity in Asian populations. The increased numbers of overweight and obese children and adolescents is becoming an emerging health issue in Asia. Developing interventions for decreasing adolescent overweight/obesity requires the development of psychometrically sound measures. The goal of this investigation was to examine the applicability of the concept of decisional balance to weight management behavior in an adolescent population in Taiwan. The first goal of the study was to develop and evaluate a 14-item Chinese version of Decisional Balance using a sample of 491 adolescents in a high school in Taiwan. Using split-half, cross-validation procedures, a two-factor model fit the data best $(\mathrm{CFI}=.971, \mathrm{RMSEA}=.042)$ with good internal consistency for both Pros (.85) and Cons (.72). Construct validity of the scales was assessed with MANOVA, ANOVAs, and follow-up Tukey tests examining the relationships between the scales with the stages of change for weight management for all participants, students who were overweight and obese, and participants whose BMIs were in the normal range but who intended to lose weight Results supported the reliability and validity of the Decisional Balance Inventory and suggested that these measures are similar to the measures for US adolescents. These measures may be useful for developing and tailoring interventions to adolescents' level of readiness for weight management.
\end{abstract}




\section{Chapter 2. Development of the Chinese version of the decisional balance inventory for weight management with adolescents}

Westernized dietary preferences and sedentary lifestyle patterns are thought to have a significant impact on the increasing prevalence of obesity in Asian populations. Thanks to globalization and fast economic growth, the supply of food in various parts of Asia has become more stable and abundant. Globalization has also brought with it westernized diets - widely accepted by many Asians, and a whole range of consumer equipment - TV and automobiles, for instance - that have made life more comfortable but led to people spending less time and energy in physical activities.

As this trend continues, more Asians suffer from obesity (Bray; 1985; Feinleib, 1985; Gidding, 1995, Hoffmans, Kromhout, de Lezenne, \& Coulander, 1988; Kissebah, Freedman, \& Peiris, 1989; Manson. Willett, Stampfer et al., 1995; Simopolous, \& Van Itallie, 1984). For example, in a 2002 nationwide survey of 86,967 children and adolescents in Taiwan and Fuchien Areas, the prevalence of obesity was $18.5 \%$ in males and $15.0 \%$ in females. In comparison with results from 1997 , the prevalence of childhood and adolescent obesity for both sexes was higher in 2002 . The 2002 survey found an increasing prevalence of obesity during childhood and adolescence for both genders in recent years (Huang, Wu, \& Yang, 2003).

As in Western countries, research results have suggested that overweight and obesity can be treated as important cardiovascular risk factors, such as insulin and glucose concentrations, and plasma lipids among Asian populations (Liu, Choudhury, Okayama, Hayakawa, Kita, \& Ueshima, 1999; Masuda, Imai, \& Komiya, 1993). It is therefore critical to address the issue in Asian populations.

The Transthoeretical Model (TTM; Prochaska, DiClemente, \& Norcross, 1992), an empirically supported theory, is one theory that may serve as a possible framework for investigating the issues of weight management in Asian cultures. The TTM has been applied to health related problems in various

populations (Greene, Rossi, Rossi, Velicer, Fava, \& Prochaska, 1999; Hargreaves et at, 1999; Rossi, 1995; Rossi, Rossi, Rossi-DelPrete, Prochaska, Banspach, \& Carleton, 1994; Rossi, Rossi, Velicer, \& Prochaska, 1995; Vallis et al., 2003). In the field of weight control, TTM has been mostly applied to clinical obese/overweight adult populations (Clark et al., 1991; Prochaska, Norcross, Fowler, Follick \& 
Abrams. 1992: Rossi, Rossi, Rossi-DelPrete, Prochaska, Banspach \& Carleton, 1994), and in some cases to college student populations (O’Connell \& Velicer, 1998).

The main components of the TTM include stages of change (SC), decisional balance, self-efficacy and processes of change. We focused on decisional balance in this investigation. The decision-making component of the TTM is based on a model first conceptualized by Janis and Mann (1977). Eight specific categories of decision-making were proposed in the Janis and Mann (1977) model; however, only two general dimensions, the pros and cons of behavior change, have been supported consistently by factor analytic studies (Hall \& Rossi, 2005; Prochaska, Velicer, Rossi et al, 1994). The pros describe positive aspects of changing behavior, including facilitators of change. The cons describe negative aspects of changing behavior and may be thought of as a disadvantag or barrier to change. In general, the pros of healthy behavior increase as a function of SC whereas the cons decrease. In progressing from precontemplation to action, the pros of a healthy change tend to increase by about one standard deviation; whereas, the cons of change tend to decrease by about one-half of a standard deviation (Hall \& Rossi, 2005; Prochaska, Velicer, Rossi et al., 1994). These results have led to the development of strong and weak principles of behavior change (Prochaska, 1994).

Previous studies have indicated that adolescents' self-perceived weight is poorly related to the medical definition of overweight, and considerable numbers of clinically normal-weight persons are trying to or wish to control weight. For instance, in the NHANES III sample, $52 \%$ of girls who perceived themselves as overweight were actually of normal weight, while $25 \%$ of boys who believed themselves overweight were of normal weight (Strauss, 1999). The 1999 national Youth Risk Behavior Survey showed that $25 \%$ of U.S. high school students were either overweight (11\%) or at risk for becoming overweight ( $14 \%$ ); however, $43 \%$ of students were trying to lose weight (Lowr); Galuska, Fulton, Wechsler, Kann, 2002). Due to the considerable prevalence of desire for weight control among adolescents who are not overweight /obese, it is important for researchers to look at the issue of weight management in non-clinical populations.

Developing interventions for decreasing adolescent overweight/obesity requires the development of psychometrically sound measures. The goal of this investigation was to examine the applicability of the concept of decisional balance to weight management behavior in an adolescent 
population in Taiwan. Several analyses were conducted to fulfill the purpose of the investigation. The goal of Step 1 was to develop Chinese-language versions of the Decisional Balance Inventory for an adolescent population in Taiwan. The specific aims for Step 1 were to explore the underlying dimensionality of the Decisional Balance Questionnaires. It is hypothesized that two uncorrelated components would best represent the decisional balance data. Step 2 focused on confirming the validity of measures developed in Step 1. The specific aim for Step 2 was to verify the expected two-factor model for decisional balance for weight control using confirmatory factor analysis. The purpose of Step 3 was to examine the external validity of the Decisional Balance Questionnaires in weight management. The relationship between decisional balance and stage of change using multivariate analyses of variance (MANOVA) was examined. It is expected that a crossover pattern of the two factors would be produced. That is, the cons would be higher than the pros at precontemplation, and the pros would be higher than the cons at action and maintenance. The goals of Step 4 were to examine the level of factorial invariance of the measure across two sets of demographic variables: (1) high school students with different BMI status, and (2) gender. Thus, two sub-steps were conducted to achieve the goals. In sub-step one, multiple sample model analyses were applied to examine the factor invariance between students whose BMI were in normal range but with intention of losing weight, and those were overweight and obese. In sub-step two, male and female students were compared with multiple sample model analysis.

\section{Methods}

\section{Participants}

During the 2005 school year, 780 senior high students from a high school in Taiwan were recruited into a cross-sectional study examining weight management behaviors. Of the 780 students, 492 (63.16\%) were first-year senior high students, and 287 (36.84\%) were second-year students; 388 $(49.87 \%)$ were male and $390(50.13 \%)$ were female students. The majority of participants' parents had junior-, senior- or vocational- high school degrees (Table 1.3).

Weight Group Definitions

Obesity is defined as a status of excessive fat accumulation in the body to the level that health and well-being are adversely affected (World Health Organization, 2000). A popular index to describe 
the individual's weight status is the Body Mass Index (BMI), which is defined as body weight (kg) divided by squared body height $\left(\mathrm{m}^{2}\right)$. The conventional operational definition for obesity is BMI $\geq 30$ $\mathrm{kg} / \mathrm{m}^{2}$, while overweight is described as BMI $\geq 25 \mathrm{~kg} / \mathrm{m}^{2}$ (World Health Organization, 1998).

However, the appropriateness of adopting a BMI greater than 25 for defining overweight and a BMI greater than 30 for obesity for the Asian population has been questioned. There are a least two reasons to believe why "Western" BMI cutoffs might be inappropriate when applied to Asians. First, it has been shown that a different $\mathrm{BMI} /$ percent body fat (BF\%) relationship among ethnic groups might result in different cut-off points for obesity, since obesity is defined as a condition where there is excess body fat (WHO, 2000). Empirical research and meta-analysis have shown inconsistent relationships between BMI and BF\% across various ethnic groups (Chang, Wu, Chang, Yao, Yang, Wu, \& Lu, 2003; Deurenberg, Deurenberg-Yap, \& Guricci, 2002; Deurenberg, Yap, \& van Staveren, 1998). It is generally indicated that Asians have a lower BMI but a higher BF\% than Caucasians of the same age and sex (Deurenberg-Yap, Schmidt, van Staveren, \& Deurenberg, 2000; Guricci, Hartriyanti, Hautvast, \& Deurenberg, 1998; Wang. Thornton, Russell, Burastero, Shen, Tanenbaum, Heymsfield, \& Pierson, 1996). Second, from the viewpoint of the risk factors for morbidity and mortality; it might be more practical to have ethnic-group specific BMI cutoffs. The reason is that the prevalence of obesity would be low in Asia-Pacific region when based on WHO obesity cutoffs (World Health Organization, 1998). However, the prevalence of cardiovascular diseases and diabetes mellitus were similar for Asia-Pacific region and Western countries (Deurenberg- Yap, Tan, Chew, Deurenberg, \& van Staveren, 1999; Lu, Yang, Wu, Wu, \& Chang, 1998). For example, research suggested that the prevalence of hypertension, diabetes, and hyperuricemia were higher in Taiwanese than in white Americans for most BMI values. Moreover, as BMI increases, Taiwanese have are at higher risk for hypertriglyceridemia and hypertension as compared to white Americans (Pan, Flegal, Chang. Yeh, Yeh, \& Lee, 2004).

Based on the criteria recommended by Department of Health in Taiwan, the BMI cutoffs for underweight, normal, overweight and obesity among first-year male students were $<18.2,18.2-23.1$, 23.1, 25.5, respectively; while for first-year female students were $<18,18.0-22.7,22.7,25.3$, respectively: The BMI cutoffs for underweight, normal, overweight and obesity among second-year male students were $<18.6,18.6-23.4,23.4,25.6$, respectively; while for first-year female students were 
$<18.2,18.2-22.7,22.7,25.3$, respectively. The BMI distribution by school year and gender are shown in Table 1.1.

Based on the response for the question 'how do you feel about your current weight', participants were distinguished as "with intention of losing weight', "stay the same weight' and 'with intention of gaining weight'. In this study; the non-clinical population with intention of losing weight and overweight/obese students are the focus. Therefore, students who were underweight and whose BMI was in the normal range with intention of maintaining, or gaining weight were excluded. That is, only students who were either overweight, obese or in the normal range but intended to lose weight were included in the analyses. Thus, of the original 780 students, 491 students met the criteria and were used for the analyses in the investigation. The BMI distributions of participants by weight management intention gender and school year were shown in Table 1.4. The BMI distribution of students used in the analyses are shown in Table 1.2. The sample consisted of 202 males (41.1\%) and 289 females (58.9\%); 310 were first year students $(63.1 \%)$ and 181 were second year students $(36.9 \%)$. The distributions of stages of exercise behavior of students and days of exercise were shown in Table 1.5 and 1.6. Analysis Plan

The 491 students used for analyses in this investigation were split in half randomly: Exploratory analyses were conducted on the first half of the data in Step 1 and confirmatory analyses on the second half of the data in Step 2. Two hundred forty four students were included in Step 1. Of sample $1,154(63.1 \%)$ were first year students, and 90 (36.9\%) were second year students; 96 were male $(39.3 \%)$ and 148 female $(60.7 \%)$. Of sample $2,156(63.2 \%)$ were first year students, and 91 (36.8\%) were second year students; 106 were male (42.9\%) and 141 female $(57.1 \%)$ Procedure

The sample was recruited from classes at a senior high school in Taiwan. Participation was anonymous, voluntary, took about 40 minutes, and involved no incentives to the subjects for their participation. Participants were provided with complete information regarding the purpose, benefits, and possible risks of the study. They completed questionnaires in the classrooms. The survey was conducted as a paper-and-pencil measure in the participants' classrooms. Procedures of the study were approved by the Institutional Review Board at the University of Rhode Island. 


\section{Measures}

\section{Stage of Change for Weight Management}

This is a one item scale for weight management evaluating individuals' stage of readiness to control weight. This measure classified students into one of five possible stages of change. The strategies for weight management included exercising, eating smaller amount of food, eating less junk food, and eating more fruits and vegetables. Stage of change developed for weight management included: (a) Precontemplation: individuals who do not plan to start the weight management strategies in the next 6 months; (b) Contemplation: individuals who do not use weight management strategies, but intend to do so within the next 6 months; (c) Preparation: individuals who do not use weight management strategies, but plan to start in the next 30 days; (d) Action: individuals who use weight management strategies and have done so for less than 6 months; (e) Maintenance: individuals who use weight management strategies and have done so for more than 6 months.

Decisional Balance Inventory (DBI)

The original English language Decisional Balance Inventory (DBI) is composed of 20 items measuring two hypothesized dimensions (Pros and Cons) of decision making for weight management (O'Connell \& Velicer, 1988). The Pros are positive aspects of changing behavior, including facilitators of change. An example of a Pros item is: "My health would improve if I lost weight." The Cons represent negative aspects of changing behavior. An example of a Con is "Trying to lose weight could end up being expensive when eventhing is taken into account." Research showed that coefficient Alpha was .91 for the pros scale and .84 for the cons scale (O'Connell $\&$ Velicer, 1988; Rossi et al., 1995).

Since the first language of survey participants is Mandarin Chinese, the assessment was conducted in that language. The original English-language questionnaires were translated into Chinese and then backtranslated into English by a panel of bilingual psychologists. During the process of back translation, the equivalence of Chinese and English version was ensured. The questionnaires were then applied to groups of students to verify their understanding of the questions. The necessary modifications were applied to ensure the understandability of the instruments. 


\section{Preliminary Analyses}

\section{Stage of Weight Control}

Chi-square tests were applied to examine the independence across stage of weight control and school year, stage of weight control and gender, stage of weight control and BMI status, stage of weight control and stage of exercise. The results showed that there was no association between stage of weight control and school year; $\chi_{(4)}^{2}=4.365, p=.359$. The stage of weight control for male students did not differ from the stage of weight control of female students; $\chi_{(4)}^{2}=4.239, \mathrm{p}=.375$. The stage of weight control for normal BMI differed from the stage of weight control of overweight/obesity BMI groups; $\chi^{2}(4)=12.563, p=.014$. The result indicated that there was an association between stage of exercise behavior and stage of weight control; $\chi^{2}{ }_{(16)}=154.804, p<.0001$.

\section{BMI Status}

The results showed that there was no association between BMI status and school year; $\chi^{2}{ }_{(1)}=$ $0.027, p=.870$. The BMI status for male differed from the BMI status of female students; $\chi_{(1)}^{2}=$ $57.683, \mathrm{p}<.0001$.

\section{Stage of Exercise Behovior}

Chi-square tests were applied to examine the independence across stage of exercise behavior and school year, stage of exercise behavior and gender, stage of exercise behavior and BMI status, stage of exercise behavior and stage of weight control. The results showed that there was no association between stage of exercise behavior and school year; $\chi_{(4)}^{2}=5.309, p=.257$. The stage of exercise behavior for male differed from the stage of exercise behavior of female students; $\chi^{2}(4)=47.705, \mathrm{p}<$ .0001 . The results showed that there was no association between stage of exercise behavior and BMI status; $\chi_{(4)}^{2}=9.109, \mathrm{p}=.058$

$\mathrm{T}$ test was applied to examine the school year difference in time of doing exercise. The results indicate that there was a statistically significant difference between first-year and second-year senior high students in length of doing exercise; $t(414)=2.23, p=.027$. In other words, first-year students spent statistically significantly much more time on exercise (mean= 6.013 days) than second-year students (mean $=4.651$ days). Results from t-test showed that there was not a statistically significant difference between BMI groups in terms of exercise behaviors; $t(485)=1.76, \mathrm{p}=.079$. 
Gender difference in time of doing exercise was also examined by the t-test. The results indicate that there was a statistically significant difference between male and female students in length of doing exercise; $\mathrm{t}(319)=6.60, \mathrm{p}<.0001$. In other words, male students spent statistically significantly more time on exercise (mean $=7.975$ days) than female students (mean $=3.782$ days).

Step 1: Exploratory analyses

The characteristics of items were first examined. Mean, standard derivation, skewness, and kurtosis for each item are shown in Table 2.1. No items were deleted due to poor distributions.

Principal components analyses (PCA) were conducted to determine the psychometric properties and measurement structure of the Decisional Balance Inventory; Horn's (1965) parallel analysis, and the minimum average partial (MAP) technique (Velicer, 1976) were used to decide the optimal number of factors, since simulation studies have shown that they are two of the most accurate methods (Velicer, Eaton, \& Fava, 2000). The scree test, and theoretical considerations about decisional balance were also applied to decide the numbers of components to retain. Varimax rotation of the factor pattern was then employed. Items on Crobach's coefficient alpha reliabilities, component interpretability, component loadings, and the length of the final instrument were criteria used to make the reduction. Items with low loadings (i.e., less than 0.40 on all components), items that contribute negatively to the reliability of a subscale, and complex items (i.e., items with loadings larger than 0.40 on two or more components) were removed.

A two-component solution, the optimal result, was produced for interpretation. Seven Pros items and seven Cons items were selected, accounting for $46.6 \%$ of the total item variance. All items loaded heavily on their individual components. Table 2.2 displays the component loadings for each item on each component. Cronbach coefficient alphas were calculated for each subscale. Alpha coefficients for the Pros subscale was .859, and for the Cons was .717. These results imply fair to good internal consistency of scale. Scale means and standard deviations are shown in Table 2.3. The correlation between the Pros and Cons scale was .197.

\section{Step 2: Confirmatory Analyses}

The second step involved an examination of the cross-validation of the measurement structures from Step 1 with the second half of the sample $(\mathrm{N} 2=241)$ using confirmatory factor analysis 
procedures. To prevent confirmation bias, and as an advanced analysis of the adequacy of the models derived from sample 1, several alternative models illustrating different conceptualizations of the structure of decisional balance were compared to best interpret the data. The characteristics of items from Sample 2 were also examined. Mean, standard deviation, skewness, and kurtosis for each item are shown in Table 2.4.

Several indices were used to examine various aspects of fit for the structural models. At a macro-level, significance tests are expected to show that a hypothesized model provides a good fit to the data, with small chi-square values relative to the degrees of freedom (normalized $\chi^{2}$ index). Small chi-square values and a nonsignificant $p$ value indicate that there is little difference between the hypothesized model and the data. However, even good fitting models often fail this test since the statistical power of the test is often very high due to large sample sizes, so that even small departures from perfect model fit result in statistically significant $p$ values. Furthermore, it has been shown that the $\chi^{2}$ test of model fit is not especially robust to nonnormality and other violations of assumptions that might be expected, especially when item-level data serve as the manifest indicators of the models (Bentier, 1995). Standardized residuals between a hypothesized model and the pattern of variances and covariances are expected to be relatively small for a reasonable model. This is evaluated by examining the root mean square error of approximation (RMSEA). It is suggested that RMSEA should be smaller than 0.08 to be consider a good fit (Byrne, 2001).

The comparative fit index (CFI) will also be examined, and it should be relatively large (>.90) if a model is providing a better approximation of the data than a model that hypothesized no covariances among variables. At a micro level, the significance of specific hypothesized paths, and the percentage of explained variance for all dependent constructs was examined. Significant and meaningful predictors are identified by significant path coefficients to the dependent constructs, and at least a moderate degree of explained variance is expected. Chi-square difference tests were conducted to compare nested models represented in the current study. By subtracting the chi-square and degrees of freedom values for relevant nested models from a fuller model and assessing the significance of the incremental difference, the importance of competing models can be evaluated. If the difference in 
models is significant, this indicates that the fuller (less restricted) model is preferred to help explain the data.

To prevent confirmation bias, and as an advanced analysis of the adequacy of the models derived from sample 1, four alternative models illustrating different conceptualizations of the structures of the Decisional Balance Inventory were compared to best interpret the data.

The models examined in Step 2 were:

(1) The Null Model. There are no latent factors in the Null Model, and this implies that all items of Decisional Balance Inventory are independent. The Null Model is applied as a baseline against which other models may be compared.

(2) One Factor Model. This model assumes one general decisional balance factor. Support for this model would suggest that subjects do not or cannot differentiate among the dimensions.

(3) Two Uncorrelated Factors Model. This model suggests that subjects could distinguish the two decisional balance factors and further that these factors are best represented as independent dimensions.

(4) Two Correlated Factors Model. This model is similar to the two uncorrelated factors model, except that the two factors are correlated. This model assumes that subjects' discrimination of decisional balance was best represented as two related dimensions.

Model results are given in Table 2.5. The one-factor model did not fit well, $\chi^{2}(7)=382.651$, $\mathrm{CFI}=.728, \mathrm{GFI}=.748, \mathrm{AGFI}=.656$, and $\mathrm{RMSEA}=.127$. The two-factor uncorrelated model fit reasonably well, $\chi_{(n)}^{2}=125.504, \mathrm{CFI}=.957, \mathrm{GFI}=.933, \mathrm{AGFI}=.909$. and $\mathrm{RMSEA}=.051$. On the other hand, the two-factor correlated model was the best-fitting model, $\chi_{(i 6)}^{2}=109.070, \mathrm{CFI}=.971, \mathrm{GFI}=$ $.940, \mathrm{AGFI}=.917$, and RMSEA $=.042 . \mathrm{A} \chi^{2}$ difference comparison of the two-factor uncorrelated and the two-factor correlated models was significant, $\chi_{(1)}^{2}=16.434, \mathrm{p}<.001$, indicating that the two-factor correlated model is a better representation of the data. The correlation between the two factors was . 305 . The models are presented in Figure 2.1.

\section{Step 3: External Validity of Decisional Balance Inventory}

In step 3, all 491 students were included to examine the external validity of Decisional Balance Inventory: Of the 419 students, $103(21.0 \%)$ were in Precontemplation, $137(27.9 \%)$ were in 
Contemplation, 61 (12.4\%) were in Preparation, $162(33.0 \%)$ were in Action, 24 (4.9\%) were in Maintenance, and $4(0.8 \%)$ did not provide this information. The summary statistics of Decisioinal Balance Inventory and Stage of Weight Managament were shown in Table 2.6 and 2.7.

External validity of DBI: Overall Participants: Gender by Stoge

Sample size did not permit a 3-way analysis of stage, gender, and BMI-group effects, so 2-way analysis was conducted. A first two-way multivariate analysis of variance (MANOVA) was applied to decide if the pros and cons of losing weight differ across the stages of change and gender. The assumptions for MANOVA were first examined and no violations were detected. Stage of change and gender served as the independent variables, while pros and cons were used as dependent variables. The MANOVA resulted in a significant main effect for Stage of change Wilk's $\Lambda=.884$, approximate $F(8,952)=7.60, p<.0001$, and multivariate $\eta^{2}=.12$. The MANOVA resulted in a non-significant main effect for gender, Wilk's $\Lambda=.988$, approximate $\mathrm{F}(2,476)=2.82, \mathrm{p}=.061$, and multivariate $\eta^{2}=$ 012. The MANOVA also resulted in a non-significant interaction effect for Stage and gender, Wilk's $\Lambda$ $=.981$, approximate $\mathrm{F}(8,952)=1.17, \mathrm{p}=.319$, and multivariate $\eta^{2}=.019$. This indicates that the effect of Stage did not depend on gender. Therefore, the effect of gender was not considered further in the analyses.

Since the results indicate that pros and cons varied by stage of change, these provided evidence of external validity for the instrument. Post-hoc follow-up tests included analyses of variance (ANOVA) and Tukey tests.

A ANOVA showed that the Pros scale was significantly different across the five stages of change, $F(4,477)=5.12, p<.001, \eta^{2}=.088$, which was a moderate effect size. Post-hoc tests showed the Pros for Precontemplators was significantly lower compared with participants in all other stages.

The Cons scale was also significantly different across the stages of change, $F(4,477)=2.55, p$ $=0.007, \eta^{2}=.046$. However, post-hoc tests did not show any specific significant differences among the stages of change.

External validity of DBI: Overall Participants: BMI by Stage

A second Two-way MANOVA was conducted using stage and the two BMI (normal vs. overweight/obesity) groups as independent variables. The assumptions for MANOVA were first 
examined and no violations were detected. The MANOVA resulted in a significant main effect for Stage of change, Wilk's $\Lambda=.912$, approximate $F(8,952)=5.60, p<.0001$, multivariate $\eta^{2}=.088$. The MANOVA resulted in a significant main effect for BMI status, Wilk's $\Lambda=.961$, approximate $F(2,476)$ $=9.75, \mathrm{p}<.0001$, and multivariate $\eta^{2}=.039$. The MANOVA resulted in a non-significant interaction effect for Stage and BMI, Wilk's $\Lambda=.978$, approximate $F(8,952)=1.31, p=.2347$, and multivariate $\eta^{2}$ $=.022$.

A ANOVA showed that the Pros scale was significantly different across the five stages of change, $F(9,477)=7.21, p<.001, \eta^{2}=.120$, which was a moderate effect size. Post-hoc tests showed the Pros for Precontemplators was significantly lower compared with participants in all other stages.

The Cons scale was also significantly different across the stages of change, $F(9,477)=2.61$, $p$ $=0.006, \eta^{2}=.047$. However, post-hoc tests did not show any specific significant differences among the stages of change. The standardized $(M=50, S D=10)$ patterns of decisional balance across stages are presented in Figures 2.2, 2.3 and 2.4.

Step 4: Factor Invariance of Decisional Balance Inventory

For researchers, it is a crucial question to ask whether an instrument measures the same trait among groups of populations and whether or not the measure functions equivalently across the participants from subgroups. Previous researchers have applied exploratory factor analy sis to evaluate the factor invariance across various groups. However, this approach has been criticized (Alwin \& Jackson, 1981). Confirmatory factor analysis was then recommended (Cole, 1987). Some researchers fit identical models to different groups and then conducted confirmatory factor analysis separately for each group. This approach examines only individual parameter estimates and does not compare goodness of fit among groups directly. Multiple-group confirmatory factor analysis (i.e., multiple sample modeling) could deal with the concerns when single confirmatory factor analysis is used, because the same model is imposed among groups and is analyzed simultaneously (Jöreskog \& Sorbom, 1989).

The purposes of this step were to examine the level of factorial invariance of the Decisional Balance Inventory across two sets of demographic variables: (1) high school students with different BMI status, and (2) gender. 
Chi-square difference tests were conducted to compare nested models to decide the best fitting model. By subtracting the chi-square and degrees of freedom values for relevant nested models from a fuller model and assessing the significance of the incremental difference, the importance of competing models was evaluated. In other words, if the difference in models is significant, it indicates that the fuller model is preferred to help explain the data. However, even good fitting models often fail this test since the statistical power of the test is often very high due to large sample sizes, so that even small departures from perfect model fit result in statistically significant $\mathrm{p}$ values. Cheung and Rensvold (2002) recommended $\triangle C F I$ test to evaluate the best fitting model. They suggested that if the absolute value of $\triangle C F I$ is equal or small than the cutoff (i.e., 01), the null hypothesis of invariance cannot be rejected. Chi-square difference tests and $\Delta$ CFI test were applied to evaluate the best model.

Pre-Study: tests for factor invariance across high school student

In pre-study; four hierarchical analyses with different parameter invariance assumptions (Jöreskog \& Sörbom, 1989) were presented and examined.

Model 1, a congeneric model, assumes the same conceptual mapping in Sample One and Sample Two. The two groups have the same factor and/or regression structure, but may have different loadings, factor variances, and error variances.

Model 2, a lambda-invariant model, assumes the two groups have the same factor structure and their item factor loadings are also held equal.

Model 3, a tau-equivalent model has the same assumptions as model 2, except model 3 also limits the factor variances to be equivalent across subgroup.

Model 4, a parallel model, tests whether the entire measurement structure is equal across groups. A parallel model assumes that factor loadings, factor variances, and error variances are the same across samples.

The congeneric model fit well, $\chi_{(152)}^{2}=298.99, \mathrm{CFI}=930$, and RMSEA $=.044$. The lambdainvariance model fitted reasonably well, $\chi_{(166)}^{2}=312.15, \mathrm{CFI}=.930$, and RMSEA $=.042$. A $\chi^{2}$ difference comparison of the congeneric model and the lambda-invariance model was not significant, $\chi_{(14)}^{2}=13.16, \mathrm{p}>0.01$. 
The tau equivalent model fitted reasonably well, $\chi_{(167)}^{2}=312.36, \mathrm{CFI}=.930$, and RMSEA $=$ $.042 . \mathrm{A} \chi^{2}$ difference comparison of the lambda-Invariance model and the tau equivalent model was not significant, $\chi_{(1)}^{2}=0.21, \mathrm{p}>0.01$.

The parallel model fitted reasonably well, $\chi_{(181)}^{2}=324.46, \mathrm{CFI}=.931$, and RMSEA $=.040 . \mathrm{A}$ $\chi^{2}$ difference comparison of the tau equivalent model and the parallel model was not significant $\chi_{(14)}^{2}=$ 12.1, $\mathrm{p}>0.01$. Thus, results indicated that the parallel equivalent model was the preferred model for the pros and cons across randomly-split-half groups (see Table 2.8).

Tests for factor invariance across high school students with different BMI status

In sub-step one, four hierarchical analyses with different parameter invariance assumptions (Jöreskog \& Sörbom, 1989) were presented and examined. The models tested were the congeneric model, lambda-invariant model, tau-equivalent model and parallel model.

The congeneric model fit well, $\chi_{(152)}^{2}=322.87, \mathrm{CFI}=.917$, and RMSEA $=.048$. The lambdainvariance model fitted reasonably well, $\chi_{(166)}^{2}=346.31$, CFI $=.912$, and RMSEA $=.047 . \mathrm{A} \chi^{2}$ difference comparison of the congeneric model and the lambda-invariance model was not significant, $\chi_{(14)}^{2}=23.44, p>0.01$

The tau equivalent model fitted reasonably well, $\chi_{(16 i)}^{2}=353.67, \mathrm{CFI}=.909$, and RMSEA $=.048$. A $\chi^{2}$ difference comparison of the lambda-Invariance model and the tau equivalent model was significant, $\chi_{(1)}^{2}=7.36, \mathrm{p}<0.01$, indicating that the tau equivalent model is a better representation of the data.

The parallel model fitted reasonably well, $\chi_{(181)}^{2}=369.44, \mathrm{CFI}=.909$, and RMSEA $=.046 . \mathrm{A}$ $x^{2}$ difference comparison of the tau equivalent model and the paralleled model was not significant. $\chi^{2}(14)$ $=15.77, \mathrm{p}>0.01$.

The detail results of hierarchical models for decisional balance were demonstrated in Table 2.8. Results indicated that the tau equivalent model was the preferred model for the decisional balance across the two BMI groups. In this study; the parallel model was not preferred, and implied that the two BMI subgroups may be treated as arising from different populations.

Tests for factor invariance across gender 
In sub-step 2, four hierarchical analyses with different parameter invariance assumptions (Jöreskog \& Sörbom, 1989) were presented and examined. The models tested were the congeneric model, lambda-invariant model, tau-equivalent model and parallel model.

The congeneric model fit well, $\chi_{(152)}^{2}=341.02, \mathrm{CFI}=.911$, and RMSEA $=.050$. The lambdainvariance model fitted reasonably well, $\chi_{(166)}^{2}=354.53, \mathrm{CFI}=.911$, and RMSEA $=.048 . \mathrm{A} \chi^{2}$ difference comparison of the congeneric model and the lambda-invariance model was not significant; $\gamma_{(14)}^{2}=13.51, \mathrm{p}>0.01$

The tau equivalent model fitted reasonably well, $\chi^{2}{ }_{(167)}=354.73$. CFI $=.912$, and RMSEA $=$ $.048 . \mathrm{A} \chi^{2}$ difference comparison of the lambda-Invariance model and the tau equivalent model was not significant, $\chi_{(1)}^{2}=0.2, \mathrm{p}>0.01$.

The parallel model fitted reasonably well, $\chi_{(181)}^{2}=369.80, \mathrm{CFI}=.911$, and RMSEA $=.046 . \mathrm{A}$ $\chi^{2}$ difference comparison of the tau equivalent model and the parallel model was not significant, $\chi^{2}(14)=$ $15.07, \mathrm{p}>0.01$.

The detail results of hierarchical models for decisional balance were demonstrated in Table 2.8. Results indicated that the parallel equivalent model was the preferred model for the decisional balance across gender groups. The result of preference of parallel model implied that the gender subgroups can be treated as arising from the same population.

\section{Discussion}

Developing interventions for decreasing adolescent overweight/obesity requires the development of psychometrically sound measures. The goal of the investigation was to examine the applicability of the concept of decisional balance for weight management behavior in an adolescent population in Taiwan. A 14-item instrument that examines two dimensions of decisional balance, Pros and Cons, was generated from the item selection procedures. Each dimension included seven items, and demonstrated reasonable imternal consistency reliability. Confirmatory factor analysis verified the competence of the two-factor model for decisional balance for high school students in Taiwan.

The results suggest that the two-factor structure covers the area adequately. This result supports the conceptual framework of decisional balance, and strengthens the robustness of existing theories of decision making (Janis \& Mann, 1977). The two-dimensional Decisional Balance Inventory 
Chinese version also supports findings from previous empirical research (Akamatsu, Otake \& Shimai, 2003; O'Connell \& Velicer, 1988). Overall, the significant MANOVA results implied perceived pros and cons of losing weight were different across stages of change in adolescent population. Results from two-way MANOVAs showed that the main effect of Stage depended on neither the level of gender nor the level of BMI status. There was no main effect for gender. However, there was statistically: significant main effect from BMI status.

The strong and weak principles of the concept of decisional balance (Prochaska, 1994) indicate that the pros increase by a standard deviation, and the cons decrease by half a standard deviation from the stage with least pros (or cons) to the stage with greatest pros (or cons). In this study, the pros increased almost one standard deviation (0.739), and the cons decreased less than one-half standard deviation (0.332). Therefore, the results support the strong and weak principles.

Equivalence of the Decisional Balance Inventory Chinese edition among high school students in Taiwan was also examined. A multisampling model was applied to examine factor invariance of the DBI across two sets of demographic variables (i.e., different BMI status, gender). Results from multiple-sample confirmatory factor analysis suggested that gender subgroups can be treated as arising from the same population. On the other hand, results indicated that the tau equivalent model, instead of parallel model, was the preferred model for the decisional balance across the two BMI groups. Based on this result, the concept of decisional balance in students whose BMI was in the normal range with intention of losing weight may be different from the students who were overweight or obese. However, since the tau equivalent model is a very restrict model, this strict interpretation may not be realistic or practical. The reason why the parallel model was not preferrd in this case since the error variances were not same across among BMI groups.

This study has several limitations. Participants for the investigation were from a high school in rural area in Taiwan. Therefore, the results from the study may not be representative of the situation of all high school students in Taiwan, limiting generalizability. This investigation is cross-sectional study; therefore, it is hard to draw a causal relationship among variables.

When applying the Transtheoretical model in Asian cultures, one of the most important concerns is whether the psychological constructs (e.g., self-efficacy) still maintain the same 
meanings/psychological qualities, which refers to the issue of conceptual equivalence (Brislin, 1993; Okazaki, \& Sue, 1995). Even the back-translation techniques were applied to develop the Chinese versions of questionnaires to ensure equivalence; however, there is no direct evidence of conceptual. and/or metrical equivalence.

This investigation should stimulate research toward an increased understanding of weight management in adolescents in Asia. The current study provided support for application of the concept of decisional balance to weight management in an adolescent population. However, these data are cross sectional in nature. It is recommended that future researchers conduct longitudinal studies in this topic. Current investigation was not an experimental study; but a correlational one. Future researchers may collect experimental data to test casual effects.

Other characteristics of students may also contribute the students' status of stage of change in weight management in Asia, such as social economics status, family influences, and peer influences; future researchers may investigate those factors. Researchers should also make efforts to assess the relevance of and control for as many background conditions as possible.

Research results are limited by using high school students in rural area in Taiwan. It is recommended that future studies should be conducted in larger, more diverse and representative samples. Replication of the current findings with other samples will provide increased validity for the application of the TTM to the study of weight management. Moreover, future researchers should crossvalidate the current findings on other data. Decisional balance, an empirically supported behavior change concept, would enable researchers and clinicians to more effectively design, target, and monitor the progress of interventions for weight management in adolescents in Asia. 


\section{Reference}

Alwin, D. F. \& Jackson. D. J. (1981). Applications of simultaneous factor analysis to issues of factorial invariance. In D. D. Jackson \& E. P. Borgotta (Eds.) Factor analysis and measurement in sociological research: A multidiniensional perspective. Beverly Hills, CA: Sage.

Akamatsu R., Otake K., \& Shimai, S. (2003). Development of Japanese Decision Balance Index (DBI) and stage of behavioral change. Japanese Journal of Health Psychology, 16, 1-9.

Bray; G.A.(1985). Complications of obesity. Amnuals of Internal Medicine, 103, 1052-1062.

Brislin. R. (1993). Understanding culture's infuence on behavior. New York: Harcourt Brace.

Byrne, B.N. (2001). Structural Equation Modeling with AMOS. Rahwah, NJ: Lawrence Erlbaum Associates.

Chang, C-J., Wu, C-H., Chang, C-S., Yao, W-J., Yang, Y-C., Wu, J-S., \& Lu, F-H. (2003). Low body mass index but high percent body fat in Taiwanese subjects: implications of obesity cutoffs. International journal of Obesity, 27, 253-259.

Cheung. G.W., \& Rensvold, R. B. (2002). Evaluating goodness-of-fit indexes for testing measurement invariance. Struciural Equation Modeling, 9, 233-255.

Clark, M. M., Abrams, D. B., Niaura, R. S., Eaton, C. A., \& Rossi, J. S. (1991). Self-efficacy in weight management. Journal of Consulting and Clinical Psychology, 59, 739-744.

Cole, D. A. (1987). Utility of confirmatory factor analysis in test validation research. Journal of Consulting and Clinical Psychology, 55, 584-594.

Deurenberg, P., Deurenberg-Yap, M.. \& Guricci, S. (2002). Asians are different from Caucasians and from each other in their body mass index/body fat per cent relationship. The International Association for the Study of Obesity. Obesity reviews, 3, 141-146.

Deurenberg-Yap, M., Schmidt, G., van Staveren, W.A., \& Deurenberg, P. (2000). The paradox of low body mass index and high body fat percentage among Chinese, Malays and Indians in Singapore. International Journal of Obesity, 24, 1011-1017.

Deurenberg- Yap, M., Tan, B.Y., Chew, S.K., Deurenberg, P., \& van Staveren, W.A. (1999). Manifestation of cardiovascular risk factors at low levels of body mass index and waist-hip ratio in Singaporearr-Chinese. Asia Pacific Journal of Clinical Nutrition, 8, 177-183. 
Deurenberg, P., Yap, M., van Staveren, W.A. (1998). Body mass index and percent body fat: a metaanalysis among different ethnic groups. International Journal of Obesity, 22, 1164-1 171.

Feinleib, M. (1985). Epidemiology of obesity in relation to health hazards. Anmuals of Internal Medicine, 103, 1019-1024.

Gidding. S.S. (1995). A perspective on obesity. The American Journal of the Medical Sciences, 310, S68-71.

Greene, G.W., Rossi, S.R., Rossi, J.S., Velicer, W.F., Fava, J.L., \& Prochaska, J.O. (1999). Dietary applications of the stages of change model. Journal of the American Dietetic Association, 99, 673678.

Guricci, S., Hartriyanti, Y., Hautvast, JGAJ, Deurenberg, P. (1998). Relationship between body fat and body mass index: differences between Indonesians and Dutch Caucasians. Europe Journal of Clinical Nutrition, 52, 779-783.

Hall, K.L., \& Rossi, J.S. (2005). Meta-analysis of the structure, function, and effect size of decisional balance across the stages of change for 25 health behaviors. Annals of Behovioral Medicine, 24 , S051.

Hargreaves, M.K, Schlundt, D.G., Buchowski, M.S., Hardy; R.E., Rossi, S.R., \& Rossi, J.S. (1999). Stages of change and the intake of dietary fat in African-American women: Improving stage assignment using the Eating Styles Questionnaire. Journal of the American Dietetic Association. 99, 1392-1399.

Hoffmans MDAF, Kromhout D, de Lezenne Coulander C. (1988). The impact of body mass index of 78,612 18-year old Dutch men on 32-year mortality from all causes. Journal of Clinical Epidemiologv, 41, 749-756.

Horn, J. L. (1965). A rationale and test for the number of factors in factor analysis. Psychometrika, 32. 179-185.

Huang, Y.C., Wu, J.Y., \& Yang, M.J. (2003). Weight-for-height reference and the prevalence of obesity for school children and adolescents in Taiwan and Fuchien Areas. Journal of Chinese Medical Association, 66, 599-606. 
Janis, I. \& Mann. L. (1977). Decision Making: A Psychological Analysis of Conflict, Choice and Conmitment. New York: Free Press.

Joreskog, K.G. \& Sorbom, D. (1989). LISREL 7 (2nd ed.). A Guide to the Program and Applications. Chicago: SPSS.

Kissebah, A.H., Freedman, D.S., \& Peiris, A.N. (1989). Health risks of obesity: The Medical Clinics of North Anerica, 73, 111-138.

Liu, L., Choudhury, S.R., Okayama, A., Hayakawa, T., Kita,Y., \& Ueshima, H. (1999). Changes in body mass index and its relationships to other cardiovascular risk factors among Japanese population: results from the 1980 and 1990 national cardiovascular surveys in Japan. Journal of Epidemiology, 9, 163-174.

Lowry; R., Galuska, D.A., Fulton, J.E., Wechsler, H., \& Kann, L. (2002). Weight management goals and practices among US high school students: Associations with physical activity; diet, and smoking. Journal of Adolescent Health, 31, 133-144.

Lu. F.H.,Yang, Y.C. Wu.J.S.,Wu,C.H., \& Chang, C.J.(1998). A population-based study of the prevalence and associated factors of diabetes mellitus in southern Taiwan. Diabetic Medicine: a Journal of the British Diabetic Assaciation, 15, 564-572.

Manson, J., Willett, W.C., Stampfer, M.J., et al. (1995). Body weight and mortality among women. New England Journal of Medicine, 333, 677-685.

Masuda, T., Imai, K., \& Komiya, S. (1993). Relationship of anthropometric indices of body fat to cardiovascular risk in Japanese women. The Annuals of Physiological Anthropology, 12, 135-144.

O'Connell, D., \& Velicer, W. F. (1988). A decisional balance measure and the stages of change model for weight loss. International Journal of the Addictions, 23, 729-750.

Okazaki, S., \& Sue, S. (1995). Methodological issues in assessment research with ethnic minorities. Psychological Assessment, 7, 367-375.

Pan, W.H., Flegal, K.M., Chang, H.Y., Yeh, W.T., Yeh, C.J., \& Lee, W.C. (2004). Body mass index and obesity-related metabolic disorders in Taiwanese and US whites and blacks: implications for definitions of overweight and obesity for Asians. American Journal of Clinical Nutrition, 79, 31 39. 
Prochaska, J.O. (1994). Strong and weak principles for progressing from precontemplation to action on the basis of twelve problem behaviors. Health Psychology, 13, 47-51.

Prochaska, J.O., DiClemente, C.C., \& Norcross, J.C. (1992). In Search of how people change, American Psychologist, 1102-1114.

Prochaska, J. O., Norcross, J. C., Fowler, J. L., Follick, M. J., \& Abrams, D. B. (1992). Attendance and outcome in a work site weight control program: Processes and stages of change as process and predictor variables. Addictive Behaviors, $17,35-45$.

Prochaska, J.O., Velicer, W.F., Rossi, J.S., Goldstein, M.G., Marcus, B.H., Rakowski, W., Fiore, C., Harlow, L.L., Redding, C.A., Rosenbloom, D., \& Rossi, S.R. (1994). Stages of change and decisional balance for 12 problem behaviors. Health Psychology, 13, 39-46.

Rossi. J.S. (1995). Why do people fail to maintaim weight loss? In D.B. Allison \& F.X. Pi-Sunyer (Eds.), Obesity treatment: Establishing goals, improving outcomes, and reviewing the research agenda (pp. 97-102). New York: Plenum.

Rossi, J.S., Rossi, S.R., Velicer, W.F., \& Prochaska, J.O. (1995). Motivational readiness to control weight. In D.B. Allison (Ed.), Handbook of assessment methods for eating behoviors and weightrelated problems: Measures, theory, and research (pp. 387-430). Thousand Oaks, CA: Sage.

Rossi, S.R., Rossi, J.S., Rossi-DelPrete, L.M., Prochaska, J.O., Banspach, S.W., \& Carleton, R.A. (1994). A processes of change model for weight control for participants in community-based weight loss programs. International Journal of the Addictions, 29, 161-177.

Simopolous, A.P. \& Van Itallie, T.B. (1984). Body weight, health and longevity: Annuals of Internal Medicine, 100, 285-295.

Strauss, R. S. (1999). Childhood obesity. Current Problems in Pediatrics, 29, 1-29.

Vallis, M., Ruggiero, L., Greene, G., Jones, H., Zinman, B., Rossi, S., Edwards, L., Rossi, J.S., \& Prochaska, J.O. (2003). Stages of change for healthy eating in diabetes: Relation to demographic, eating-related, health care utilization, and psychosocial factors. Diabetes Care, 26, 1468-1474.

Velicer, W. F. (1976). Determining the number of components from the matrix of partial correlations. Psychometrika, 41, 321-327. 
Velicer; W. F., Eaton, C. A., \& Fava, J. L. (2000). Construct explication through factor or component analysis: A review and evaluation of alternative procedures for determining the number of factors or components. In R. D. Goffin \&amp; E. Helmes (Eds.), Problems and solutions in human assessment: Honoring Douglas N. Jackson at seventy. Norwell, MA: Kluwer Academic.

Wang. J., Thornton, J.C., Russell, M., Burastero, S., Shen, J., Tanenbaum, S., Heymsfield, S., Pierson, R. N.(1996). Comparison for BMI and body fat percent among Puerto Ricans, Blacks, Whites and Asians living in the New York City area. Obesity Research, 4, 377-384.

Wang, J., Thomton, J.C., Russell, M., Burastero, S., Heymsfield, S., \& Pierson, Jr, R. N. (1994). Asians have lower body mass index (BMI) but higher percent body fat than do whites: comparisons of anthropometric measurements. American Journal of Clinjcal Nutrition, 60, 23-28.

World Health Organization. Obesity: preventing and managing the global epidemic. Report of a WHO consultation on obesity; Geneva, 3-5 June, 1997. WHO: Geneva, 1998.

World Health Organization. Obesity: Preventing and Managing the Global Epidemic. WHO Obesity Technical Report Series no. 894. WHO: Geneva, 2000. 
Table 2.1. Summary statistics for Decisional Balance Inventory (by item): sample 1

\begin{tabular}{|c|c|c|c|c|c|}
\hline Item & $\mathrm{N}$ & Mean & Std Dev & Skewness & Kurtosis \\
\hline 1 & 244 & 2.311 & 1.101 & 0.553 & -0.291 \\
\hline 2 & 244 & 3.262 & 1.219 & -0.212 & -0.951 \\
\hline 3 & 244 & 2.115 & 1.145 & 0.817 & -0.143 \\
\hline 4 & 244 & 2.348 & 1.360 & 0.695 & -0.707 \\
\hline 5 & 244 & 2.074 & 1.258 & 0.947 & -0.191 \\
\hline 6 & 244 & 2.836 & 1.422 & 0.163 & -1.280 \\
\hline 7 & 244 & 2.242 & 1.297 & 0.683 & -0.671 \\
\hline 8 & 244 & 1.963 & 1.232 & 1.096 & 0.164 \\
\hline 9 & 244 & 2.693 & 1.388 & 0.378 & -1.077 \\
\hline 10 & 244 & 2.816 & 1.380 & 0.146 & -1.180 \\
\hline 11 & 244 & 2.377 & 1.366 & 0.652 & -0.787 \\
\hline 12 & 244 & 2.500 & 1.359 & 0.486 & -0.931 \\
\hline 13 & 244 & 2.344 & 1.301 & 0.685 & -0.573 \\
\hline 14 & 244 & 3.066 & 1.447 & -0.091 & -1.285 \\
\hline 15 & 244 & 2.193 & 1.224 & 0.835 & -0.248 \\
\hline 16 & 244 & 3.918 & 1.274 & -0.953 & -0.218 \\
\hline 17 & 244 & 2.475 & 1.338 & 0.443 & -0.933 \\
\hline 18 & 244 & 3.520 & 1.284 & -0.457 & -0.925 \\
\hline 19 & 244 & 3.057 & 1.366 & -0.055 & -1.164 \\
\hline 20 & 244 & 2.824 & 1.470 & 0.175 & -1.315 \\
\hline
\end{tabular}


Table 2.2. Items by scale and varimax pattern for the Decisional Balance Inventory

\begin{tabular}{|l|l|l|}
\hline Item & Pros & Cons \\
\hline 6. My self-respect would be greater if I lost weight. & $\mathbf{. 8 4 3}$ & .003 \\
\hline 10. I would be less self-conscious if I lose weight. & $\mathbf{. 8 0 1}$ & .132 \\
\hline 12. Others would have more respect for me if I lost weight. & $\mathbf{. 8 0 0}$ & .151 \\
\hline 20. I would be able to accomplish more if I carried fewer pounds. & .694 & .055 \\
\hline 2. I would feel more optimistic if I lost weight. & .684 & -.075 \\
\hline 8. My family would be proud of me if I lose weight. & $\mathbf{. 6 7 3}$ & .156 \\
\hline 4. I would feel sexier if I lost weight. & .531 & -.039 \\
\hline $\begin{array}{l}\text { 13. I would have to cut down on some of my favorite activities if I try to } \\
\text { lose weight. }\end{array}$ & .135 & .679 \\
\hline $\begin{array}{l}\text { 7. My dieting could make meal planning more difficult for my family or } \\
\text { housemates. }\end{array}$ & -.135 & .628 \\
\hline 11. Dieting would take the pleasure out of meals. & -.178 & .626 \\
\hline $\begin{array}{l}\text { 17. Trying to lose weight could end up being expensive when everything } \\
\text { is taken into account. }\end{array}$ & -.065 & $\mathbf{. 6 0 5}$ \\
\hline $\begin{array}{l}\text { 15. I would have to avoid some of my favorite places if I were trying to } \\
\text { lose weight. }\end{array}$ & .240 & .5294 \\
\hline 5. In order to lose weight I would be forced to eat less appetizing foods & .237 & .556 \\
\hline 3. I would be less productive in other areas if I was trying to lose weight. & .132 & .540 \\
\hline
\end{tabular}


Table 2.3. Means, standard derivations, and coefficient alphas for Decisional Balance Inventory Chinese version

\begin{tabular}{|c|c|c|c|c|c|c|}
\hline & \multicolumn{3}{|c|}{ Sample 1 $(\mathrm{N}=244)$} & \multicolumn{3}{c|}{ Sample 2 (N=247) } \\
\hline Scale & Alpha & Mean & SD & Alpha & Mean & SD \\
\hline Pros (7 items) & .849 & 18.549 & 6.861 & .878 & 18.591 & 7.130 \\
\hline Cons (7 items) & .717 & 15.820 & 5.445 & .771 & 15.943 & 5.936 \\
\hline
\end{tabular}


Table 2.4. Summary statistics for Decisional Balance Inventory (by item): sample 2

\begin{tabular}{|c|c|c|c|c|c|}
\hline Item & $\mathrm{N}$ & Mean & Std Dev & Skewness & Kurtosis \\
\hline 1 & 247 & 2.255 & 1.080 & 0.727 & 0.154 \\
\hline 2 & 247 & 3.320 & 1.252 & -0.311 & -0.857 \\
\hline 3 & 247 & 2.045 & 1.180 & 0.976 & 0.094 \\
\hline 4 & 247 & 2.502 & 1.312 & 0.458 & -0.872 \\
\hline 5 & 247 & 2.057 & 1.228 & 0.966 & -0.070 \\
\hline 6 & 247 & 2.785 & 1.367 & 0.259 & -1.087 \\
\hline 7 & 247 & 2.247 & 1.403 & 0.729 & -0.811 \\
\hline 8 & 247 & 1.858 & 1.158 & 1.324 & 0.915 \\
\hline 9 & 247 & 2.818 & 1.415 & 0.179 & -1.242 \\
\hline 10 & 247 & 2.919 & 1.457 & 0.062 & -1.338 \\
\hline 11 & 247 & 2.457 & 1.348 & 0.628 & -0.760 \\
\hline 12 & 247 & 2.336 & 1.348 & 0.614 & -0.843 \\
\hline 13 & 247 & 2.510 & 1.388 & 0.494 & -1.042 \\
\hline 14 & 247 & 2.960 & 1.422 & -0.014 & -1.290 \\
\hline 15 & 247 & 2.166 & 1.220 & 0.856 & -0.194 \\
\hline 16 & 247 & 3.883 & 1.216 & -0.841 & -1.253 \\
\hline 17 & 247 & 2.462 & 1.358 & 0.475 & -0.942 \\
\hline 18 & 247 & 3.449 & 1.305 & -0.392 & -0.940 \\
\hline 19 & 247 & 2.980 & 1.336 & -0.025 & -1.146 \\
\hline 20 & 247 & 2.870 & 1.451 & 0.131 & -1.307 \\
\hline
\end{tabular}


Table 2.5. Decisional Balance Inventory Chinese version: Summary of model fit indices

\begin{tabular}{|l|l|l|l|l|l|l|}
\hline Model & $\chi^{2}$ & Df & CFI & GFI & AGFI & RMSEA \\
\hline One-factor & 382.651 & 77 & .728 & .748 & .656 & .127 \\
\hline Two-factor uncorrelated & 125.504 & 77 & .957 & .933 & .909 & .051 \\
\hline Two-factor correlated & 109.070 & 76 & .971 & .940 & .917 & .042 \\
\hline
\end{tabular}


Table 2.6. Summary statistics for overall participants

\begin{tabular}{|l|l|l|l|l|l|}
\hline Variable & N & Mean & Std Dev & Skewness & Kurtosis \\
\hline Pros & 491 & 18.570 & 6.990 & 0.382 & -0.583 \\
\hline Cons & 491 & 15.882 & 5.692 & 0.491 & -0.223 \\
\hline
\end{tabular}


Table 2.7. Summary Statistics by Stage of Change

\begin{tabular}{|c|c|c|c|c|c|}
\hline \multicolumn{6}{|c|}{ Overall participants $(\mathrm{N}=491)$} \\
\hline \multirow[t]{2}{*}{ Stage of Change } & \multirow[t]{2}{*}{$N$} & \multicolumn{2}{|c|}{ Pros } & \multicolumn{2}{|c|}{ Cons } \\
\hline & & Mean & SD & Mean & SD \\
\hline Precontemplation & 103 & 15.175 & 6.282 & 17.136 & 6.275 \\
\hline Contemplation & 137 & 18.453 & 6.823 & 15.431 & 4.897 \\
\hline Preparation & 61 & 20.148 & 6.663 & 16.869 & 6.278 \\
\hline Action & 162 & 19.778 & 6.771 & 15.265 & 5.441 \\
\hline Maintenance & 24 & 22.000 & 7.885 & 14.833 & 6.357 \\
\hline \multicolumn{6}{|c|}{ Normal BMI with intention of losing weight $(\mathrm{N}=324$, Missing $=2)$} \\
\hline \multirow[t]{2}{*}{ Stage of Change } & $N$ & \multicolumn{2}{|c|}{ Pros } & \multicolumn{2}{|c|}{ Cons } \\
\hline & & Mean & SD & Mean & SD \\
\hline Precontemplation & 82 & 14.780 & 5.848 & 17.366 & 6.508 \\
\hline Contemplation & 81 & 16.506 & 5.831 & 15.407 & 4.795 \\
\hline Preparation & 42 & 19.429 & 6.829 & 16.881 & 6.306 \\
\hline Action & 102 & 19.206 & 6.512 & 16.137 & 5.624 \\
\hline Maintenance & 17 & 21.765 & 7.718 & 16.529 & 6.709 \\
\hline \multicolumn{6}{|c|}{ Participants who were overweight or obese $(\mathrm{N}=165)$} \\
\hline \multirow[t]{2}{*}{ Stage of Change } & $\mathrm{N}$ & \multicolumn{2}{|c|}{ Pros } & \multicolumn{2}{|c|}{ Cons } \\
\hline & & Mean & SD & Mean & SD \\
\hline Precontemplation & 21 & 16.71 & 7.72 & 16.24 & 5.31 \\
\hline Contemplation & 56 & 21.27 & 7.21 & 15.46 & 5.08 \\
\hline Preparation & 19 & 21.74 & 6.15 & 16.84 & 6.39 \\
\hline Action & 60 & 20.75 & 7.14 & 13.78 & 4.80 \\
\hline Maintenance & 7 & 22.57 & 8.89 & 10.71 & 2.63 \\
\hline
\end{tabular}


Table 2.8. Summary of Multiple Sample Model Results

\begin{tabular}{lllllllll}
\hline Construct & CFI & RMSEA & $\chi^{2}$ & df & $\chi^{2} / d f$ & $\chi^{2}$ diff & P & $\Delta C F I$
\end{tabular}

(df)

\begin{tabular}{|c|c|c|c|c|c|c|c|c|}
\hline \multicolumn{9}{|l|}{ Random selected } \\
\hline Congeneric & .930 & .044 & 298.99 & 152 & 1.97 & & & \\
\hline Lambda-Invariant & .930 & .042 & 312.15 & 166 & 1.88 & $13.16(14)$ & ns & 0 \\
\hline Tau Equivalent & .930 & .042 & 312.36 & 167 & 1.87 & $0.21(1)$ & ns & 0 \\
\hline Paralleled & .931 & .040 & 324.46 & 181 & 1.79) & 12.1(14) & ns & .01 \\
\hline \multicolumn{9}{|l|}{ Different BMI } \\
\hline Congeneric & .917 & .048 & 322.87 & 152 & 2.12 & & & \\
\hline Lambda-Invariant & .912 & .047 & 346.31 & 166 & 2.09 & $23.44(14)$ & ns & -.005 \\
\hline Tau Equivalent & .909 & .048 & 353.67 & 167 & 2.12 & $7.36(1)$ & $\begin{array}{l}< \\
.01\end{array}$ & -.003 \\
\hline Paralleled & .909 & .046 & 369.44 & 181 & 2.04 & $15.77(14)$ & $\mathrm{ns}$ & 0 \\
\hline \multicolumn{9}{|l|}{ Different gender } \\
\hline Congeneric & .911 & .050 & 341.02 & 152 & 2.24 & & & \\
\hline Lambda-Invariant & .911 & .048 & 354.53 & 166 & 2.14 & $13.51(14)$ & ns & 0 \\
\hline Tau Equivalent & .912 & .048 & 354.73 & 167 & 2.12 & $0.2(1)$ & ns & .01 \\
\hline Paralleled & .911 & .046 & 369.80 & 181 & 2.04 & $15.07(14)$ & ns & -.01 \\
\hline
\end{tabular}




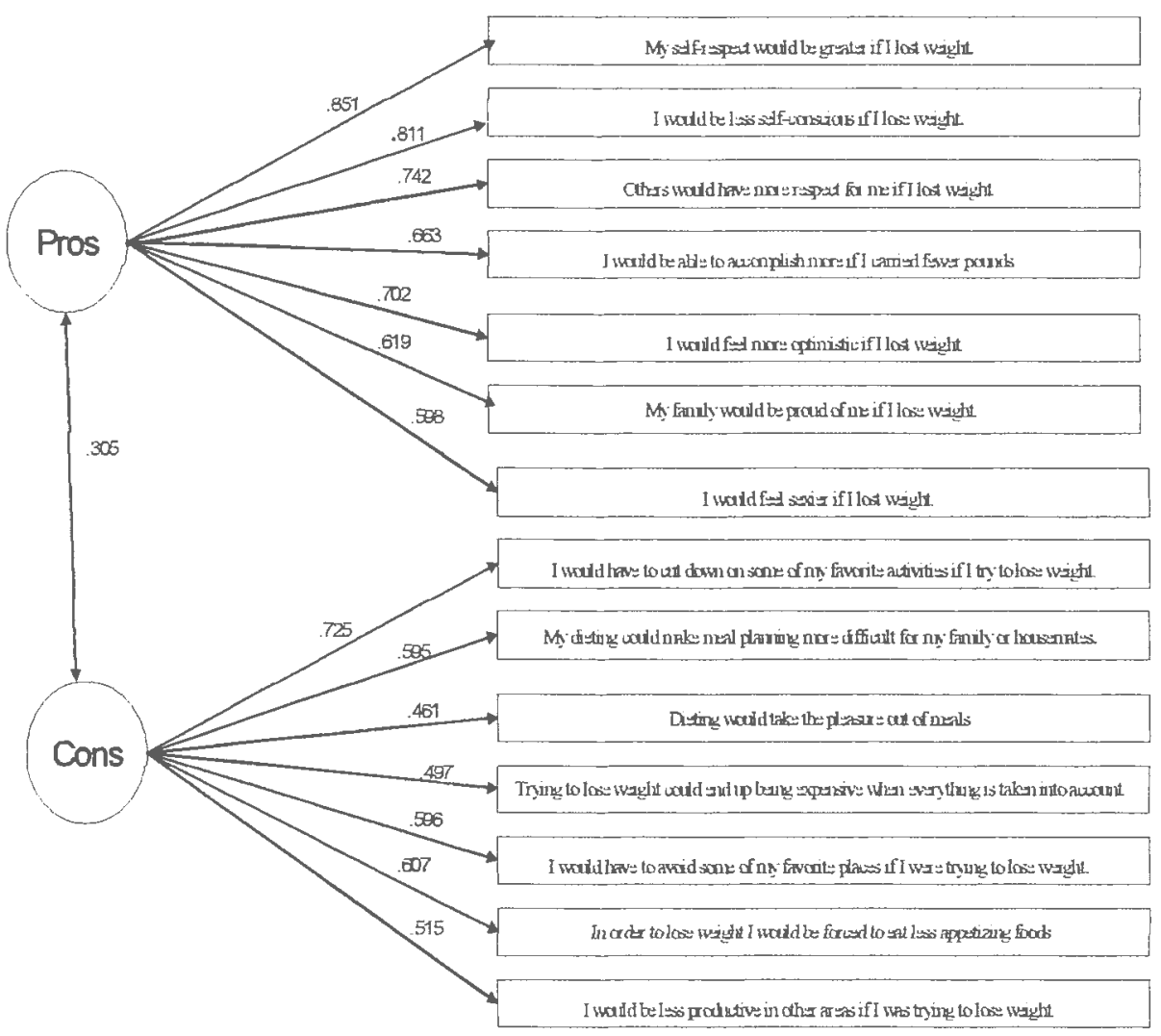

Figure 2.1. Two correlated factor model for decisional balance 
Decisional Balance: overall participants

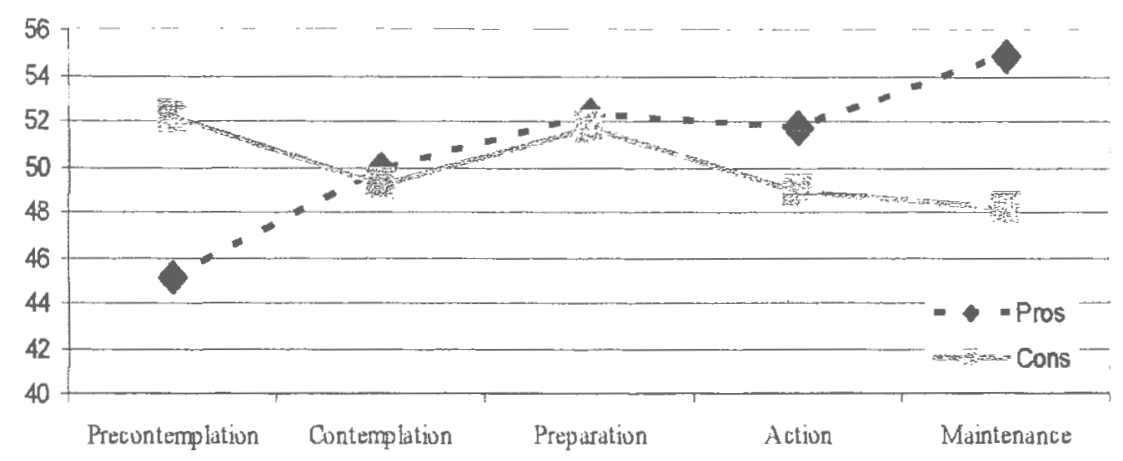

Figure 2.2: Overall participants: Standardizes T score pattern for decisional balance 
Decisional Balance: Normal BMI

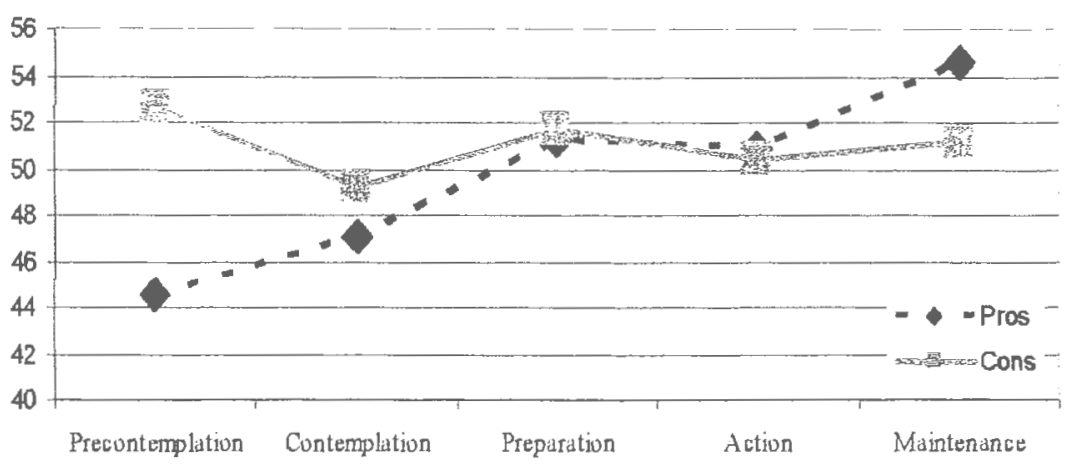

Figure 2.3. Participants with normal BMI: Standardizes T score pattem for decisional balance 
Decisional Balance: overweight/obesity

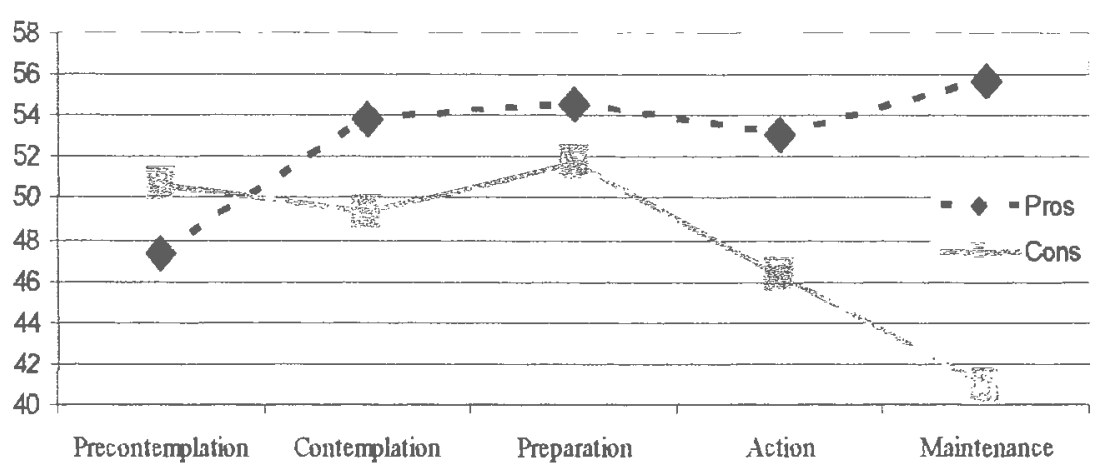

Figure 2.4. Participants who were overweight or obese: Standardizes T score pattern for decisional balance 


\section{Chapter 3. Self-efficacy for weight management in an adolescent population in Taiwan}

\section{Abstract}

Obesity in adolescents is increasing and becoming a more pervasive health problem worldwide. The increased numbers of overweight and obese children and adolescents is also an emerging health issue in Asia. Developing interventions for decreasing adolescent overweight/obesity requires the development of psychometrically well-developed measures. This investigation examines the applicability of the concept of self-efficacy in weight management behavior in an adolescent population in Taiwan. The aim of the study was to develop and evaluate a 15-item Chinese language version of the Weight Efficacy Questionnaire using a sample of 491 adolescents in Taipei high schools. Using split-half, cross-validation procedures, a hierarchical four-factor model fit the data well (CFI=.940, RMSEA $=.059)$ with adequate internal consistency for all scales: negative emotion (.80), availability and positive activities $(.80)$, social pressure $(.68)$, and physical discomfort $(.80)$. Construct validity of the scales was assessed with MANOVA, ANOVAs, and follow-up Tukey tests examining the relationships between the scales with the stages of change for weight management for all participants, students who were overweight and obese, and participants whose BMI was in the normal range but who intended to lose weight. Results supported the reliability and validity of these measures and suggested that these measures are similar to the measures for US adolescents. 


\section{Chapter 3. Self-efficacy for weight management in an adolescent population in Taiwan}

Obesity in children is growing and becoming a pervasive health problem worldwide (Troiano, Flegal, Kuczmarski, Campbell, \& Johnson, 1995). The National Health and Nutrition Examination Survey (NHANES) conducted in the US in 1999-2000 indicated that the prevalence of overweight was $15.5 \%$ among 12 through 19-year-olds, $15.3 \%$ among 6 through $11-$ year-olds, and $10.4 \%$ among 2 through 5 -year-olds. This is an increase from with $10.5 \%, 11.3 \%$, and $7.2 \%$, respectively, in 1988-1994 (NHANES III). The number of overweight children is growing rapidly in many countries in Europe as well (Ebbeling. Pawlak \& Ludwig, 2002; Guillaume, \& Lissau, 2002; Wang, Monteiro, \& Popkin, 2002).

The increased numbers of overweight and obese children and adolescents is not limited to major industrialized countries, but is also becoming an emerging health issue throughout the developing world, and even in the non-industrialized and underdeveloped nations of the world. Many areas in Asia experienced an economic transition, and, consequently; those areas also experienced a shift in nutrition intake and lifestyles. Benefiting from the growing economies, food supplies in Asia have become more stable, and more foods are available. Due to increasing globalization, westernized diet has been broadly accepted and adopted by many Asians. Changing dietary patterns and sedentary lifestyle has had a considerable impact on the prevalence of overweight and obesity in Asian adolescent populations.

A cross-sectional survey among junior high school students in Taipei in 1994 indicated the percentage of overweight children remained stable from 1980 to 1994 in both genders; however, the incidence and tendency of obesity considerably increased, especially among boys and older girls (Chu. 2001). In a 2002 nationwide survey of 86,967 children and adolescents in Taiwan and Fuchien Areas, the prevalence of obesity was $18.5 \%$ in males and $15.0 \%$ in females. In comparison with 1997 , the prevalence of childhood and adolescent obesity for both sexes was higher in 2002 (Huang, Wu, \& Yang, 2003). As in Western countries, research results have suggested that overweight and obesity can be treated as important cardiovascular risk factors, such as insulin and glucose concentrations, plasma lipid, among Asian populations (Liu, Choudhury, Okayama, Hayakawa, Kita, \& Ueshima, 1999; Masuda, Imai, \& Komiya, 1993). The research in diseases related to obesity and the statistics showing 
the growing incidence of obesity in the population strongly suggest the importance of weight control in Asian adolescents.

Meanwhile, studies also indicate that adolescents' self-perceived weight is poorly related to the medical definitions of overweight and obesity: Many adolescents who are in the range of clinically normal-weight either try to or wish to control or lose weight (Brugman et al., 1997; Kaneko, Kiriike, Ikenaga, Miyawaki, \& Yamagami, 1999; Neumark-Sztainer, Rock, Thornquist, Cheskin, Neuhouser, \& Barnett, 2000; Nowak, Speare, \& Crawford, 1996; Steen, Wadden, Foster, \& Andersen, 1996). Therefore, it is also important for researchers to look at weight management in non-clinical populations because of the population of normal-weight-range adolescents who intend to lose weight.

The Transthoeretical Model (TTM; Prochaska, DiClemente, \& Norcross, 1992) is an empirically supported theory that may serve as a possible framework for investigating the issues of weight management in Asian cultures. In the field of weight control, TTM has been mostly applied to clinical obese/overweight adult populations (Clark et al., 1991; Prochaska, Norcross, Fowler. Follick \& Abrams, 1992; Rossi, Rossi, Rossi-DelPrete, Prochaska, Banspach \& Carleton, 1994), and in some cases to college student populations (O'Connell \& Velicer, 1998). Stages of change, decisional balance, self-efficacy and processes of change are the main components of the TTM. Self-efficacy was main focus of this investigation.

The self-efficacy dimension of the TTM was originally based on Bandura's (1977) concept of self-efficacy, but has since undergone considerable elaboration within the context of the TTM. Another similar concept is situational temptations that reflect the intensity of urges to engage in a specific habit when in the midst of difficult situations. Self-efficacy has been found to monotonically increase across the five stages, whereas temptation monotonically decreases (Prochaska, Velicer, Guadagnoli, Rossi, \& DiClemente, 1991). These relations are often linear as well.

The purpose of the current investigation was to examine the applicability of the concept of Self-Efficacy in TTM in weight management behavior in an adolescent population in Taiwan. Several studies were conducted. The goal of Step 1 was to develop Chinese version of the Weight Efficacy Questionnaire for an adolescent population in Taiwan. The specific aim was to explore the underlying dimensionality of self-efficacy in weight management. It is hypothesized that five correlated 
components would best represent the self-efficacy data. Step 2 focused on confirming the validity of the Weight Efficacy Questionnaire developed in Step 1 using confirmatory factor analysis. In Step 3, the external validity of the Weight Efficacy Questionnaire was examined. MANOVA was applied to test the connection between self-efficacy and stage of change. It is expected that self-efficacy would be low for the early stages, and gradually increasing in the later stages of change. The goals of Step 4 were to examine the level of factorial invariance of the Weight Efficacy Questionnaire across two sets of demographic variables: (1) high school students with different BMI status, and (2) gender. Thus, two sub-steps were conducted to achieve the goals. In sub-step one, multiple sample model analyses were applied to examine the factor invariance between students whose BMI were in normal range but with intention of losing weight, and those were overweight and obese. In sub-step two, male and female students were compared with multiple sample model analysis.

Methods

Participants

During the 2005 school year, 780 senior high students from a high school in Taiwan were recruited into a cross-sectional study examining weight management behaviors. Of the 780 students, $492(63.16 \%)$ were first-year senior high students, and $287(36.84 \%)$ were second-year students; 388 (49.87\%) were male $390(50.13 \%)$ were female students. The majority of participants' parents had junior-, senior- or vocational- high school degrees (Table 1.3).

Weight Group Definitions

Obesity is defined as a status of excessive fat accumulation in the body to the level that health and well-being are adversely affected (World Health Organization, 2000). A popular index to describe the individual's weight status is the Body Mass Index (BMI), which is defined as body weight (kg) divided by squared body height $\left(\mathrm{m}^{2}\right)$. The conventional operational definition for obesity is BMI $\geq 30$ $\mathrm{kg} / \mathrm{m}^{2}$, while overweight is described as BMI $\geq 25 \mathrm{~kg} / \mathrm{m}^{2}$ (World Health Organization, 1998).

However, the appropriateness of adopting BMI greater than 25 for defining overweight and BMI greater than 30 for obesity for the Asian population has been questioned. There are a least two reasons to believe why "Western" BMI cutoffs might be inappropriate when applied to Asians. First, it has been shown that a different $\mathrm{BMI} /$ percent body fat $(\mathrm{BF} \%)$ relationship among ethnic groups might 
result in different cut-off points for obesity; since obesity is defined as a condition where there is excess body fat (WHO, 2000). Empirical research and meta-analysis have shown inconsistent relationship between BMI and BF\% among various ethnic groups (Chang, Wu, Chang, Yao, Yang, Wu, \& Lu, 2003; Deurenberg, Deurenberg-Yap, \& Guricci, 2002; Deurenberg, Yap, \& van Staveren, 1998). It is generally indicated that Asians have a lower BMI but a higher BF\% than Caucasians of the same age and sex (Guricci, Hartriyanti, Hautvast, \& Deurenberg, 1998; Wang, Thomton, Russell, Burastero, Shen, Tanenbaum, Heymsfield, \& Pierson, 1996). Second, from the viewpoint of the risk factors for morbidity and mortality, it might be more practical to have ethnic-group specific BMI cutoffs. That's because the prevalence of obesity would be low in Asia-Pacific region when based on WHO obesity cutoffs (World Health Organization, 1998). However, the prevalence of cardiovascular diseases and diabetes mellitus were similar for Asia-Pacific region and Western countries (Deurenberg- Yap, Tan, Chew, Deurenberg, \& van Staveren, 1999; Lu, Yang, Wu, Wu, \& Chang, 1998).

Based on the criteria recommended by Department of Health in Taiwan, the BMI cutoffs for underweight, normal, overweight and obesity among first-year male students were $<18.2,18.2-23.1$, $23.1,25.5$, respectively; while for first-year female students were $<18,18.0-22.7,22.7,25.3$, respectively: The BMI cutoffs for underweight, normal, overweight and obesity among second-year male students were $<18.6,18.6-23.4,23.4,25.6$, respectively; while for first-year female students were $<18.2,18.2-22.7,22.7,25.3$, respectively. The BMI distribution by school year and gender are shown in Table 1.1 .

Based on the response on the item asked 'how do you feel about your current weight', participants were distinguished as 'with intention of losing weight', 'stay' the same weight' and 'with intention of gaining weight'. The focus of this study is the non-clinical population with intend to lose weight and overweight/obese students. Therefore, students who were underweight and whose BMI was in the normal range but intended to maintain or gain weight were excluded. That is, only students who were either overweight, obese or in the normal range but intended to lose weight were included in the analyses. Since 491 students from the group of 780 met the criteria, they were recruited for the invesigation. Table 1.4. shows the BMI distributions of participants by weight management intention, gender, and school year. Table 1.2 shows the BMI distribution of students who participated in the 
analyses. The sample consisted of 202 males $(41.1 \%)$ and 289 females $(58.9 \%) ; 310$ were first year students $(63.1 \%)$ and 181 were second year students $(36.9 \%)$. The distributions of stages of exercise behavior of students and days of exercise were shown in Tables 1.5 and 1.6.

Analysis Plan

The 491 students used for analyses in this investigation were split in half randomly. Exploratory analyses were conducted on the first half of the data in Step 1 and confirmatory analyses on the second half of the data in Step 2. Two hundred fourth four students were included in Step 1. Of sample 1, 154 (63.1\%) were first year students, and 90 (36.9\%) were second year students; 96 were male (39.3\%) and 148 female (60.7\%). Of sample $2,156(63.2 \%)$ were first year students, and 91 (36.8\%) were second year students; 106 were male (42.9\%) and 141 female $(57.1 \%)$

Procedure

The sample was recruited from classes at a senior high school in Taiwan. Participation was anonymous, voluntary, took about 40 minutes, and involved no incentives to the subjects for their participation. Participants were provided with complete information regarding the purpose, benefits, and possible risks of the study. They completed questionnaires in the classtooms. The survey was conducted as a paper-and-pencil measure in the participants' classrooms. Procedures of the study were approved by the Institutional Review Board at the University of Rhode Island.

\section{Measures}

\section{Stage of Change for Weight Management}

This is a one item scale for weight management evaluating individuals' stage of readiness to control weight. This measure would classify students into one of five possible stage of change. The strategies of weight management included exercising, eating smaller amount of food, eating less junk food, and eating more fruits and vegetables. Stage of change developed for weight management included: (a) Precontemplation: individuals who do not plan to start using weight management strategies in the next 6 months; (b) Contemplation: individuals who do not use weight management strategies, but intend to do so within the next 6 months; (c) Preparation: individuals who do not use weight management strategies, but plan to start in the next 30 days; (d) Action: individuals who use 
weight management strategies and have done so for less than 6 months; (e) Maintenance: individuals who use weight management strategies and have done so for more than 6 months.

\section{Weight Efficacy Life-Style Questionnaire (WELSQ)}

The Weight Efficacy Life-Style Questionnaire (WELSQ) comprises 20 items evaluating five dimensions (Availability; Negative Emotions, Physical Discomfort Positive Activities, and Social Pressure) of self-efficacy for weight management (Clark, Abrams, Niaura, Eaton, \& Rossi, 1991). Using a 10-point Likert-type format, respondents are asked to rate their self-assurance in resisting overeating in various tempting situations. Alphas were .76 and .83 for the Availability scale, .87 and .88 for the Negative Emotions scale, .82 and .84 for the Physical Discomfort scale, .70 and .79 for the Positive Activities scale, and .90 and .89 for the Social Pressure scale (Clark et al., 1991; Rossi et al., 1995).

Since the first language of survey participants is Mandarin Chinese, the assessment was conducted in that language. The original English-language questionnaires were translated into Chinese and then backtranslated into English by a panel of bilingual psychologists. During the process of back translation, the equivalence of Chinese and English version was ensured. The questionnaires were then applied to groups of students to verify their understanding of the questions. The necessary modifications were applied to ensure the understandabililty of the instruments.

Results

$$
\text { Preliminary Analyses }
$$

\section{Stage of Weight Control}

Chi-square tests were applied to examine the independence across stage of weight control and school year, stage of weight control and gender, stage of weight control and BMI status, stage of weight control and stage of exercise. The results showed that there was not an association between stage of weight control and school year; $\chi_{(4)}^{2}=4.365, p=.359$. The stage of weight control for male did not differ from the stage of weight control of female students; $\chi_{(4)}^{2}=4.239, p=.375$. The stage of weight control for normal BMI differed from the stage of weight control of overweight/obesity BMI groups; $\chi_{(4)}^{2}=12.563, \mathrm{p}=.014$. The result indicated that there is an association between stage of exercise behavior and stage of weight control; $\chi^{2}(16)=154.804, p<.0001$. 
BMI Status

The results showed that there was not an association between BMI status and school year; $\chi^{2}(1)$ $=0.027, \mathrm{p}=.870$. The BMI status for male differed from the BMI status of female students; $\chi^{2}(1)=$ $57.683, \mathrm{p}<.0001$.

\section{Stage of Exercise Behavior}

Chi-square tests were applied to examine the independence across stage of exercise behavior and school year, stage of exercise behavior and gender, stage of exercise behavior and BMI status, stage of exercise behavior and stage of weight control. The results showed that there was not an association between stage of exercise behavior and school year; $\chi_{(4)}^{2}=5.309, \mathrm{p}=.257$. The stage of exercise behavior for male differed from the stage of exercise behavior of female students; $\chi_{(4)}^{2}=47.705, \mathrm{p}<$ .0001 . The results showed that there was not an association between stage of exercise behavior and BMI status; $\chi_{(4)}^{2}=9.109, \mathrm{p}=.058$.

The $t$ test was applied to examine the school year difference in time of doing exercise. The results indicate that there was a statistically significant difference between first-year and second-year senior high students in the duration of exercise; $\mathrm{t}(414)=2.23, \mathrm{p}=.027$. In other words, first-year students spent statistically significantly much more time on exercise (mean=6.013 days) than secondyear students (mean= 4.651 days). Results from the t-test showed that there was no statistically significant difference between $\mathrm{BMI}$ groups in terms of exercise behaviors; $\mathrm{t}(485)=1.76, \mathrm{p}=.079$.

Gender difference in time of doing exercise was also examined by $t$ test. The results indicate that there was a statistically significant difference between male and female students in length of doing exercise; $\mathrm{t}(319)=6.60, p<.0001$. In other words, male students spent statistically significantly much more time on exercise (mean $=7.975$ days) than female students (mean $=3.782$ days).

Step 1: Exploratory analyses

The characteristics of items from Sample 1 were examined first. Mean, standard deviation, skewness, and kurtosis for each item are showed in Table 3.1. No items were deleted due to poor distributions.

Principal components analyses (PCA) were conducted to determine the psychometric properties and measurement structure of Weight Efficacy Questionnaire (WEQ). Horn's (1965) parallel 
analysis, and the minimum average partial (MAP) technique (Velicer, 1976) were used to decide the optimal number of factors, since simulation studies have shown that they are two of the most accurate methods (Velicer, Eaton, \& Fava, 2000). The scree test, and theoretical considerations about selfefficacy in weight management were also applied to decide the numbers of components to retain. Varimax rotation of the factor pattern was then employed. Items on Crobach's coefficient alpha reliabilities, component interpretability, component loadings, and the length of the final instrument were criteria used to make the reduction. Items with low loadings (i.e., less than .50 on all components), items that contribute negatively to the reliability of a subscale, and complex items (i.e., items with loadings larger than .50 on two or more components) were removed.

A four-component solution, the optimal result, was produced for interpretation. Fifteen items were selected, accounting for $61.8 \%$ of the total item variance. All items loaded heavily on their individual components. Table 3.2 displays the component loadings for each item on each component. Cronbach coefficient alphas were calculated for each subscale. For Sample $1(\mathbb{N}=244)$, Alpha coefficient for the Negative Emotions subscales was .80, for the Availability and Positive Activities was .80 , for the Social Pressure was .65, and for the Physical Discomfort was .78. These results imply fair to good internal consistency of scale. Scale means and standard derivations of subscales were shown in Table 3.3 .

\section{Step 2: Confirmatory Analyses}

In the second step, the cross-validation of the measurement structures from Step 1 with the second half of the sample $(\mathrm{N} 2=247)$ using confirmatory factor analysis procedures was examined. Of the 247 participants, 156 were first-year senior high school students, and 91 were second-year senior high school students. 106 male students and 141 female students were included in step 2. For Sample 2 $(\mathrm{N}=247)$, Alpha coefficients for Negative Emotions subscales were .79 , for Availability and Positive Activities were .81, for Social Pressure was .71, and for Physical Discomfort was .82.

To prevent confirmation bias, and as an advanced analysis of the adequacy of the models derived from sample 1, several alternative models illustrating different conceptualizations of the structure of decisional balance were compared to best interpret the data. The characteristics of items 
from Sample 2 were also examined. Mean, standard derivation, skewness, and kurtosis for each item are shown in Table 3.4.

Several indices were used to examine various aspects of fit for the structural models. At a macro-level, significance tests are expected to show that a hypothesized model provides a good fit to the data, with small chi-square values relative to the degrees of freedom (normalized $\chi^{2}$ index). Small chi-square values and a nonsignificant $\mathrm{p}$ value indicate that there is little difference between the hypothesized model and the data. However, even good fitting models often fail this test since the statistical power of the test is often very high due to large sample sizes, so that even small departures from perfect model fit result in statistically significant p values. Furthermore, it has been shown that the $x^{2}$ test of model fit is not especially robust to nonnormality and other violations of assumptions that might be expected; especially when item-level data serve as the manifest indicators of the models. Standardized residuals between a hypothesized model and the pattern of variances and covariances are expected to be relatively small for a reasonable model. This is evaluated by examining the root mean square error of approximation (RMSEA). It is suggested that RMSEA should be smaller than 0.08 to be consider a good fit (Byrne, 2001).

The comparative fit index (CFI) will also be examined, and it should be relatively large $(>.90)$ if a model is providing a better approximation of the data than a model that hypothesized no covariances among variables. At a micro level, the significance of specific hypothesized paths, and the percentage of explained variance for all dependent constructs will be examined. Significant and meaningful predictors are identified by significant path coefficients to the dependent constructs, and at least a moderate degree of explained variance is expected. Chi-square difference tests were conducted to compare nested models represented in the current study. By subtracting the chi-square and degrees of freedom values for relevant nested models from a fuller model and assessing the significance of the incremental difference, the importance of competing models can be evaluated. If the difference in models is significant, this indicates that the fuller model is preferred to help explain the data.

To prevent confirmation bias, and as an advanced analysis of the adequacy of the models derived from sample 1 , four alternative models illustrating different conceptualizations of the structures of the Weight Efficacy Questionnaire were compared to best interpret the data. 
The models examined in Step 2 were:

(1) The Null Model. There are no latent factors in the Null Model, and this implies that all items of Weight Efficacy Questionnaire independent. The Null Model is applied as a baseline against which other models may be compared.

(2) One Factor Model. This model assumes one general self-efficacy factor. Support for this model would suggest that subjects do not or cannot differentiate among the dimensions.

(3) Four Uncorrelated Factors Model. This model suggests that subjects could distinguish between the four self-efficacy factors and further that these factors are best represented as independent dimensions.

(4) Four Correlated Factors Model. This model is similar to the four uncorrelated factors model, except that the four factors are correlated. This model suggests that subjects' discrimination of self-efficacy in weight management was best represented as four related dimensions. Based on previous evidence (Clark et al, 1991), this model was expected to fit best.

Model results are given in Table 3.5. The one-factor model did not fit well, $\chi_{(44)}^{2}=543.429$, $\mathrm{CFI}=.639, \mathrm{GFI}=.725, \mathrm{AGFI}=.633$, amd $\mathrm{RMSEA}=.143$. The four-factor uncorrelated model did not fit well. $\chi^{2}(90)=343.103, \mathrm{CFI}=.799, \mathrm{GFI}=.834, \mathrm{AGFI}=.779$, and $\mathrm{RMSEA}=.107$. On the other hand, the four-factor correlated model was the best-fitting model, $\chi_{(84)}^{2}=137.748, \mathrm{CFI}=.957, \mathrm{GFI}=.930$, $\mathrm{AGFI}=.900$, and $\mathrm{RMSEA}=.051 . A \chi^{2}$ difference comparison of the four-factor uncorrelated and the four-factor conrelated models was significant, $\chi_{(6)}^{2}=205.355, \mathrm{p}<0.001$ indicating that the four-factor correlated model is a better representation of the data. Hicrarchical model was also examined, $\chi^{2}(89)$ $=164.383, \mathrm{CFI}=.940, \mathrm{GFI}=.917, \mathrm{AGFI}=.887$, and $\mathrm{RMSEA}=.059$. The models are presented in Figures 3.1 and 3.2 .

\section{Step 3: Extemal validity of WEQ}

In step 3, all 491 students were included to examine the external validity of Weight Efficacy Questionnaire. Of the 419 students, $103(21.0 \%)$ were in Precontemplation, $137(27.9 \%)$ were in Contemplation, 61 (12.4\%) were in Preparation, $162(33.0 \%)$ were in Action, 24 (4.9\%) were in Maintenance, and $4(0.8 \%)$ did not provide this information. Weight efficacy and Stage of Weight Managament were shown in Table 3.6, 3.7 and 3.8. 
External validity of WEQ: Overall Participants: Gender by Stage

Sample size did not permit a 3-way analysis of stage, gender, and BMI-group effects, so 2-way analysis was conducted. A first two-way multivariate analysis of variance (MANOVA) was applied to decide if self-efficacy for losing weight differs across the stages of change and gender. The assumptions for MANOVA were first examined and no violations were detected. Stage of change and gender served as the independent variables, while Negative Emotions (NE), Availability and Positive Activities (APA), Social Pressure (SP), and Physical Discomfort (PD) were used as dependent variables. The MANOVA resulted in a significant main effect for Stage of change, Wilk's $\Lambda=.889$, approximate $\mathrm{F}(16,1448.7)=3.55, \mathrm{p}<.0001$, and multivariate $\eta^{2}=.111$. The MANOVA resulted in a significant main effect for gender, Wilk's $\Lambda=.978$, approximate $F(4,474)=2.64, p=.033$, and multivariate $\eta^{2}=$ 022. The MANOVA resulted in a non-significant interaction effect for Stage and gender, Wilk's $\Lambda=$ .984 , approximate $\mathrm{F}(16,1448.7)=0.48, \mathrm{p}=.957$, and multivariate $\eta^{2}=.016$. This indicates that the effect of Stage did not depend on gender. Therefore, the effect of gender was considered in analyses.

A ANOVA test showed that the Negative Emotion scale was not significantly different across the five stages of change, $F(9,477)=1.44, p=.167$, and $\eta^{2}=.027$. A ANOVA test showed that the Availability and Positive Activities scale was significantly different across the five stages of change, $\mathrm{F}(9,477)=5.15, \mathrm{p}<.0001$, and $\eta^{2}=.089$. Post-hoc tests showed that the APA for Maintenance subjects was significantly higher compared with participants in Precontemplation, Contemplation, and Preparation. The results also indicated that students in Preparation stage were more confident they could avoid overeating in perceived more availability and positive activities compared with those who were in Precontemplation and Contemplation.

The SP scale was not significantly different across the stages of change, $F(9,477)=1.12, p=$ .3432, $\eta^{2}=.02$. The PD scale was not significantly different across the stages of change, $F(9,477)=$ $1.10, p=.3610, \eta^{2}=.020$. The pattern of self-efficacy across stages for overall participants is presented in Figure 3.3.

External validity of WEQ: Overall Participants: BMI by Stage

A Two-way MANOVA was applied to decide if the self-efficacy for losing weight differs by stage of change as predicted by the TTM. The assumptions for MANOVA were first examined and no 
violations were detected. BMI and Stage of change served as the independent variables, while NE, APA, SP and PD were used as dependent variables. The MANOVA resulted in a significant main effect for BMI status, Wilk's $\Lambda=.970$, approximate $F(4,476)=3.66, p=.006$, and multivariate $\eta^{2}=.030$. The MANOVA resulted in a significant main effect for Stage of change, Wilk's $\Lambda=.889$, approximate $F$ $(16,1448.7)=3.56, \mathrm{p}<.0001$, multivariate $\eta^{2}=.111$. The MANOVA resulted in a non-significant interaction effect for Stage and BMI status, Wilt's $\Lambda=.968$, approximate $F(16,1448.7)=0.96, \mathrm{p}=$ .494 , and multivariate $\eta^{2}=.032$. This indicates that the effect of Stage did not depend on BMI. Therefore, the effect of BMI status was also considered in analyses.

A ANOVA test showed that the Negative Emotion scale was not significantly different across the five stages of change, $F(9,477)=1.16, p=.321$, and $\eta^{2}=.021$. A ANOVA test showed that the Availability and Positive Activities scale was significantly different across the five stages of change, $F(9,477)=5.31, p<.0001$, and $\eta^{2}=.091$. Post-hoc tests showed the APA for Maintenance subjects is significantł higher compared with participants in Precontemplation, Contemplation, and Preparation. The results also indicated that students were in Preparation stage perceived more availability and positive activities compared with those who were in Precontemplation and Contemplation.

The SP scale was not significantly different across the stages of change, $F(9,477)=1.05, \mathrm{p}=$ $.398, \eta^{2}=.019$. The PD scale was not significantly different across the stages of change, $F(9,477)=$ 0.94. $\mathrm{p}=.489, \mathrm{\eta}^{2}=.017$. The pattern of self-efficacy across stages for overall participants is presented in Figure 3.3.

Step 4: Factor Invariance of Weight Efficacy Questionnaire

For researchers, it is a crucial question to ask whether an instrument measures the same trait among groups of populations and whether or not the measure functions equivalently across the participants from subgroups. Previous researchers have applied exploratory factor analysis to evaluate the factor invariance across various groups. However, this approach has been criticized (Alwin \& Jackson, 1981). Confirmatory factor analysis was then recommended (Cole, 1987). Some researchers fit identical models to different groups and then conducted confirmatory factor analysis separately for each group. This approach exarnines only individual parameter estimates and does not compare goodness of fit among groups directly. Multiple-group confirmatory factor analysis (i.e., multiple 
sample modeling) could deal with the concerns when single confirmatory factor analysis is used, because the same model is imposed among groups and is analyzed simultaneously (Jöreskog \& Sörbom, 1989).

In Step 4, equivalence of the Weight Efficacy Questionnaire Chinese edition among high school students in Taiwan was evaluated. Multisampling model was applied to examine factor invariance of WEQ across two sets of demographic variables (i.e., different BMI status, gender).

Chi-square difference tests were conducted to compare nested models to decide the best fitting model. By subtracting the chi-square and degrees of freedom values for relevant nested models from a fuller model and assessing the significance of the incremental difference, the importance of competing models was evaluated. In other word, if the difference in models is significant, this indicates that the fuller model is preferred to help explain the data. However, even good fitting models often fail this test since the statistical power of the test is often very high due to large sample sizes, so that even small departures from perfect model fit result in statistically significant $\mathrm{p}$ values. Cheung and Rensvold (2002) recommended $\triangle \mathrm{CFI}$ test to evaluate the best fitting model. They suggested that if the absolute value of $\triangle C F I$ is equal or small than the cutoff (i.e., 01), the null hypothesis of invariance cannot be rejected. Chi-square difference tests and $\triangle \mathrm{CFI}$ test were applied to evaluate the best model.

\section{Pre-Study: tests for factor invariance across high school student}

In pre-study; four hierarchical analyses with different parameter invariance assumptions (Jöreskog \& Sörbom, 1989) were presented and examined.

Model 1, a congeneric model, assumes the same conceptual mapping in Sample One and Sample Two. The two groups have the same factor and/or regression structure, but different loadings, factor variances, and error variances.

Model 2, a lambda-invariant model, assumes the two groups have the same factor structure and their factor loadings are also held equal.

Model 3, a tau-equivalent model has the same assumptions as model 2, except model 3 also limit the factor variance to be equivalent across two subgroups. 
Model 4, a parallel model, study whether the entire measurement structure is equal. A paralle1 model assumes that factor loadings, factor variances, and error variances were the same across two samples.

The congeneric model fit well, $\chi_{(168)}^{2}=279.85, \mathrm{CFI}=.954$, and RMSEA $=.037$. The lambdainvariance model fitted reasonably well, $\chi_{(183)}^{2}=291.99, \mathrm{CFI}=.955$, and $\mathrm{RMSEA}=.035 . \mathrm{A} \chi^{2}$ difference comparison of the congeneric model and the lambda-invariance model was not significant, $\chi_{(15)}^{2}=0.14, \mathrm{p}>0.01$

The tau equivalent model fitted reasonably well, $\chi_{(189)}^{2}=302.31$, CFI $=.953$, and RMSEA $=$ 035. A $\chi^{2}$ difference comparison of the lambda-invariance model and the tau equivalent model was not significant, $\chi_{(6)}^{2}=10.32, p>0.01$

The parallel model fitted reasonably well, $\chi_{(204)}^{2}=313.65, \mathrm{CFI}=.955$, and RMSEA $=.033 . \mathrm{A}$ $\chi^{2}$ difference comparison of the tau equivalent model and the parallel model was not significant, $\chi_{(15)}^{2}=$ $11.34, \mathrm{p}>0.01$. Thus, results indicated that the parallel equivalent model was the preferred model for the self-efficacy across randomly-split-half groups (see Table 3.9).

Tests for factor invariance across high school student with different BMI status

In study one, four hierarchical analyses with different parameter invariance assumptions (Jöreskog \& Sörbom, 1989) were presented and examined. The models tested were the congeneric model, lambda-invariant model, tau-equivalent model and parallel model.

The congeneric model fit well, $\chi_{(168)}^{2}=320.30, \mathrm{CFI}=.939$, and RMSEA $=.043$. The lambdainvariance model fitted reasonably well, $\chi_{(1 \times 3)}^{2}=340.91, \mathrm{CFI}=.936$ and $\mathrm{RMSEA}=.042 . \mathrm{A} \chi^{2}$ difference comparison of the congeneric model and the lambda-invariance model was not significant, $\chi_{(15)}^{2}=$ $20.62, \mathrm{p}>0.01$

The tau equivalent model fitted reasonably well, $\chi_{(189)}^{2}=355.02, \mathrm{CFI}=.933$, and RMSEA $=$ 042. A $\chi^{2}$ difference comparison of the lambda-Invariance model and the tau equivalent model was significant, $\chi^{2}{ }_{(6)}=14.11, \mathrm{p}<0.01$, indicating that the tau equivalent model is a better representation of the data. 
The parallel model fitted reasonably well, $\chi^{2}{ }_{(204)}=388.65 . \mathrm{CFI}=.926$. and $\mathrm{RMSEA}=.043 . \mathrm{A}$ $\chi^{2}$ difference comparison of the tau equivalent model and the parallel model was not significant, $\chi_{(15)}^{2}=$ $33.63, \mathrm{p}>0.01$.

The results of hierarchical models for self-efficacy were demonstrated in Table 3.9. Results indicated that the tau equivalent model was the preferred model for the self-efficacy across the two BMI groups. In this study, the parallel model was not preferred, and implied that the two BMI subgroups may be treated as arising from different populations.

\section{Tests for factor invariance across gender}

Four hierarchical analyses with different parameter invariance assumptions (Jöreskog \& Sörbom, 1989) were presented and examined. The models tested were the congeneric model, lambdainvariant model, tau-equivalent model and parallel model.

The congeneric model fit well, $\chi_{(16 x)}^{2}=292.51, \mathrm{CFI}=.949$, and RMSEA $=.039$. The lambdainvariance model fitted reasonably well, $\chi_{(183)}^{2}=306.55, \mathrm{CFI}=.949$, and $\mathrm{RMSEA}=.037 . \mathrm{A} \chi^{2}$ difference comparison of the congeneric model and the lambda-invariance model was not significant, $\chi_{115)}^{2}=14.04, \mathrm{p}>0.01$.

The tau equivalent model fitted reasonably well, $\chi_{(189)}^{2}=309.78, \mathrm{CFI}=.950$, and $\mathrm{RMSEA}=$ .036. A $\chi^{2}$ difference comparison of the lambda-Invariance model and the tau equivalent model was not significant, $\chi_{(6)}^{2}=3.23, \mathrm{p}>0.01$.

The parallel model fitted reasonably well, $\chi_{(204)}^{2}=339.66, \mathrm{CFI}=.944$, and RMSEA $=.037 . \mathrm{A}$

$\chi^{2}$ difference comparison of the tau equivalent model and the parallel model was not significant, $\chi_{(15)}^{2}=$ $29.88, \mathrm{p}>0.01$

The detail results of hierarchical models for self-efficacy were demonstrated in Table 3.9. Results indicated that the parallel equivalent model was the preferred model for the self-efficacy across gender groups. The result of preference of parallel model implied that the gender subgroups can be treated as arising from the same population.

\section{Discussion}

The main objective of the investigation was to develop the Weight Efficacy Questionnaire Chinese version with an adolescent population in Taiwan. Based on the original twenty-item form, the 
four-factor fifteen-item WEQ was found to represent the area appropriately. A 15-item instrument that examines four dimensions of self-efficacy was generated from the item selection procedures. Confirmatory factor analysis verified the competence of the four-factor model for weigh efficacy for high school students in Taiwan.

Results based on the investigation implied that the factor patterns from the Weight Efficacy Questionnaire did not reflect a five-factor (i.e., Negative Emotions, Availability, Social Pressure, Physical Discomfort, and Positive Activities) pattern. Instead, a four-factor model provided a better fit of the data. The original Availability factor combined with original Positive Activities into one factor, Availability and Positive Activities, in WEQ Chinese version. The hierarchical model structure has been suggested in other TTM related empirical research for other behaviors (e.g., Plummer, Velicer, Redding et al, 2001).

Overall, MANOVA results implied perceived self-efficacy of losing weight were different among stages of change in adolescent population. Results from two-way MANOVAs showed that the effect of Stage depended on neither gender nor BMI group. There was main effect for gender. There was also statistically significant main effect for BMI group.

Results from multiple-sample confirmatory factor analyses suggested that gender subgroups can be treated as arising from the same population. On the other hand, results indicated that the tau equivalent model, instead of parallel model, was the preferred model for self-efficacy across the two BMI groups. Based on these result, the concept of self-efficacy for weight management in students whose BMI were in normal range with intention of losing weight are different from the students who were overweight or obese. However, since the tau equivalent model is a very restricted model, this strict interpretation may not be realistic or practical. The reason why the parallel model was not preferrd in this case may due to the error variances were not the same among BMI groups.

This study has several limitations. Participants for the investigation were from a high school in rural area in Taiwan. Therefore, the results from the study may not be generalizable to all high school students in Taiwan or other areas. This investigation is cross-sectional study; therefore, it is hard to draw a causal relationship among variables. 
When applying Transtheoretical model in Asian cultures, one of the most important concerns is whether the psychological constructs (e.g., self-efficacy; decisional balance) of TTM still maintain the same meanings/psychological qualities, which refers to the issue of conceptual equivalence (Brislin, 1993; Okazaki, \& Sue, 1995). Even the back-translation techniques were applied to develop Chinese versions of questionnaires to ensure the equivalence; however, there is no direct evidence of conceptual, and/or metrical equivalence.

This investigation should stimulate research toward an understanding of the weight management in adolescents in Asia. Current study provided support for application of the TTM to weight management in an adolescent population. However, these data are cross sectional in nature. It is recommended that future researchers conduct longitudinal studies in this topic. Current investigation was not experimental study, but a correlational study. Future researchers may collect experimental data to test casual effects.

Other characteristics of students may also contribute the students' status of stage of change in weight management in Asia, such as socioeconomic status, family influences, and peer influences; future researchers may investigate those factors. Researchers should also make efforts to assess the relevance of and control for as many background conditions as possible.

Research results are limited by using high school students in rural area in Taiwan. It is recommended that future studies should be conducted in larger, more diverse and representative samples. Replication of the current findings with other samples will provide increased validity for the application of the concept of self-efficacy to the study of weight management. Moreover, future researchers should cross-validate the current findings on other data. Self-efficacy, an empirically supported behavior change concept, would enable researchers and clinicians to more effectively design, target, and monitor the progress of interventions for weight management in adolescents in Asia. 


\section{Reference}

Alwin, D. F. \& Jackson, D. J. (1981). Applications of simultaneous factor analysis to issues of factorial invariance. In D. D. Jackson \& E. P. Borgotta (Eds.) Factor analysis and measurement in sociological research: A multidimensional perspective. Beverly Hills, CA: Sage.

Bandura, A. (1997). Self-efficacy: The exercise of control. New York: W.H. Freeman.

Brislin, R. (1993). Understanding culture's influence on behovior. New York: Harcourt Brace.

Brugman, E, Meulmeester, J.F., Spee-van der Wekke, A, Beuker, R,J., Zaadstra, B.M., Radder, J.J., \& Verloove-Vanhorick, P.S. (1997) Dieting, weight and health in adolescents in the Netherlands International Journal of Obesity, 21, 54-70,

Byme, B.N. (2001). Structural Equation Modeling uith AMOS. Rahwah. NJ: Lawrence Erlbaum Associates.

Cheung, G.W., \& Rensvold, R. B. (2002). Evaluating goodness-of-fit indexes for testing measurement invariance. Structural Equation Modeling, 9, 233-255.

Chu, N.F.(2001). Prevalence and trends of obesity among school children in Taiwan-the Taipei Children Heart Study; International Journal of Obesity, 25, 170-176.

Chang, C-J., Wu, C-H., Chang, C-S., Yao, W-J., Yang, Y-C., Wu, J-S., \& Lu, F-H. (2003), Low body mass index but high percent body fat in Taiwanese subjects: implications of obesity cutoffs. International Journal of Obesity, 27, 253-259.

Clark, M.M., Abrams, D.B., Niaura, R.S., Eaton, C.A., \& Rossi, J.S. (1991). Self-efficacy in weight management. Journal of Consulting and Clinical Psychology, 59, 739-744.

Cole, D. A. (1987). Utility of confirmatory factor analysis in test validation research. Journal of Consulting and Clinical Psychology, 55, 584-594.

Deurenberg, P., Deurenberg-Yap, M., Guricci, S. (2002). “Asians are different from Caucasian and from each other in their body mass index/ body fat per cent." Obesity Reviews, 3, 141-146.

Deurenberg- Yap, M., Tan, B.Y., Chew, S.K., Deurenberg, P., \& van Staveren, W.A. (1999). Manifestation of cardiovascular risk factors at low levels of body mass index and waist-hip ratio in Singaporearr-Chinese. Asia Pacjfic Journal of Cljnical Nutrition, 8, 177-183. 
Deurenberg, P., Yap, M., \& van Staveren, W.A. (1998). Body mass index and percent body fat: a metaanalysis among different ethnic groups. International Journal of Obesity, 22, 1164-1171.

Ebbeling, C.B., Pawlak, D.B., \& Ludwig, D.S. (2002). Childhood obesity: public health crisis, common sense cure. Lancet, $360,473-482$.

Guillaume, M. \& Lissau, I. Epidemiology. In: Burniat W, Cole T, Lissau I, Poskitt EME (eds). Child and Adolescent Obesity: Causes and Consequences, Prevention and Managenent. Cambridge University Press: Cambridge, 2002, 28-49.

Guricci, S., Hartriyanti, Y., Hautvast, JGAJ, \& Deurenberg, P. (1998). Relationship between body fat and body mass index: differences between Indonesians and Dutch Caucasians. Europe Journal of Clinical Nutrition, 52,779-783.

Horn, J. L. (1965). A rationale and test for the number of factors in factor analysis. Psychometrika, 32, 179-185.

Huang, Y.C., Wu, J.Y., \& Yang, M.J.(2003)Weight-for-height reference and the prevalence of obesity for school children and adolescents in Taiwan and Fuchien Areas. Journal of Chinese Medical Association, 66, 599-606.

Jöreskog, K.G. \& Sörbom, D. (1989). LISREL 7 (2nd ed.). A Guide to the Program and Applications. Chicago: SPSS.

Kaneko, K., Kiriike, N., Ikenaga, K., Miyawaki, D., \& Yamagami, S (1999). Weight and shape concerns and dieting behaviours among pre-adolescents and adolescents in Japan Psychiatry and Clinical Neurosciences. Psychiatry and Clinical Neurosciences, 53, 365.

Liu, L., Choudhury, S.R., Okayama, A., Hayakawa, T., Kita, Y., \& Ueshima, H. (1999). Changes in body mass index and its relationships to other cardiovascular risk factors among Japanese population: results from the 1980 and 1990 national cardiovascular surveys in Japan. Journal of Epidemiology, 9, 163-174.

Lu, F.H., Yang, Y.C., Wu, J.S., Wu, C.H., \& Chang, C.J.(1998). A population-based study of the prevalence and associated factors of diabetes mellitus in southern Taiwan, Diabetic Medicine: a Journal of the British Diabetic Association, $15,564-572$. 
Masuda, T., Imai, K., \& Komiya, S. (1993). Relationship of anthropometric indices of body fat to cardiovascular risk in Japanese women. The Annuals of Physiological Anthropology, 12, 135-144.

Neumark-Sztainer, D., Rock, C.L., Thornquist, M.D., Cheskin, L.J., Neuhouser, M.L., \& Barnett, M.J.(2000). Weight-Control Behaviors among Adults and Adolescents: Associations with Dietary: Intake. Preventive Medicine, 30, 301-391.

Nowak, M., Speare, R. \& Crawford, D.(1996). Gender differences in adolescent weight and shaperelated beliefs and behaviour. Journal of Pediatrics and Child Health, 32, 148-152.

O'Connell, D., \& Velicer, W. F. (1988). A decisional balance measure and the stages of change model for weight loss. International Journal of the Addictions, 23, 729-750.

Okazaki, S., \& Sue, S. (1995). Methodological issues in assessment research with ethnic minorities. Psychological Assessment, 7, 367-375.

Plummer, B.A., Velicer, W.F., Redding, C.A., Prochaska, J.O., Rossi, J.S., Pallonen, U.E., \& Meier, K.S. (2001). Stage of change, decisional balance, and temptations for smoking. Measurement and validation in a large, school-based population of adolescents. Addictive Behaviors, 26, 551-571

Prochaska, J.O., DiClemente, C.C., \& Norcross, J.C. (1992). In Search of how people change, American Psychologist, 1102-1114.

Prochaska, J. O., Norcross, J. C., Fowler, J. L., Follick, M. J., \& Abrams, D. B. (1992). Attendance and outcome in a work site weight control program: Processes and stages of change as process and predictor variables. Addictive Behaviors, $17,35-45$.

Prochaska, J.O., Velicer, W.F., Guadagnoli, E., Rossi, J.S., \& DiClemente, C.C. (1991). Patterns of change: Dynamic typology applied to smoking cessation. Multivariate Behavioral Research, 26, $83-107$.

Rossi, J.S., Rossi, S.R., Velicer, W.F., \& Prochaska, J.O. (1995). Motivational readiness to control weight. In D.B. Allison (Ed.), Handbook of assessment methods for eating behoviors and weightrelated problems: Measures, theory, and research (pp. 387-430). Thousand Oaks, CA: Sage.

Rossi, S.R., Rossi, J.S., Rossi-DelPrete, L.M., Prochaska, J.O., Banspach, S.W., \& Carleton, R.A. (1994). A processes of change model for weight control for participants in community-based weight loss programs. International Journal of the Addictions, 29, 161-177. 
Steen, S.N., Wadden, T.A., Foster, G.D., \& Andersen, R.E. (1996). Are obese adolescent boys ignoring an important health risk? The International Journal of Eating Disorders, 20, 281-286.

Troiano, R.P., Flegal, K.M., Kuczmarski, R.J., Campbell, S.M., \& Johnson, C.L. (1995). Overweight prevalence and trends for children and adolescents. The National Health and Nutrition' Examination Surveys, 1963 to 1991. Archives of Pediatrics \& Adolescent Medicine, 149, $1085-$ 1091.

Velicer, W. F. (1976). Determining the number of components from the matrix of partial correlations. Psychonetrika, 41, 321-327.

Velicer, W. F., Eaton, C. A., \& Fava, J. L. (2000). Construct explication through factor or component analysis: A review and evaluation of alternative procedures for determining the number of factors or components. In R. D. Goffin \&amp; E. Helmes (Eds.), Problems and solutions in human assessment: Honoring Douglas N. Jackson at seventy. Norwel1, MA: Kluwer Academic.

Wang, J., Thornton, J.C., Russell, M., Burastero, S., Shen, J., Tanenbaum, S., Heymsfield, S., \& Pierson, R. N.(1996). Comparison for BMI and body fat percent among Puerto Ricans, Blacks, Whites and Asians living in the New York City area. Obesity Research, 4, 377-384.

Wang, Y., Monteiro, C., \& Popkin, B.M. (2002). Trends of obesity and underweight in older children and adolescents in the United States, Brazil, China, and Russia. American Journal of Clinical Nutrition, 75, 971-977.

World Health Organization. Obesity: preventing and managing the global epidemic: Report of a WHO consultation on obesity; Geneva, 3-5 June, 1997. WHO: Geneva, 1998.

World Health Organization. Obesity: Preventing and Managing the Global Epidemic. WHO Obesity Technical Report Series no. 894. WHO: Geneva, 2000. 
Table 3.1. Summary statistics of Weight Efficacy Questionnaire (by item): Sample 1

\begin{tabular}{|l|r|r|r|r|r|}
\hline Variable & N & Mean & \multicolumn{1}{c|}{ Std Dev } & Skewness & \multicolumn{1}{c|}{ Kurtosis } \\
\hline I & 244 & 3.225 & 1.290 & -0.068 & -1.064 \\
\hline 2 & 244 & 2.439 & 1.089 & 0.506 & -0.248 \\
\hline 3 & 244 & 2.889 & 1.130 & 0.185 & -0.594 \\
\hline 4 & 244 & 3.041 & 1.286 & 0.005 & -1.071 \\
\hline 5 & 244 & 2.717 & 1.199 & 0.301 & -0.776 \\
\hline 6 & 244 & 3.328 & 1.336 & -0.305 & -1.005 \\
\hline 7 & 244 & 2.148 & 1.071 & 0.756 & 0.103 \\
\hline 8 & 244 & 2.639 & 1.115 & 0.426 & -0.323 \\
\hline 9 & 244 & 3.955 & 1.152 & -0.905 & -0.090 \\
\hline 10 & 244 & 3.352 & 1.230 & -0.150 & -0.983 \\
\hline 11 & 244 & 3.434 & 1.358 & -0.408 & -1.015 \\
\hline 12 & 244 & 2.328 & 1.088 & 0.536 & -0.248 \\
\hline 13 & 244 & 3.045 & 1.180 & 0.170 & -0.849 \\
\hline 14 & 244 & 3.926 & 1.116 & -0.731 & -0.379 \\
\hline 15 & 244 & 3.127 & 1.160 & 0.132 & -0.779 \\
\hline 16 & 244 & 3.393 & 1.257 & -0.289 & -0.890 \\
\hline 17 & 244 & 2.480 & 1.153 & 0.530 & -0.368 \\
\hline 18 & 244 & 2.422 & 1.073 & 0.628 & -0.011 \\
\hline 19 & 244 & 3.865 & 1.163 & -0.842 & -0.148 \\
\hline 20 & 244 & 2.902 & 1.250 & 0.009 & -0.878 \\
\hline
\end{tabular}


Table 3.2. Items by scale and varimax pattern for the Weight Efficacy Questionnaire $(N=244)$

\begin{tabular}{|c|c|c|c|c|}
\hline & \multicolumn{4}{|c|}{ Factor loading } \\
\hline Item & $\widehat{A P A}$ & $\mathrm{NE}$ & $\mathrm{SP}$ & $\mathrm{PD}$ \\
\hline 2. I can control my eating on the weekend. & 0.687 & & & \\
\hline 5. I can resist eating when I am watching TV. & 0.549 & & & \\
\hline $\begin{array}{l}\text { 7. I can resist eating when there are many different } \\
\text { kinds of food available. }\end{array}$ & 0.530 & & & \\
\hline $\begin{array}{l}\text { 17. I can resist eating even when high-calorie foods } \\
\text { are available }\end{array}$ & 0.518 & & & \\
\hline 15. I can resist eating just before going to bed. & 0.512 & & & \\
\hline 20. I can resist eating when I am happy. & 0.440 & & & \\
\hline 6. I can resist eating when I am depressed (or down). & & 0.687 & & \\
\hline 1. I can resist eating when I am anxious (nervous). & & 0.651 & & \\
\hline 11. I can resist eating when I am angry (or irritable). & & 0.587 & & \\
\hline $\begin{array}{l}\text { 8. I can resist eating even when I feel it is impolite to } \\
\text { refuse a second helping. }\end{array}$ & & & 0.661 & \\
\hline $\begin{array}{l}\text { 18. I can resist eating even when I think others will be } \\
\text { upset if I don't eat. }\end{array}$ & & & 0.473 & \\
\hline $\begin{array}{l}\text { 13. I can resist eating even when others are pressuring } \\
\text { me to eat. }\end{array}$ & & & 0.442 & \\
\hline 14. I can resist eating when I am in pain. & & & & 0.735 \\
\hline 9. I can resist eating even when I have a headache. & & & & 0.633 \\
\hline 19. I can resist eating when I feel uncomfortable. & & & & 0.593 \\
\hline
\end{tabular}


Table 3.3. Means, standard derivations, and coefficient alphas for Weight Efficacy Questionnaire Chinese version

\begin{tabular}{|l|l|l|l|l|l|l|}
\hline & \multicolumn{4}{|l|}{ Sample 1 $(\mathrm{N}=244)$} & \multicolumn{3}{l|}{ Sample 2 $(\mathrm{N}=247)$} \\
\hline Scale & Alpha & Mean & SD & Alpha & Mean & SD \\
\hline NE & 0.80 & 9.99 & 3.38 & 0.79 & 10.02 & 3.33 \\
\hline APA & 0.80 & 15.81 & 4.88 & 0.81 & 15.40 & 5.04 \\
\hline SP & 0.65 & 8.11 & 2.58 & 0.71 & 8.22 & 2.87 \\
\hline PD & 0.78 & 11.75 & 2.85 & 0.82 & 11.92 & 3.02 \\
\hline
\end{tabular}


Table 3.4. Summary statistics of Weight Efficacy Questionnaire (by item): Sample 2

\begin{tabular}{|c|c|c|c|c|c|}
\hline Variable & $\mathrm{N}$ & Mean & Std Dev & Skewness & Kurtosis \\
\hline 1 & 247 & 3.146 & 1.238 & 0.109 & -0.962 \\
\hline 2 & 247 & 2.344 & 1.051 & 0.524 & -0.224 \\
\hline 3 & 247 & 2.814 & 1.122 & 0.304 & -0.586 \\
\hline 4 & 247 & 2.972 & 1.308 & 0.053 & -1.103 \\
\hline 5 & 247 & 2.599 & 1.238 & 0.541 & -0.628 \\
\hline 6 & 247 & 3.291 & 1.413 & -0.258 & -1.231 \\
\hline 7 & 247 & 2.126 & 1.121 & 0.850 & 0.079 \\
\hline 8 & 247 & 2.664 & 1.228 & 0.532 & -0.644 \\
\hline 9 & 247 & 4.057 & 1.143 & -1.068 & 0.237 \\
\hline 10 & 247 & 3.401 & 1.277 & -0.278 & -1.011 \\
\hline 11 & 247 & 3.583 & 1.328 & -0.563 & -0.876 \\
\hline 12 & 247 & 2.300 & 1.151 & 0.620 & -0.325 \\
\hline 13 & 247 & 3.053 & 1.176 & 0.154 & -0.794 \\
\hline 14 & 247 & 3.907 & 1.187 & -0.803 & -0.412 \\
\hline 15 & 247 & 3.057 & 1.235 & 0.100 & -0.934 \\
\hline 16 & 247 & 3.417 & 1.316 & -0.309 & -1.049 \\
\hline 17 & 247 & 2.530 & 1.147 & 0.471 & -0.495 \\
\hline 18 & 247 & 2.506 & 1.196 & 0.597 & -0.416 \\
\hline 19 & 247 & 3.960 & 1.178 & -0.928 & -0.076 \\
\hline 20 & 247 & 2.749 & 1.260 & 0.262 & -0.811 \\
\hline
\end{tabular}


Table 3.5. Weight Efficacy Questionnaire: Summary of model fit indices

\begin{tabular}{|l|l|l|l|l|l|l|}
\hline \multicolumn{1}{|c|}{ Model } & $\chi^{2}$ & df & CFI & GFI & AGFI & RMSEA \\
\hline One-factor & 543.429 & 90 & .639 & .725 & .633 & .143 \\
\hline Four-factor uncorrelated & 343.103 & 90 & .799 & .834 & .779 & .107 \\
\hline Four-factor correlated & 137.748 & 84 & .957 & .930 & .900 & .051 \\
\hline Hierarchal Model & 164.838 & 89 & .940 & .917 & .887 & .059 \\
\hline
\end{tabular}


Table 3.6. Summary Statistics: Self-efficacy (by BMI status)

\begin{tabular}{cccccc}
\hline Variable & $\mathrm{N}$ & Mean & Std Dev & Skewness & Kurtosis \\
\hline Overall participants & & & & & \\
\hline Negative Emotion (NE) & 491 & 10.004 & 3.3503 & -0.251 & -0.702 \\
\hline $\begin{array}{c}\text { Availability and Positive } \\
\text { Activities (APA) }\end{array}$ & 491 & 15.607 & 4.9617 & 0.285 & -0.139 \\
\hline Social Pressure (SP) & 491 & 8.165 & 2.7239 & 0.4394 & -0.109 \\
\hline Physical Discomfort (PD) & 491 & 11.835 & 2.9345 & -0.718 & -0.149 \\
\hline Normal BMI & & & & & \\
\hline Negative Emotion (NE) & 326 & 9.8528 & 3.3782 & -0.212 & -0.682 \\
\hline $\begin{array}{c}\text { Availability and Positive } \\
\text { Activities (APA) }\end{array}$ & 326 & 15.218 & 5.0449 & 0.3832 & -0.144 \\
\hline Social Pressure (SP) & 326 & 8.1718 & 2.8395 & 0.4779 & -0.18 \\
\hline Physical Discomfort (PD) & 326 & 11.887 & 2.9377 & -0.792 & 0.069 \\
\hline Overweight/Obesity & & & & & \\
\hline Negative Emotion (NE) & 165 & 10.303 & 3.2842 & -0.325 & -0.722 \\
\hline $\begin{array}{c}\text { Availability and Positive } \\
\text { Activities (APA) }\end{array}$ & 165 & 16.376 & 4.7142 & 0.1351 & 0.0923 \\
\hline Social Pressure (SP) & 165 & 8.1515 & 2.488 & 0.3154 & -0.018 \\
\hline Physical Discomfort (PD) & 165 & 11.733 & 2.9345 & -0.578 & -0.526 \\
\hline
\end{tabular}


Table 3.7. Summary statistics: Self-efficacy (by gender and Stage)

\begin{tabular}{|c|c|r|r|r|r|r|r|r|r|r|r|}
\hline & & \multicolumn{2}{|c|}{ NE } & \multicolumn{2}{c|}{ APA } & \multicolumn{2}{|c|}{ SP } & \multicolumn{2}{c|}{ PD } \\
\hline Stage of Change & $\mathrm{N}$ & Mean & SD & Mean & SD & Mean & SD & Mean & SD \\
\hline \multicolumn{8}{|c|}{ Male $(\mathrm{N}=202)$} \\
\hline Precontemplation & 47 & 10.28 & 3.80 & 15.51 & 5.80 & 8.28 & 2.95 & 11.55 & 3.45 \\
\hline Contemplation & 60 & 10.05 & 3.73 & 15.00 & 4.90 & 8.30 & 2.90 & 11.83 & 2.98 \\
\hline Preparation & 23 & 9.91 & 3.25 & 16.30 & 5.09 & 7.83 & 2.61 & 11.22 & 2.63 \\
\hline Action & 58 & 11.02 & 2.72 & 17.28 & 4.28 & 8.31 & 2.28 & 12.29 & 2.93 \\
\hline Maintenance & 12 & 10.25 & 3.44 & 20.50 & 4.48 & 9.58 & 1.98 & 12.67 & 3.39 \\
\hline & & & Female $(N=289)$ & & & & \\
\hline Precontemplation & 56 & 9.59 & 3.17 & 14.34 & 4.79 & 8.50 & 3.21 & 11.30 & 2.86 \\
\hline Contemplation & 77 & 9.35 & 3.42 & 13.84 & 4.27 & 7.81 & 2.51 & 11.91 & 2.85 \\
\hline Preparation & 38 & 9.34 & 3.22 & 13.97 & 4.58 & 7.39 & 2.63 & 11.66 & 2.99 \\
\hline Action & 104 & 10.27 & 3.26 & 16.47 & 4.84 & 8.07 & 2.77 & 12.19 & 2.68 \\
\hline Maintenance & 12 & 8.92 & 3.32 & 17.75 & 3.25 & 8.83 & 2.04 & 10.50 & 3.34 \\
\hline
\end{tabular}


Table 3.8. Summary Statistics: self-efficacy (by BMI status and Stage)

\begin{tabular}{|c|c|c|c|c|c|c|c|c|c|c|}
\hline & & \multicolumn{2}{|c|}{ NE } & \multicolumn{2}{c|}{ APA } & \multicolumn{3}{c|}{ SP } & \multicolumn{2}{c|}{ PD } \\
\hline Stage of Change & $\mathrm{N}$ & Mean & SD & Mean & SD & Mean & SD & Mean & SD \\
\hline \multicolumn{8}{|c|}{ Overall participants (N=491) } \\
\hline Precontemplation & 103 & 9.90 & 3.47 & 14.87 & 5.28 & 8.40 & 3.08 & 11.42 & 3.13 \\
\hline Contemplation & 137 & 9.66 & 3.56 & 14.35 & 4.58 & 8.02 & 2.69 & 11.88 & 2.89 \\
\hline Preparation & 61 & 9.56 & 3.22 & 14.85 & 4.87 & 7.56 & 2.60 & 11.49 & 2.84 \\
\hline Action & 162 & 10.54 & 3.09 & 16.76 & 4.65 & 8.15 & 2.60 & 12.23 & 2.76 \\
\hline Maintenance & 24 & 9.58 & 3.37 & 19.13 & 4.08 & 9.21 & 2.00 & 11.58 & 3.48 \\
\hline & \multicolumn{7}{|c|}{ Normal BMI N=326) } & & & \\
\hline Precontemplation & 82 & 9.76 & 3.56 & 14.93 & 5.61 & 8.45 & 3.20 & 11.61 & 3.11 \\
\hline Contemplation & 81 & 9.74 & 3.51 & 13.48 & 4.22 & 7.89 & 2.63 & 12.02 & 2.94 \\
\hline Preparation & 42 & 9.36 & 3.34 & 14.26 & 4.97 & 7.40 & 2.75 & 11.57 & 3.12 \\
\hline Action & 102 & 10.33 & 3.21 & 16.73 & 4.88 & 8.25 & 2.77 & 12.22 & 2.77 \\
\hline Maintenance & 17 & 9.18 & 3.05 & 18.12 & 3.57 & 9.41 & 2.09 & 11.71 & 2.66 \\
\hline \multicolumn{8}{|c|}{ Overweight/Obesity $(\mathrm{N}=165)$} & & & \\
\hline Precontemplation & 21 & 10.48 & 3.12 & 14.67 & 3.83 & 8.19 & 2.60 & 10.67 & 3.18 \\
\hline Contemplation & 56 & 9.54 & 3.66 & 15.61 & 4.81 & 8.21 & 2.77 & 11.66 & 2.84 \\
\hline Preparation & 19 & 10.00 & 2.96 & 16.16 & 4.49 & 7.89 & 2.28 & 11.32 & 2.16 \\
\hline Action & 60 & 10.88 & 2.86 & 16.82 & 4.26 & 7.98 & 2.30 & 12.25 & 2.77 \\
\hline Maintenance & 7 & 10.57 & 4.16 & 21.57 & 4.47 & 8.71 & 1.80 & 11.29 & 5.22 \\
\hline
\end{tabular}


Table 3.9. Weight Efficacy Questionnaire: Summary of Multiple Sample Model Results

\begin{tabular}{|c|c|c|c|c|c|c|c|c|}
\hline Construct & $\mathrm{CFI}$ & RMSEA & $x^{2}$ & $\mathrm{df}$ & $x^{2} / d f$ & $x^{2} \operatorname{diff}(\mathrm{df})$ & $\mathrm{P}$ & $\Delta \mathrm{CFI}$ \\
\hline \multicolumn{9}{|l|}{$\begin{array}{l}\text { Random } \\
\text { Selected }\end{array}$} \\
\hline Congeneric & .954 & .037 & 279.85 & 168 & 1.67 & & & \\
\hline $\begin{array}{l}\text { Lambda- } \\
\text { Invariant }\end{array}$ & .955 & .035 & 291.99 & 183 & 1.60 & $0.14(15)$ & ns & .001 \\
\hline $\begin{array}{l}\text { Tau } \\
\text { Equivalent }\end{array}$ & .953 & .035 & 302.31 & 189 & 1.60 & $10.32(6)$ & ns & -.002 \\
\hline Paralleled & .955 & .033 & 313.65 & 204 & 1.54 & $11.3+(15)$ & ns & .002 \\
\hline \multicolumn{9}{|l|}{$\begin{array}{l}\text { Different } \\
\text { BMI }\end{array}$} \\
\hline Congeneric & .939 & .043 & 320.30 & 168 & 1.91 & & & \\
\hline $\begin{array}{l}\text { Lambda- } \\
\text { Invariant }\end{array}$ & .936 & .042 & 340.91 & 183 & 1.86 & $20.62(15)$ & $\mathrm{ns}$ & -.003 \\
\hline $\begin{array}{l}\text { Tau } \\
\text { Equivalent }\end{array}$ & .933 & .042 & 355.02 & 189 & 1.88 & $14.11(6)$ & ns & -.003 \\
\hline Paralleled & .926 & .043 & 388.65 & 204 & 1.91 & $33.63(15)$ & $\begin{array}{l}< \\
.01 \\
\end{array}$ & -.007 \\
\hline \multicolumn{9}{|l|}{$\begin{array}{l}\text { Different } \\
\text { gender }\end{array}$} \\
\hline Congeneric & .949 & .039 & 292.51 & 168 & 1.74 & & & \\
\hline $\begin{array}{l}\text { Lambda- } \\
\text { Invariant }\end{array}$ & .949 & .037 & 306.55 & 183 & 1.68 & $14.04(15)$ & ns & 0 \\
\hline $\begin{array}{l}\text { Tau } \\
\text { Equivalent }\end{array}$ & .950 & .036 & 309.78 & 189 & 1.64 & $3.23(6)$ & ns & .01 \\
\hline Paralleled & .944 & .037 & 334.66 & 204 & 1.67 & $29.88(15)$ & ns & -.006 \\
\hline
\end{tabular}

Note. $\mathrm{p}=.01$ 


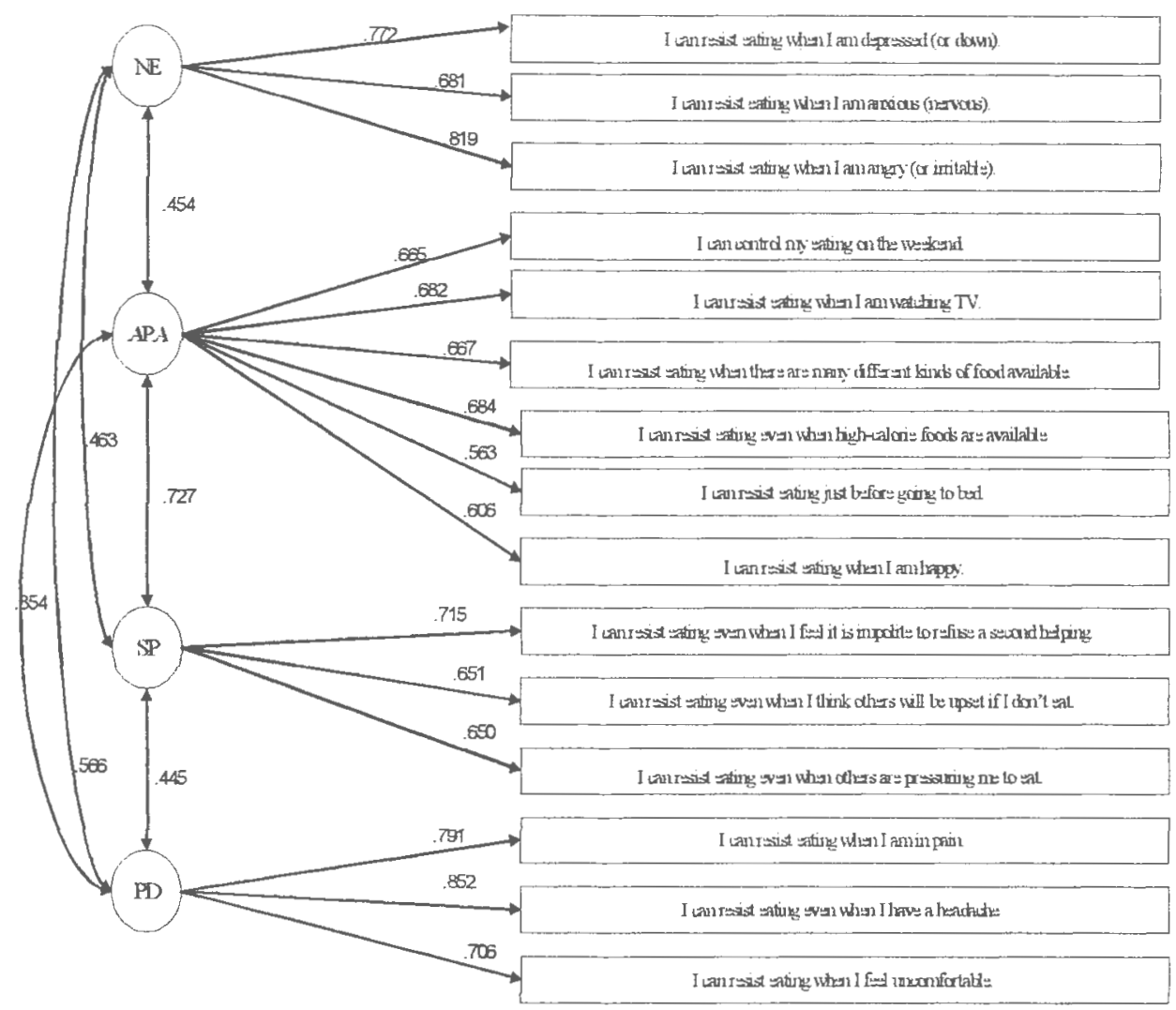

Figure 3.1. Four correlated factor model for self-efficacy 


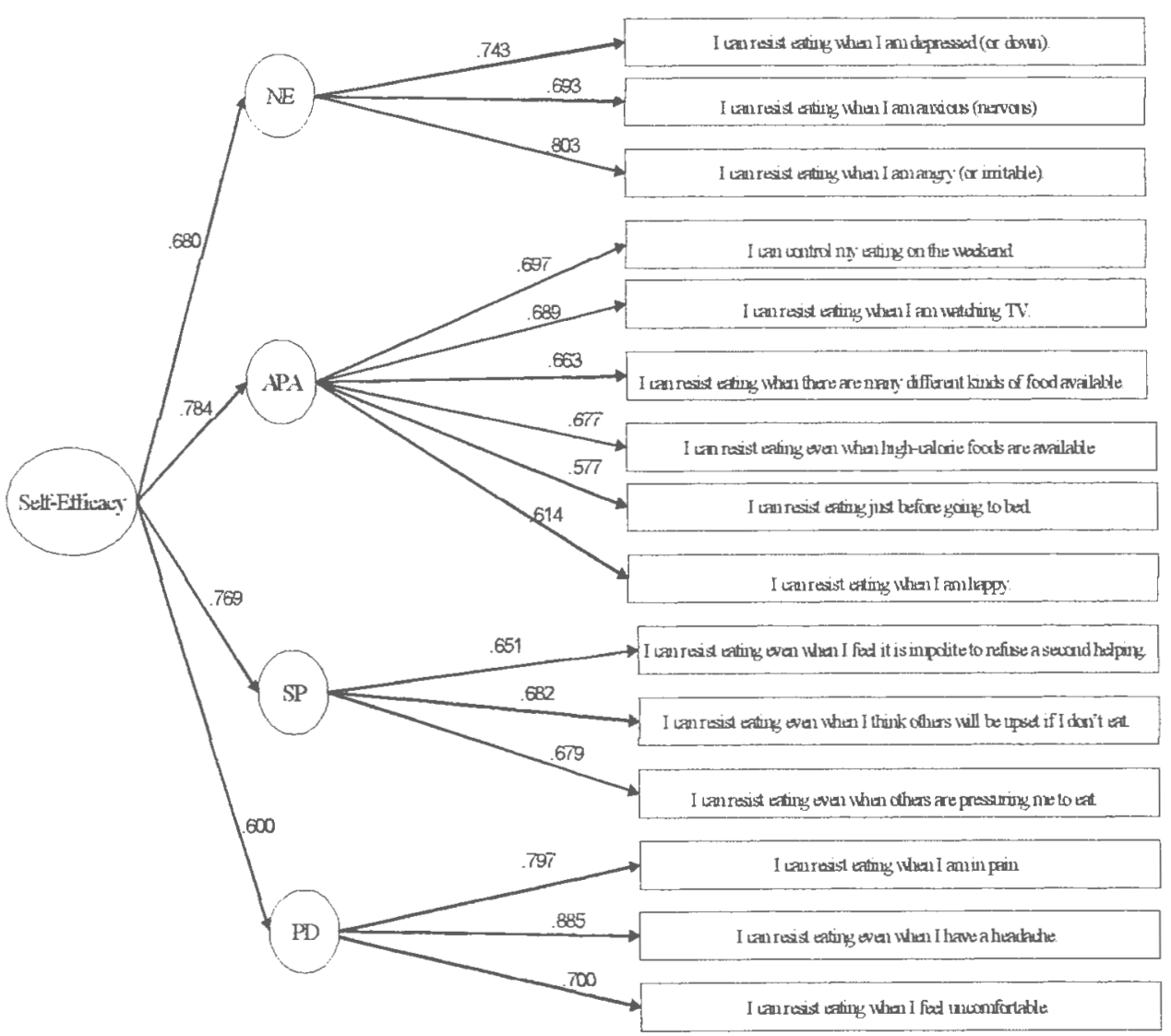

Figure 3.2. Hierarchical model for self-efficacy 
Self-efficacy: Overall Participants

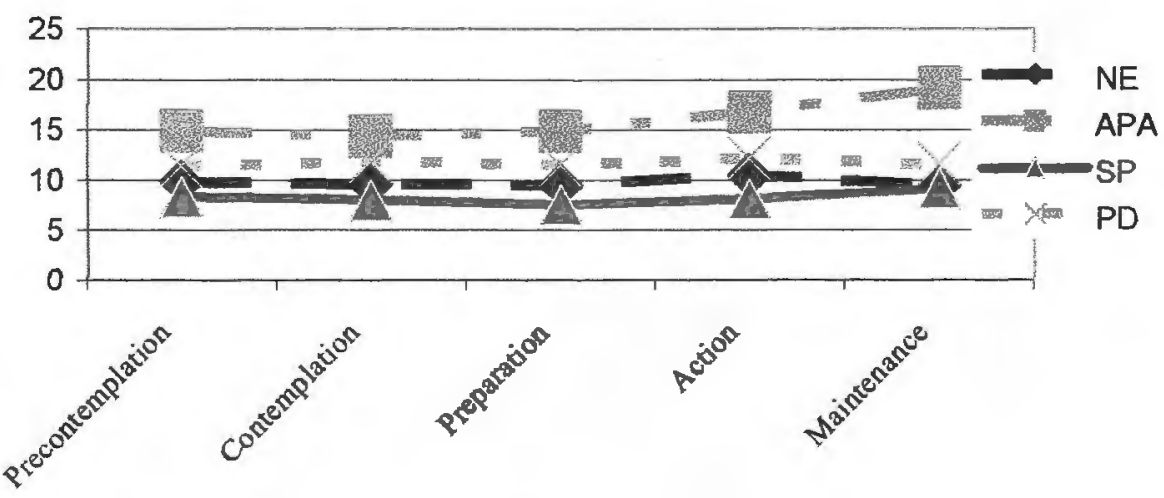

Figure 3.3: Overall participants: pattern for self-efficacy 
Self-efficacy: Normal BMI

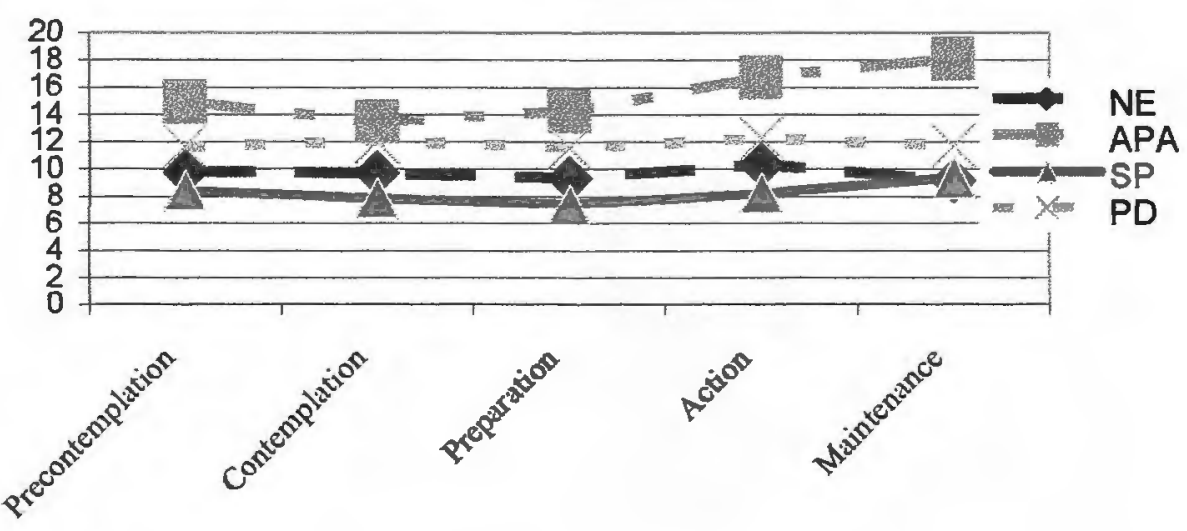

Figure 3.4. Participants with normal BMI: pattern for self-efficacy 
Self-efficacy: Overweight/Obesity

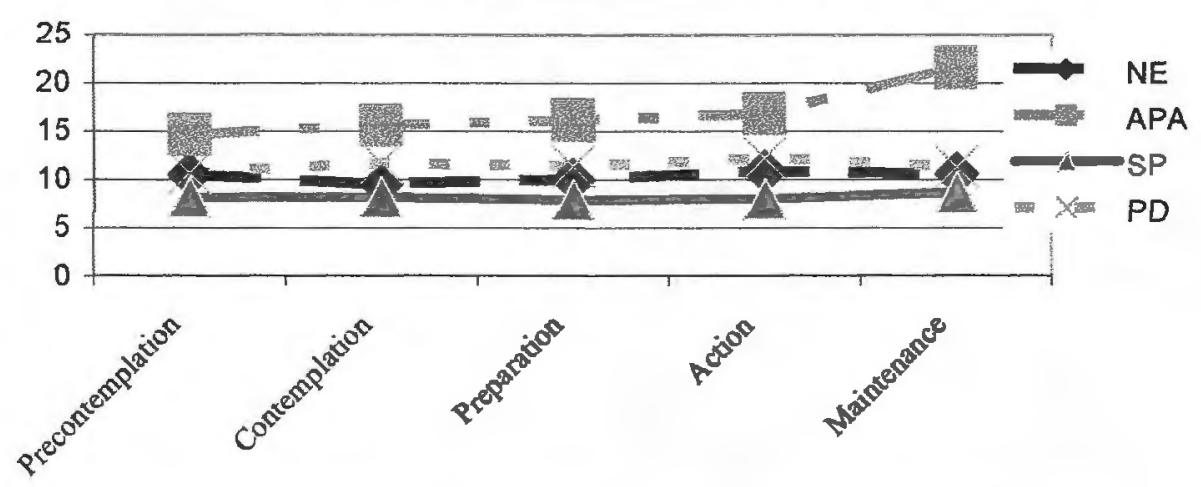

Figure 3.5. Participants who were overweight or obese: pattem for self-efficacy 
Chapter 4. Prediction of stage of change in weight management from decisional balance and selfefficacy

Food supplies in various parts of Asia have become more stable and consumers have greater choice due to economic growth and globalization, leading to broader acceptance of western diets. Economic prosperity and the availability of many time-saving electrical appliances has helped decrease the amount of physical effort and led to a sedentary lifestyle. These factors have had a considerable impact on the prevalence of obesity - and the associated health problems -in Asian populations, especially the adolescent demographic.

Studies indicate that adolescents' self-perceived weight is poorly related to the medical definition of overweight, and considerable numbers of clinically normal-weight persons are trying to or wish to control weight. For instance, an investigation done in the Osaka Prefecture, Japan, showed that $48 \%$ of 10 -year-old females and $84 \%$ of 17 -year-old females self-categorized themselves as 'fat' or "too fat' (Kaneko, Kiriike, Ikenaga, Miyawaki, \& Yamagami, 1999).

The diseases related to obesity, and increased incidences of obesity in the adolescent population strongly suggest the importance of the issue of weight management in overweight/obese adolescents in Asia. The issue of weight control in non-clinical adolescents is also of concern. Therefore, it is important to understand motivational readiness for weight management in adolescent population in Asia in order to develop and tailor interventions to adolescents' level of readiness for weight management.

The Transtheoretical Model (TTM; Prochaska, DiClemente, \& Norcross, 1992) is one of several theories that could serve as the framework for investigating the issue of weight management. Stages of change, decisional balance, and self-efficacy are three of the main components of the TTM. Stage of Change (SC), the central construct of the TTM, represents a sign of motivational readiness to change. Stage of Change makes it possible to understand when particular types of change occur. Five stages of change have been defined for most problem behaviors, including precontemplation, contemplation, preparation, action, and maintenance (Rossi \& Rossi, 1999). The decision-making component of the TTM is based on a model first conceptualized by Janis and Mann (1977). Eight specific categories of decision-making were proposed in the Janis and Mann (1977) model; however; 
only two general dimensions, the pros and cons of behavior change, have been supported consistently by factor analytic studies (Prochaska, Velicer, Rossi et al., 1994). The self-efficacy dimension of the model was originally based on Bandura's (1977) concept of self-efficacy, but has since undergone considerable elaboration within the context of the TTM (DiClemente et al., 1991; Prochaska, Velicer, Guadagnoli, Rossi, \& DiClemente, 1991).

The goal of this investigation was to predict which students were ready for weight management. Another purpose was to collect information on the possible reasons students were in different stage of change for weight management.

Discriminant function analyses were conducted using decisional balance (i.e., Pros, Cons) and self efficacy (i.e., Negative Emotion, Availability and Positive Activities, Social Pressure, Physical Discomfort) to predict the five stages of change in weight management in adolescents in Taiwan. The ability of Decisional Balance and Self Efficacy to correctly classify study participants into their reported stage of change will also be investigated.

\section{Methods}

\section{Participants}

During the 2005 school year, 780 senior high students from a high school in Taiwan were recruited into a cross-sectional study examining weight management behaviors. Of the 780 students, $492(63.16 \%)$ were first-year senior high students, and 287 (36.84\%) were second-year students; 388 (49.87\%) were male and $390(50.13 \%)$ were female students.

Based on the criteria recommended by Department of Health in Taiwan, the BMI cutoffs for underweight, normal, overweight and obesity among first-year male students were $<18.2,18.2-23.1$, 23.1, 25.5, respectively; while for first-year female students were $<18,18.0-22.7,22.7,25.3$, respectively. The BMI cutoffs for underweight, normal, overweight and obesity among second-year male students were $<18.6,18.6-23.4,23.4,25.6$, respectively; while for first-year female students were $<18.2,18.2-22.7,22.7,25.3$, respectively. The BMI distribution by school year and gender are shown in Table 4.1.

Based on the response on the item asked 'how do you feel about your current weight', participants were distinguished as 'with intention of losing weight', 'stay the same weight' and 'with intention of 
gaining weight'. In this study; the non-clinical population with intention of losing weight and overweight/obese students are the focus. Therefore, students who were underweight and whose BMI were in normal range with intention of maintaining, or gaining weight were excluded. That is, only students who are either overweight, obese or in the normal range but with the intention of losing weight were included in the analyses. Thus, of the original 780 students, 491 students met the criteria and were used for the analyses in the investigation. The BMI distribution of students used in the analyses are shown in Table 2.2. The sample comprised 202 males $(41.1 \%)$ and 289 females $(58.9 \%) ; 310$ were first year students (63.1\%) and 181 were second year students (36.9\%).

All participants were students from a senior high school in Taiwan. Based on the main goal of the study; the students, either overweight, obese or being in normal weight range but with intention of losing weight, were included in the analyses.

Of the 491 participants, 202 were male and 289 female. 310 of the students were first year senior high school students and 181 of them were second year senior high school students. The BMI status of the participants in study 1 are shown in Table 4.1.

Procedure

The sample was recruited from classes at a senior high school in Taiwan. Participation was anonymous, voluntary; took about 40 minutes, and involved no incentives to the subjects for their participation. Participants were provided with complete information regarding the purpose, benefits, and possible risks of the study. They completed questionnaires in the classrooms. The survey was conducted as a paper-and-pencil measure in the participants' classrooms. Study procedures were approved by the Institutional Review Board at the University of Rhode Island.

Material

Decisional Balance Inventory (DBI)

The original Decisional Balance Inventory (DBI) is composed of 20 items and is applied to examine two hypothesized dimensions (i.e., Pros and Cons) of decision making for weight management (O'Connell \& Velicer, 1988). The Pros are positive aspects of changing behavior, including facilitators of change. Examples of Pros are as follows: "I could wear attractive clothing if I lost weight"" "My health would improve if I lost weight." The Cons represent negative aspects of changing behavior. An 
example of a Con is "Trying to lose weight could end up being expensive when everything is taken into account." Research showed that coefficient Alpha was .91 for the pros scale and .84 for the cons scale (O'Connell \& Velicer, 1988; Rossi et a1., 1995).

Chinese version of Decisional Balance Inventory (DBI)

The original English-language questionnaires were translated into Chinese and then backtranslated into English by a panel of bilingual psychologists. During the process of back translation, the equivalence of Chinese and English version was ensured. The questionnaires were then applied to groups of students to verify their understanding of the questions. The necessary modifications were applied to ensure the understandabililty of the instruments.

The 14-item Chinese version of Decisional Balance using a sample of 491 adolescents in a high school in Taiwan. Using split-half, cross-validation procedures, a two-factor correlated model fit the data best $(\mathrm{CFI}=.971, \mathrm{RMSEA}=.042)$ with good internal consistency for both Pros $(.85)$ and Cons $(.72)$.

\section{Weight Efficacy Life-Style Questionnaire (WELSQ)}

The Weight Efficacy Life-Style Questionnaire (WELSQ) consists of 20 items to evaluate five dimensions (i.e., Availability; Negative Emotions, Physical Discomfort, Positive Activities, and Social Pressure) of self-efficacy for weight management (Clark, Abrams, Niaura. Eaton, \& Rossi, 1991). Using a 10-point Likert-type format, respondents are asked to rate their self-assurance in resisting overeating in various tempting situations. Alphas were .76 and .83 for the Availability scale, .87 and .88 for the Negative Emotions scale, .82 and .84 for the Physical Discomfort scale, .70 and .79 for the Positive Activities scale, and .90 and .89 for the Social Pressure scale (Clark et al., 1991; Rossi et al.. 1995).

Chinese version of Weight Efficacy Questionnaire (WEQ)

The original English-language questionnaires were translated into Chinese and then backtranslated into English by a panel of bilingual psychologists. During the process of back translation, the equivalence of Chinese and English version was ensured. The questionnaires were then applied to groups of students to verify their understanding of the questions. The necessary modifications were applied to ensure the understandabililty of the instruments. 
The 15-item Chinese language version of the Weight Efficacy Questionnaire using a sample of 491 adolescents in Taipei high schools. Using split-half, cross-validation procedures, a hierarchical four-factor model fit the data well $(\mathrm{CFI}=.940, \mathrm{RMSEA}=.059)$ with reasonable internal consistency for all scales: negative emotion (.80), availability and positive activities $(.80)$, social pressure $(.68)$, and physical discomfort (.80).

\section{Results}

Summary statistics by groups (i.e., overall participants, normal BMI range, overweight/obesity) are shown in Table 4.1. Correlations (Table 4.2) among the variables were reasonable and none of the variables were close to collinearity levels (i.e., all correlations are $<|.70|$ ). DFA: Overall Participants

The results showed that Wilk's $\Lambda=.797$, and multivariate $\eta^{2}=.203$. The effect size implied that $20.3 \%$ of the Stage of Change is accounted for by the best linear combinations of decisional balance and self-efficacy variables.

Four discriminant function and four eigenvalues were generated the variance in. The first Ftest $[\mathrm{F}(24,1665.3)=4.67, \mathrm{P}<.0001]$ was significant, and implied that the first discriminant function was significant as well. The second F-test $[\mathrm{F}(15,1319.9)=2.45, \mathrm{P}=.0015]$ was significant, and implied that the second discriminant function was also significant. The third $F$-test $[F(8,958)=2.09, p=.0342]$ was significant, and implied that the third discriminant function was significant. The sum of squared canonical correlation for the three discriminant functions was $\mathrm{R}^{2}=.201\left(\mathrm{DF} 1, \mathrm{R}^{2}=.141, \mathrm{DF} 2, \mathrm{R}^{2}=\right.$ 040. DF $3, \mathrm{R}^{2}=.020$ ), indicating $20.1 \%$ of variance was explained between groups.

Using a guideline of $\geq|0.30|$ as a cutoff to interpret meaning loadings, Pros (.680), the highest discriminant loading in first discriminant function, showed the biggest differences across the Stage groups. The next highest loading was related to Availability and Positive Activities (.546). Therefore, the first discriminant function was largely focused on Pros, but also defined by one dimension of self-efficacy; Availability and Positive Activities.

The loadings suggested that function two was associated with Availability and Positive Activities (.758), Social Pressure (.482) and Pros (-.375). Negative Emotion had the highest 
discriminant loading (.711) in third discriminant function. The loading also suggested that function three was associated with Physical Discomfort (.425).

The first discriminant function separated Precontemplators from Contemplators, Action, Preparation and Maintenance students. The first function was linear across the Stage. Result from class means on canonical variables indicated that Maintenance subjects had the highest group centroids, while Precontemplators had the lowest group centrodis.

The second discriminant function separated Contemplators from Precontemplators, and also separate Contemplators from students who were in Maintenance stage. The second function was not linear across the Stage, but U-shape function. Result from class means on canonical variables indicated that Maintenance subjects had the highest group centroids, while Contemplators had the lowest group centrodis. There was small difference in group centroids between Precontemplation and Maintenance subjects. The pattern of group centroids across stages is presented in Figure 4.1 and 4.2.

A computer prograun was used to conduct significant test of correct classification rate (Rossi, 2000). Overall correct classification rate was $31.2 \%(\mathrm{z}=3.020, \mathrm{p}<.003)$, which was greater than chance (i.e., $25.3 \%$ ), for discriminant function predicting participants in Stage of Change. The Stage with the highest percentage of correct classification is Maintenance $(62.5 \%, z=13.030, p<.001)$. Stage 1 (Precontemplation) was with $48.5 \%(z=6.808, p<.001)$ correct classification. Participants who were in Contemplation, Preparation and Action Stages were classified better than chance $(25.6 \%, \mathrm{z}=-0.673$, $\mathrm{ns} ; 23.0 \%, \mathrm{z}=2.460, \mathrm{p}<.02 ;$ and $23.5 \%, \mathrm{z}=-2.650, \mathrm{p}<.01)$.

\section{DFA: Students' BMI were in normal range with intention of losing weight}

A Discriminant Function Analysis was performed. Predictors were the pros of weight management, the cons of weight control, Negative Emotion, Availability and Positive Activities, Social Pressure, and Physical Discomfort. Groups were students whose BMI in normal range but who intended to lose weight and were in different stage of weight management (i.e., Precontemplation, Contemplation, Preparation, Action, and Maintenance).

The F-tests for all four DFA summary indices were significant [Wilks' $\Lambda=0.757, F(24$, 1096.6) $=3.80, \quad \mathbf{p}<.0001 . \quad$ Pillai's Trace $=0.261, F(24,1268)=3.69, \quad \mathbf{p}<.0001 . \quad$ Hotelling-Lawley Trace $=0.299, \mathrm{~F}(24,733.55)=3.89, \mathrm{p}<.0001$. Roy's Greatest Root $=0.198, F(6,317)=10.45, \mathrm{p}<.0001]$, 
indicating there is significant association between the grouping variable and the linear combinations of continuous variables. The $\eta 2$ was equal to 0.243 , indicating a moderate effect size showing that $24.3 \%$ of the variance in stages of change is accounted fir by the best linear combination(s) of decisional balance and self-efficacy.

The first and second discriminant functions were significant. For the first eigenvalue, $F(24$, $1096.6)=3.80, \mathrm{p}<.0001$. For the first discriminant function, two of the six variables have loadings worth examining based on the criteria of $\geq|0.30|$ as a cutoff (see Table 4.3). The variable that showed the biggest differences across the Stage groups was Pros, with the highest discriminant loading (.733). The next highest loading was associated with Availability and Positive Activities (.530). Thus, this first discriminant function was largely focused on Pros. Based on the results of discriminant loadings and group centroids, distinguishing across Stages of change among the students, whose BMI were in normal range with intention of losing weight was mainly explained by Pros and Availability and Positive Activities.

For the second eigenvalue, $F(15,869.98)=2.11, p=0.0081$. For the second discriminant function, three of the six variables had loadings worth examining, based on the criteria of $\geq|0.30|$ as a cutoff. The continuous variable that shows the biggest differences across the Stage groups was Availability and Positive Activities, with the highest discriminant loading (.638). The next highest loading was associated with Social Pressure (.506), followed by Cons (.384). This first discriminant function was largely focused on Availability and Positive Activities. The group centroids for both functions are shown in Table 4.4 .

The sum of squared canonical correlation for the three discriminant functions was $\mathrm{R}^{2}=.226$ (DF $1, R^{2}=.165$, DF $2, R^{2}=.061$ ), indicating $22.6 \%$ of variance was explained between groups.

The first discriminant function separated Precontemplators from Contemplators, Action, Preparation and Maintenance students. The first function was linear across the Stage. Result from class means on canonical variables indicated that Maintenance subjects had the highest group centroids, while Precontemplators had the lowest group centrodis.

The second discriminant function separated Contemplators from Precontemplators, and also separate Contemplators from students who were in Maintenance stage. The second function was not 
linear across the Stage, but $U$-shape function. Result from class means on canonical variables indicated that Maintenance subjects had the highest group centroids, while Contemplators had the lowest group centrodis. There was small difference in group centroids between Precontemplation and Maintenance subjects. The pattern of group centroids across stages is presented in Figure 4.1 and 4.2.

A computer program was used to conduct significant test of correct classification rate (Rossi, 2000). The discriminant function was reasonably accurate in classifying individuals into Precontemplation, Contemplation, and Preparation (correct classification for these respective stages: $35.4 \%, \mathrm{z}=2.095, \mathrm{p}<.04 ; 38.3 \%, \mathrm{z}=2.758, \mathrm{p}<.01 ; 31.0 \%, \mathrm{z}=3.471, \mathrm{p}<.001$ )(Table 4.5 ). Maintenance-group was the group was more accurate with classification $(64.7 \%, z=10.995, p<.001)$ than others. However, accuracy in classifying individuals into Action stage $(20.6 \%, z=-2.369, \mathrm{p}<$ .02) was worse than chance. Overall, the current discriminant function resulted in $32.4 \%(\mathrm{z}=3.299, \mathrm{p}<$ .001) correct classification into Stage of Change in weight management, which was greater than a $24.5 \%$ chance classification.

\section{DFA: Students' BMI were in overweight and obese range}

A Discriminant Function Analysis was performed. Predictors were the pros of weight management, the cons of weight control, Negative Emotion, Availability and Positive Activities, Social Pressure, and Physical Discomfort. Groups were students who were overweight or obese, were in different stage of weight management (i.e., Precontemplation, Contemplation, Preparation, Action, and Maintenance).

The F-tests for all four DFA summary indices were significant [Wilks' $\Lambda=.752, F(24$, 534.96) $=1.89, \mathrm{p}=.0067 . \quad$ Pillai's Trace $=.268, \quad F(24,624)=1.87, \mathrm{p}=.0074 . \quad$ Hotelling-Lawley Trace $=.302, F(24,353.05)=1.91, p=.0068$. Roy's Greatest Root $=.181, F(6,317)=4.71, p=.0002]$, indicating there is significant association between the grouping variable and the linear combinations of continuous variables. The $\eta 2$ was equal to .243 , indicating a moderate effect size showing that $24.3 \%$ of the variance in stage is shared with the best linear combination(s) of decisional balance and selfefficacy.

The first discriminant function was significant. For the first eigenvalue, $F(24,534.96)=1.89$, $\mathrm{p}=.0067$. For the first discriminant function, three of the six variables have loadings worth examining 
based on the criteria of $\geq|0.30|$ as a cutoff. The continuous variable that shows the biggest differences across the Stage groups was Availability and Positive Activities, with the highest discriminant loading (.697). The next highest loading was associated with Cons (-.594), followed by Pros $(0.326)$. Thus, this first discriminant function was largely focused on Cons. Based on the results of discriminant loading and group centroids, the distinguishing across Stages of change among the students, who were overweight or obese, were mainly explained by Availability and Positive Activities, Cons and Pros. The sum of squared canonical correlation for the three discriminant functions was $R^{2}=.153\left(\mathrm{DF} 1 . \mathrm{R}^{2}=\right.$ .153 ), indicating $15.3 \%$ of variance was explained among groups. The group centroids for both functions are shown in Table 4.4.

The first discriminant function separated Precontemplators from Contemplators, Action. Preparation and Maintenance students. The first function was linear across the Stage. Result from class means on canonical variables indicated that Maintenance subjects had the highest group centroids, while Precontemplators had the lowest group centrodis. The pattern of group centroids across stages is presented in Figure 4.1 and 4.2 .

The discriminant function was reasonably accurate in classifying individuals (Table 4.5) into Precontemplation, Preparation and Action (correct classification for these respective stages: $57.1 \%, \mathrm{z}=$ $6.054, p<.001 ; 31.6 \%, z=2.706, p<.01 ; 33.3 \%, z=-0.558, n s)$. Maintenance-group was the group was more accurate with classification $(71.4 \%, z=8.761, p<.001)$ than others. However, accuracy in classifying individuals into Contemplation stage $(28.6 \%, \mathrm{z}=-0.912, \mathrm{~ns})$ was the same as chance. Overall, the current discriminant function resulted in $36.2 \%(z=2.160, p<.04)$ correct classification into Stage of Change in weight management, which was greater than a $28.6 \%$ chance classification.

\section{Discussion}

The main purpose of this investigation was to predict which students were ready to manage their weight using decisional balance and self-efficacy. Discriminant function analyses were conducted using the decisional balance and self efficacy subscales to predict the five stages of change in weight management in adolescents in Taiwan. 
Pros and efficacy in situations where Availability and Positive Activities (APA) were dominant in the significant discriminant functions across overall participants, students whose BMI were in normal with intention of losing weight, and students who were overweight or obese.

For overall participants and students who were normal weight, the first discriminant function separated Precontemplators from Contemplators, Action, Preparation and Maintenance students. The second discriminant function separated Contemplators from Precontemplators, and also separate Contemplators from students who were in Maintenance stage. The first function was linear across the Stages, while the second function was U-shape across the Stages. In the first function, there was big difference in group centroids between Precontemplation and Maintenance subjects. However, the difference in group centroids between these two Stages was getting small in the second function.

Based on Cohen's (1992) guidelines for effect sizes, the effect sizes for the three DFA in the investigation were medium to large. Regarding the ability of decisional balance and self efficacy to correctly classify study participants into their reported stage of change, overall classification rates were around $30-35 \%$, which were greater than chance. The accurate rate of classification in students who were in Maintenance was highest, compared with students in other stages.

Other characteristics of students may also contribute the students' status of stage of change in weight management, such as socioeconomic status, family influence, peer influences. This investigation should stimulate research toward an understanding of the weight management in adolescents in Asia. 


\section{Reference}

Bandura, A. (1997). Self-efficacy: The exercise of control. New York: W.H. Freeman.

Clark, M. M., Abrams, D. B., Niaura, R. S., Eaton, C. A., \& Rossi, J. S. (1991). Self-efficacy in weight management. Journal of Consulting and Clinical Psychology, 59, 739-744.

Cohen, J. (1992). A power primer. Psychological Bulletin, 112, 155-159.

DiClemente, C.C., Prochaska, J.O., Fairhurst, S.K., Velicer, W.F., Velasquez, M.M., \& Rossi, J.S. (1991). The process of smoking cessation: An analysis of precontemplation, contemplation and preparation stages of change. Journal of Consulting and Clinical Psychology, 59, 295-304.

Janis, I. \& Mann, L. (1977). Decision Making: A Psychological Analysis of Conflict, Choice and Commitment. New York: Free Press.

Kaneko, K., Kiriike, N., Ikenaga, K., Miyawaki, D., \& Yamagami, S (1999). Weight and shape concerns and dieting behaviours among pre-adolescents and adolescents in Japan Psychiatry and Clinical Neurosciences. Psychiatry and Clinical Neurosciences, 53, 365.

O'Connell, D., \& Velicer: W. F. (1988). A decisional balance measure and the stages of change model for weight loss. International Journal of the Addictions, 23, 729-750.

Prochaska, J.O., DiClemente, C.C., \& Norcross, J.C. (1992). In Search of how people change, American Psychologist, 1102-1114.

Prochaska, J.O., Velicer, W.F., Guadagnoli, E., Rossi, J.S., \& DiClemente, C.C. (1991). Patterns of change: Dynamic typology applied to smoking cessation. Multivariate Behavioral Research, 26, 83-107.

Prochaska, J.O., Velicer, W.F., Rossi, J.S., Goldstein, M.G., Marcus, B.H., Rakowski, W., Fiore, C., Harlow, L.L., Redding, C.A., Rosenbloom, D., \& Rossi, S.R. (1994). Stages of change and decisional balance for 12 problem behaviors. Health Psychology, 13, 39-46.

Rossi, J.S. (2000). Significance tests for classification results in discriminant function analysis with unequal sample sizes. Unpublished computer program. University of Rhode Island: Kingston, RI.

Rossi, S.R., \& Rossi, J.S. (1999). Concepts and theoretical models. In N. Jairath (Ed.), Coronary heart disease and risk factor management: A nursing perspective (pp. 47-69). Orlando, FL: W.B. Saunders. 
Rossi, J.S., Rossi, S.R., Velicer, W.F., \& Prochaska, J.O. (1995). Motivational readiness to control weight. In D.B. Allison (Ed.), Handbook of assessment methods for eating behaviors and weightrelated problems: Measures, theory, and research (pp. 387-430). Thousand Oaks, CA: Sage. 
Table 4.1. Summary Statistics: self-efficacy and decisional balance

\begin{tabular}{|c|c|c|c|c|c|}
\hline Variable & $\mathrm{N}$ & Mean & $\mathrm{SD}$ & Skewness & Kurtosis \\
\hline \multicolumn{6}{|l|}{ Overall participants } \\
\hline Pros & 491 & 18.570 & 6.990 & 0.382 & -0.583 \\
\hline Cons & 491 & 15.882 & 5.692 & 0.491 & -0.223 \\
\hline Negative Emotion (NE) & 491 & 10.004 & 3.350 & -0.251 & -0.702 \\
\hline $\begin{array}{ll}\text { Availability and } & \text { Positive } \\
\text { Activities (APA) } & \end{array}$ & 491 & 15.607 & 4.962 & 0.285 & -0.139 \\
\hline Social Pressure (SP) & 491 & 8.165 & 2.724 & 0.439 & -0.109 \\
\hline Physical Discomfort (PD) & 491 & 11.835 & 2.935 & -0.718 & -0.149 \\
\hline \multicolumn{6}{|l|}{ Normal BMI } \\
\hline Negative Emotion (NE) & 326 & 9.853 & 3.378 & -0.212 & -0.682 \\
\hline $\begin{array}{l}\text { Availability and } \\
\text { Activities (APA) }\end{array}$ & 326 & 15.218 & 5.045 & 0.383 & -0.144 \\
\hline Social Pressure (SP) & 326 & 8.172 & 2.840 & 0.4779 & -0.18 \\
\hline Physical Discomfort (PD) & 326 & 11.887 & 2.938 & -0.792 & 0.069 \\
\hline \multicolumn{6}{|l|}{ Overweight/Obesity } \\
\hline Negative Emotion (NE) & 165 & 10.303 & 3.284 & -0.325 & -0.722 \\
\hline $\begin{array}{l}\text { Availability and } \\
\text { Activities (APA) }\end{array}$ & 165 & 16.376 & 4.714 & 0.135 & 0.092 \\
\hline Social Pressure (SP) & 165 & 8.152 & 2.488 & 0.315 & -0.018 \\
\hline Physical Discomfort (PD) & 165 & 11.733 & 2.935 & -0.578 & -0.526 \\
\hline
\end{tabular}


Table 4.2. Correlation: Self-efficacy and decisional balance $(N=491)$

\begin{tabular}{|l|l|l|l|l|l|l|}
\hline & Pros & Cons & NE & APA & SP & PD \\
\hline Pros & 1 & & & & & \\
\hline Cons & 0.197 & 1 & & & & \\
\hline NE & -0.035 & -0.066 & 1 & & & \\
\hline APA & 0.036 & -0.072 & 0.412 & 1 & & \\
\hline SP & -0.082 & -0.018 & 0.358 & 0.532 & 1 & \\
\hline PD & 0.145 & 0.059 & 0.516 & 0.304 & 0.330 & 1 \\
\hline
\end{tabular}


Table 4.3. Pooled Within Canonical Structure

\begin{tabular}{|c|c|c|c|c|}
\hline \multicolumn{5}{|c|}{ Overall participants ( $\mathrm{N}=491)$} \\
\hline & CanI & Can2 & Can3 & Can 4 \\
\hline Pros & 0.680 & -0.375 & -0.195 & -0.436 \\
\hline Cons & -0.277 & 0.212 & 0.023 & -0.707 \\
\hline $\mathrm{NE}$ & 0.121 & 0.166 & 0.711 & 0.285 \\
\hline APA & 0.546 & $0.7 \overline{758}$ & 0.180 & 0.242 \\
\hline SP & 0.035 & 0.482 & -0.298 & 0.538 \\
\hline PD & 0.177 & -0.161 & 0.425 & 0.430 \\
\hline \multicolumn{5}{|c|}{ Normal BMI $(N=324)$} \\
\hline & Canl & Can2 & $\operatorname{Can} 3$ & Can4 \\
\hline Pros & 0.733 & -0.290 & -0.235 & -0.314 \\
\hline Cons & -0.049 & 0.384 & -0.006 & -0.650 \\
\hline $\mathrm{NE}$ & 0.063 & 0.022 & 0.642 & 0.382 \\
\hline APA & 0.530 & 0.638 & 0.371 & 0.408 \\
\hline SP & 0.081 & 0.506 & -0.237 & 0.664 \\
\hline$\overline{P D}$ & 0.089 & -0.138 & 0.322 & 0.492 \\
\hline \multicolumn{5}{|c|}{ Overweight/Obesity $(\mathrm{N}=165)$} \\
\hline & Canl & Can 2 & Can3 & Can4 \\
\hline Pros & 0.326 & 0.626 & 0.068 & 0.428 \\
\hline Cons & -0.594 & 0.260 & 0.346 & 0.601 \\
\hline NE & 0.174 & -0.554 & -0.353 & 0.405 \\
\hline$\overline{A P A}$ & 0.697 & -0.152 & 0.334 & -0.001 \\
\hline SP & 0.037 & 0.012 & 0.180 & -0.492 \\
\hline PD & 0.241 & 0.189 & -0.688 & 0.310 \\
\hline
\end{tabular}


Table 4.4. Group Centroids (Class Means on Canonical Variables)

\begin{tabular}{|c|c|c|c|c|}
\hline Stage of Change & Can 1 & $\operatorname{Can} 2$ & $\operatorname{Can} 3$ & Can4 \\
\hline \multicolumn{5}{|c|}{ Overall participants $(\mathrm{N}=491)$} \\
\hline Precontemplation & -0.607 & 0.245 & 0.012 & -0.001 \\
\hline Contemplation & -0.134 & -0.245 & -0.095 & 0.090 \\
\hline Preparation & 0.060 & -0.131 & -0.036 & -0.310 \\
\hline Action & 0.346 & 0.035 & 0.151 & 0.036 \\
\hline Maintenance & 0.885 & 0.440 & -0.438 & 0.035 \\
\hline \multicolumn{5}{|c|}{ Normal BMI $(\mathrm{N}=324)$} \\
\hline Precontemplation & -0.486 & 0.326 & 0.011 & -0.031 \\
\hline Contemplation & -0.331 & -0.306 & -0.069 & 0.102 \\
\hline Preparation & 0.170 & -0.227 & -0.071 & -0.278 \\
\hline Action & 0.427 & 0.015 & 0.155 & 0.040 \\
\hline Maintenance & 0.942 & 0.359 & -0.479 & 0.107 \\
\hline \multicolumn{5}{|c|}{ Overweight/Obesity $(\mathrm{N}=165)$} \\
\hline Precontemplation & -0.666 & -0.467 & 0.111 & -0.086 \\
\hline Contemplation & -0.148 & 0.284 & 0.003 & -0.088 \\
\hline Preparation & -0.146 & 0.109 & 0.290 & 0.274 \\
\hline Action & 0.253 & -0.110 & -0.198 & 0.047 \\
\hline Maintenance & 1.405 & -0.225 & 0.547 & -0.192 \\
\hline
\end{tabular}


Table 4.5. Classification of Stage of Change

\begin{tabular}{|c|c|c|c|c|c|c|c|}
\hline \multicolumn{8}{|c|}{ Overall participants $(\mathrm{N}=491$, missing $=1)$} \\
\hline & & $P$ & $\mathrm{C}$ & $\operatorname{Pr}$ & A & $\mathrm{M}$ & Total \\
\hline \multirow[t]{2}{*}{$\mathrm{P}$} & $\mathrm{N}$ & 50 & 17 & 14 & 11 & 11 & 103 \\
\hline & Percent classified & 48.54 & 16.5 & 13.59 & 10.68 & 10.68 & 100 \\
\hline \multirow[t]{2}{*}{$\mathrm{C}$} & $\mathrm{N}$ & 40 & 35 & 21 & 15 & 26 & 137 \\
\hline & Percent classified & 29.2 & 25.55 & 15.33 & 10.95 & 18.98 & 100 \\
\hline \multirow[t]{2}{*}{$\mathrm{Pr}$} & $\mathrm{N}$ & 13 & 12 & 14 & 7 & 15 & 61 \\
\hline & Percent classified & 21.31 & 19.67 & 22.95 & 11.48 & 24.59 & 100 \\
\hline \multirow[t]{2}{*}{ A } & $\mathrm{N}$ & 30 & 24 & 27 & 38 & 43 & 162 \\
\hline & Percent classified & 18.52 & 14.81 & 16.67 & 23.46 & 26.54 & 100 \\
\hline \multirow[t]{2}{*}{$\bar{M}$} & $\mathrm{~N}$ & 2 & 1 & 1 & 5 & 15 & 24 \\
\hline & Percent classified & 8.33 & 4.17 & 4.17 & 20.83 & 62.5 & 100 \\
\hline \multirow[t]{2}{*}{ Total } & $\mathrm{N}$ & 136 & 89 & 77 & 76 & 113 & 491 \\
\hline & Percent classified & 27.7 & 18.13 & 15.68 & 15.48 & 23.01 & 100 \\
\hline \multicolumn{8}{|c|}{ Normal BMI $(\mathrm{N}=326$, missing $=2)$} \\
\hline & & $P$ & $\mathrm{C}$ & $\mathrm{Pr}$ & $\bar{A}$ & $\mathrm{M}$ & Total \\
\hline \multirow[t]{2}{*}{$\mathrm{P}$} & $\mathrm{N}$ & 29 & 20 & 10 & 10 & 13 & 82 \\
\hline & Percent classified & 35.37 & 24.39 & 12.2 & 12.2 & 15.85 & 100 \\
\hline \multirow[t]{2}{*}{$\mathrm{C}$} & $\mathrm{N}$ & 16 & 31 & 14 & 10 & 10 & 81 \\
\hline & Percent classified & 19.75 & 38.27 & 17.28 & 12.35 & 12.35 & 100 \\
\hline \multirow[t]{2}{*}{$\operatorname{Pr}$} & $\mathrm{N}$ & 7 & 10 & 13 & 6 & 6 & 42 \\
\hline & Percent classified & 16.67 & 23.81 & 30.95 & 14.29 & 14.29 & 100 \\
\hline \multirow[t]{2}{*}{$\bar{A}$} & $\mathrm{~N}$ & 21 & 15 & 21 & 21 & 24 & 102 \\
\hline & Percent classified & 20.59 & 14.71 & 20.59 & 20.59 & 23.53 & 100 \\
\hline \multirow[t]{2}{*}{$\overline{\mathrm{M}}$} & $\mathrm{N}$ & 1 & 1 & 0 & 4 & 11 & 17 \\
\hline & Percent classified & 5.88 & 5.88 & 0 & 23.53 & 64.71 & 100 \\
\hline \multirow[t]{2}{*}{ Total } & $N$ & 75 & 77 & 58 & 51 & 65 & 326 \\
\hline & Percent classified & 23.01 & 23.62 & 17.79 & 15.64 & 19.94 & 100 \\
\hline \multicolumn{8}{|c|}{ Overweight/Obesity $(\mathrm{N}=165$, missing $=2)$} \\
\hline & & $\mathrm{P}$ & $\mathrm{C}$ & $\operatorname{Pr}$ & A & $\vec{M}$ & Total \\
\hline \multirow[t]{2}{*}{$P$} & $N$ & 12 & 0 & 4 & 4 & 1 & 21 \\
\hline & Percent classified & 57.14 & 0 & 19.05 & 19.05 & 4.76 & 100 \\
\hline \multirow[t]{2}{*}{$\mathrm{C}$} & $\mathrm{N}$ & 15 & 16 & 13 & 5 & 7 & 56 \\
\hline & Percent classified & 26.79 & 28.57 & 23.21 & 8.93 & 12.5 & 100 \\
\hline \multirow[t]{2}{*}{$\mathrm{pr}_{\mathrm{r}}$} & $\bar{N}$ & 5 & 4 & 6 & 3 & 1 & 19 \\
\hline & Percent classified & 26.32 & 21.05 & 31.58 & 15.79 & 5.26 & 100 \\
\hline \multirow[t]{2}{*}{ A } & $\mathrm{N}$ & 13 & 7 & 7 & 20 & 13 & 60 \\
\hline & Percent classified & 21.67 & 11.67 & 11.67 & 33.33 & 21.67 & 100 \\
\hline \multirow[t]{2}{*}{$\bar{M}$} & $\mathrm{~N}$ & 0 & 1 & 0 & 1 & 5 & 7 \\
\hline & Percent classified & 0 & 14.29 & 0 & 14.29 & 71.43 & 100 \\
\hline \multirow[t]{2}{*}{ Total } & $\mathrm{N}$ & 45 & 28 & 30 & 33 & 29 & 165 \\
\hline & Percent classified & 27.27 & 16.97 & 18.18 & 20 & 17.58 & 100 \\
\hline
\end{tabular}

Precontemplation $=\mathrm{P}$, Contemplation $=\mathrm{C}$, Preparation $=\mathrm{Pr}$, Action $=\mathrm{A}$, Maintenance $=\mathrm{M}$ 


\section{Group Centroids}

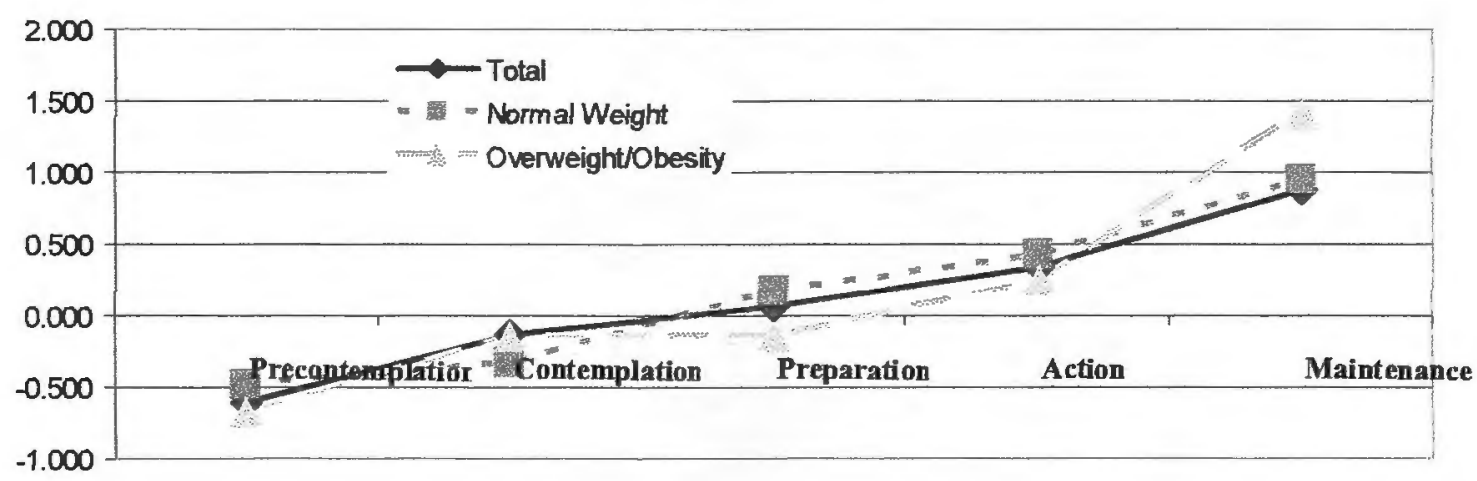

Figure 4.1. Group Centroids: first function 
Group Centroids

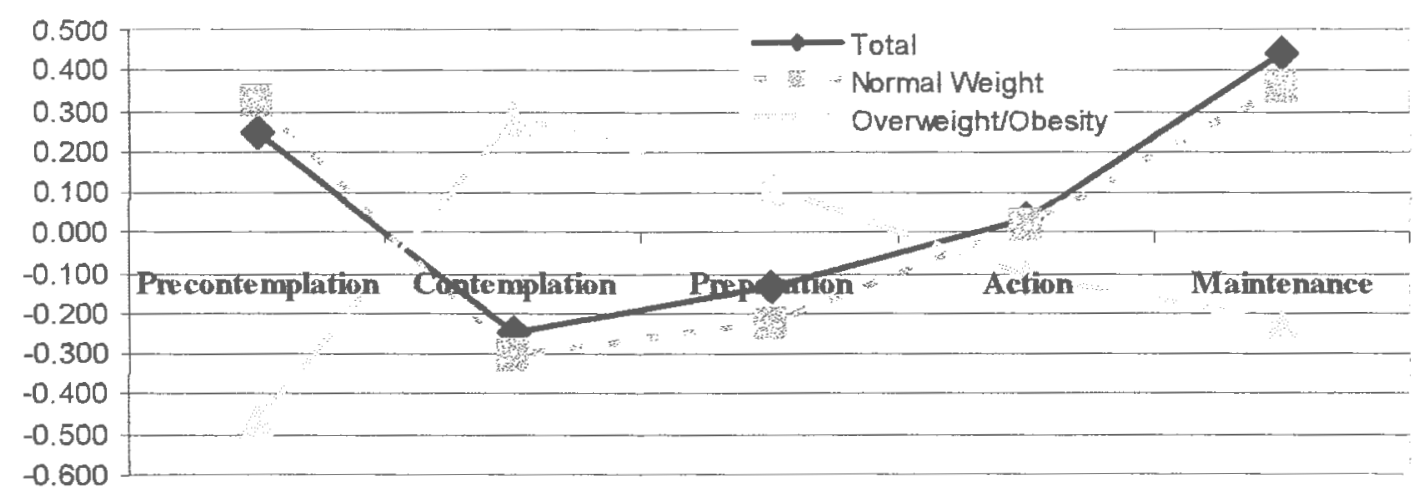

Figure 4.2. Group Centroids: second function 


\section{Chapter 5. Conclusions, limitations and future directions}

The main goal of the investigation was to examine the applicability of the TTM in weight management behavior in an adolescent population in Taiwan in order to develop and tailor future intervention for an adolescent Asian population.

To achieve the goal, several analytic steps were applied. In Step 1, Chinese version of the TTM weight control instruments (i.e., Decisional Balance Inventory, Weight Efficacy Questionnaire) for an adolescent population in Taiwan were developed. In Step 2, the internal validity of Decisional Balance Inventory and Weight Efficacy Questionnaire developed from Step 1 was evaluated using confirmatory factor analyses. In Step 3, the external validity of Decisional Balance Inventory and Weight Efficacy Questionnaire was examined. Multivariate Analyses of Variance (MANOVAs) were applied to examine the relationship between Decisional Balance and Stage of Change, and the relationship between Self-Efficacy and Stage of Change. In Step 4, the levels of factorial invariance of Decisional Balance Inventory; and Weight Efficacy Questionnaire across two sets of demographic variables (BMI status, genđer) were examined. In Step 5, discriminant function analysis was conđucted to assess the ability of Decisional Balance and Self-Efficacy to classify students into self-reported Stage of Change.

In this chapter, the summaries of findings are introduced. The limitations and future direction of the investigation are discussed as well.

\section{Summaries of research results}

\section{Decisional Balance}

A Chinese version of Decisional Balance Inventory that examines two dimensions of decisional balance, Pros and Cons, was generated from the item selection procedures. Each dimension included seven items, and demonstrated reasonable internal consistency. Confirmatory factor analysis verified the competence of the two-factor model for decisional balance for high school students in Taiwan. The results of the two-factor structure support the conceptual framework of decisional balance (Janis \& Mann, 1977), and also support findings from previous empirical research (Akamatsu, Otake \& Shimai, 2003; O'Connell \& Velicer, 1988; Prochaska et al., 1994). The significant MANOVA results showed that pros and cons of losing weight were different across the stages of change in this adolescent 
population. Results from multiple-sample confirmatory factor analysis of decisional balance supported the factorial invariance of DBI across gender subgroups, indicating the concept of decisional balance across genders can be treated as arising from the same population. On the other hand, the results of multisample models found that the concept of decisional balance in students whose BMI were in normal range but who had intention of losing weight, were different from the students who were overweight or obese.

Self-Efficacy

Based on the original twenty-item form, the four-factor 15 WEQ was found to represent the area appropriately; using exploratory factor analyses. This four-factor pattern was different from the original five-factor pattern of original English version of Weight Efficacy Questionnaire (O'Connell \& Velicer, 1988). This hierarchical structure replicated findings from measures of other behaviors (Plummer, Velicer, Redding et al, 2001). Confirmatory factor analysis verified the competence of the four-factor model for weight efficacy for high school students in Taiwan. MANOVA results found all subscales were nearly the same trend, with the exception of Availability and Positive Activities, indicating some evidence of different pattern across the stages of change. Results from multisample analyses in self-efficacy suggest the factorial invariance of WEQ across gender subgroups, indicating the concept of self-efficacy across genders can be treated as arising from the same population. However, the results of multisample model indicated that the concept of self-efficacy in students whose BMI were in normal range with intention of losing weight, were different from the students who were overweight or obese.

Predictive Ability of Decisional Balance and Self-Efficacy to Stage of Change

The ability of decisional balance and self efficacy to correctly classify study participants into their reported stage of change was reasonable; overall classification rates were around $40 \%$, which were greater than chance (i.e., 20\%). The accurate rate of classification in students who were in Maintenance was highest, compared with students in other stages. Pros and Availability and Positive Activities (APA) were dominant in the significant discriminant functions across overall participants, students whose BMI were in normal range with intention of losing weight, and students who were overweight or obese.. 


\section{Limitations}

This study has several limitations. Participants for the investigation were from a high school in rural area in Taiwan. Therefore, the results from the study may not be representative of the situation of high school students in Taiwan, and the generalization may be also limited.

When applying the Transtheoretical model in Asian cultures, one of the most important concerns is whether the psychological constructs (e.g., self-efficacy; decisional balance) of the TTM still maintain the same meanings/psychological qualities, which refers to the issue of conceptual equivalence (Brislin, 1993; Okazaki, \& Sue, 1995). Even through the back-translation techniques were applied to develop Chinese edition of questionnaires to ensure the equivalence; there was no direct evidence of conceptual, and/or metrical equivalence.

The study was also the first study that used Stage of change Algorithm of weight management based on four criteria (i.e., exercise, smaller portion size of food, less junk food, more fruit and vegetables). Since this was the first usage, the evidence of reliability and validity of the measurement was limited.

\section{Future direction}

This investigation should stimulate research toward an understanding of the weight management in adolescents in Asia. The current study provided support for application of the TTM to weight management in an Asian adolescent population. However, since these data are cross sectional in nature it is recommended that future researchers conduct longitudinal studies in this topic. The current investigation was not an experimental study, but a correlational study. Future researchers may collect experimental data to test causal effects.

Other characteristics of students may also contribute the students' stage of change for weight management in Asia, such as socioeconomic status, family influences, and peer influences; future researchers may investigate those factors. Researchers should also make efforts to assess the relevance of and control for as many background conditions as possible.

Research results are limited by using high school students in rual area in Taiwan. It is recommended that future studies should be conducted in larger, more diverse, and representative samples. Replication of the current findings with other samples will provide increased validity for the 
application of the TTM to the study of weight management. Moreover, future researchers should crossvalidate the current findings on other data. To deal with the limited understanding of reliability and validity of Stage of Change Algorithm used in this study; it is highly recommended that future researcher use this measurement to test its reliability and validity. It is also important that alternative Stage of Change Algorithms in weight management should be developed in the future.

In the current study, Processes of Change were not our focus due to limited resources. However, researchers should notice that Processes of Change are also critical in behavioral change, especially in developing tailored intervention. Therefore, it is recommended that future researchers should test the applicability of the concept of Processes of Change in Asian population.

TTM, an empirically supported behavior change model, would enable researchers and clinicians to more effectively design, target, and monitor the progress of interventions for weight management in adolescents in Asia. 


\section{Reference}

Akamatsu, R., Otake, K, \& Shimai, S. (2003). Development of Japanese Decision Balance Index (DBI) and stage of behavioral change. Japanese Journal of Health Psychologv, 16, 1-9.

Brislin. R. (1993). Understanding culture's influence on behavior. New York: Harcourt Brace.

O'Connell, D., \& Velicer, W. F. (1988). A decisional balance measure and the stages of change model for weight loss. International Journal of the Addictions, 23, 729-750.

Okazaki, S., \& Sue, S. (1995). Methodological issues in assessment research with ethnic minorities. Psychological Assessment, 7, 367-375.

Plummer, B.A., Velicer, W.F., Redding. C.A., Prochaska, J.O., Rossi, J.S., Pallonen, U.E., \& Meier, K.S. (2001). Stage of change, decisional balance, and temptations for smoking. Measurement and validation in a large, school-based population of adolescents. Addictive Behoviors, 26, 551-571.

Prochaska, J.O., Velicer, W.F., Rossi, J.S., Goldstein, M.G., Marcus, B.H., Rakowski, W., Fiore, C., Harlow, L.L., Redding, C.A., Rosenbloom, D., \& Rossi, S.R. (1994). Stages of change and decisional balance for 12 problem behaviors. Health Psychology, 13, 39-46. 


\section{Appendices}

Appendix A: Student consent form

The University of Rhode Island

Department of Psychology

Chafee Building, Kingston, RI 02881-0808

Applicability of the Transtheoretical Model in weight management in an adolescent population in Taiwan

\section{ASSENT FORM FOR RESEARCH}

\section{Dear Participant:}

We are asking you to take part in a research study because we are trying to learn more about weight management behaviors in adolescent population. We will explain the project to you in detail. You should feel free to ask questions. If you have more questions about this study later, you may contact me at yyeh9051@postoffice.uri.edu.

If you agree to be in this study, you will be asked some questions about weight and about your eating and exercising habits. Answering these questions should take about 20-30 minutes. There is no foreseeable direct benefit to you. Even though there will be no direct benefit to you for taking part in this study; we may learn more about weight management behaviors in adolescent population.

Your part in this study is anonymous. This signed form will be kept separate from your answer form. No one else will know if you were in this study and no one else can find out what answers you gave. We will keep all the records for this study:

If you do decide to participate, you can always drop out of the study at any time. Whatever you decide will not be held against you in any way. No one will be upset if you don't want to participate or even if you change your mind later and want to stop.

Participation in this study is not expected to be harmful or injurious to you. However, if this study causes you any injury, you should write or call Yating Yeh at the University of Rhode Island Kingston RI 02881-0808 U.S. at 012-1-401-874-2193.

If you have any more questions or concerns about this study, you may contact University of Rhode Island's Vice Provost for Graduate Studies, Research and Outreach, 70 Lower College Road, Suite 2, URI, Kingston, RI 02881-0808 U.S. at 012-1-401- 874-4328.

Remember, you can ask any questions you may have about this study. If you have a question later that you didn't think of now, you can call Yating Yeh at the University of Rhode Island Kingston RI 028810808 U.S. at 012-1-401-874-2193 or e-mail at yyeh9051@postoffice.uri.edu.

Signing your name at the bottom of this form means that you have read or listened to what it says and you understand it. Signing this form also means that you agree to participate in this study and your questions have been answered.

Signature of participant

Typed/printed Name
Signature of Researcher

Typed/printed Name 


\section{Appendix B: Student consent form Chinese version}

羅德島州大學

心理系

金斯頓 羅德島 02881-0808

台灣青少年減重研究

研究參與同意書

親愛的參與人:

我們想要了解青少年的減重行䍃, 所以擬邀請您參與本研究。我們會詳細告知您本研究的細 節, 您可以隨時提出問題。假如您日後還有任何疑問, 歡迎來電 yyeh9051@postoffice.uri.edu。

假如您同意參與本研究, 我們將會詢問您是否打算減重, 您在不同的情況是否克制飲食行愛的 把握程度。本研究並沒有支付您任何費用, 您也不會得到任何利益, 但我們會從您的參與之中 對青少年的減重行䍃有進一步的了解。您的作答不會透露您的姓名, 其他人也不會知道您的答 案。我們會保密與本㸴究有關的資料。假如您同意參與本研究, 您可以在研究進行中隨時退 出。不論您是否決定參與, 都不會對您有任何影響。如果您不願意參與, 或者您在中途退出, 都不會影響到任何人。

請記住, 您可以提出任何與本研究有關的問題。假如您日後有任何問題, 可以來電羅德島州大 學 012-1-401-874-2193.

請記住, 您可以提出任何與本研究有關的問題。假如您日後有任何問題, 可以來電羅德島州大 學研究所 $012-1-401-874-4328$.

如果您已讀完前述說明，而且也願意參與本研究，請在底下簽名。

參與者簽名

參與者全名

日期
研究者簽名

㗑究者全名

日期 
Appendix C: Survey battery

\section{Demographics information}

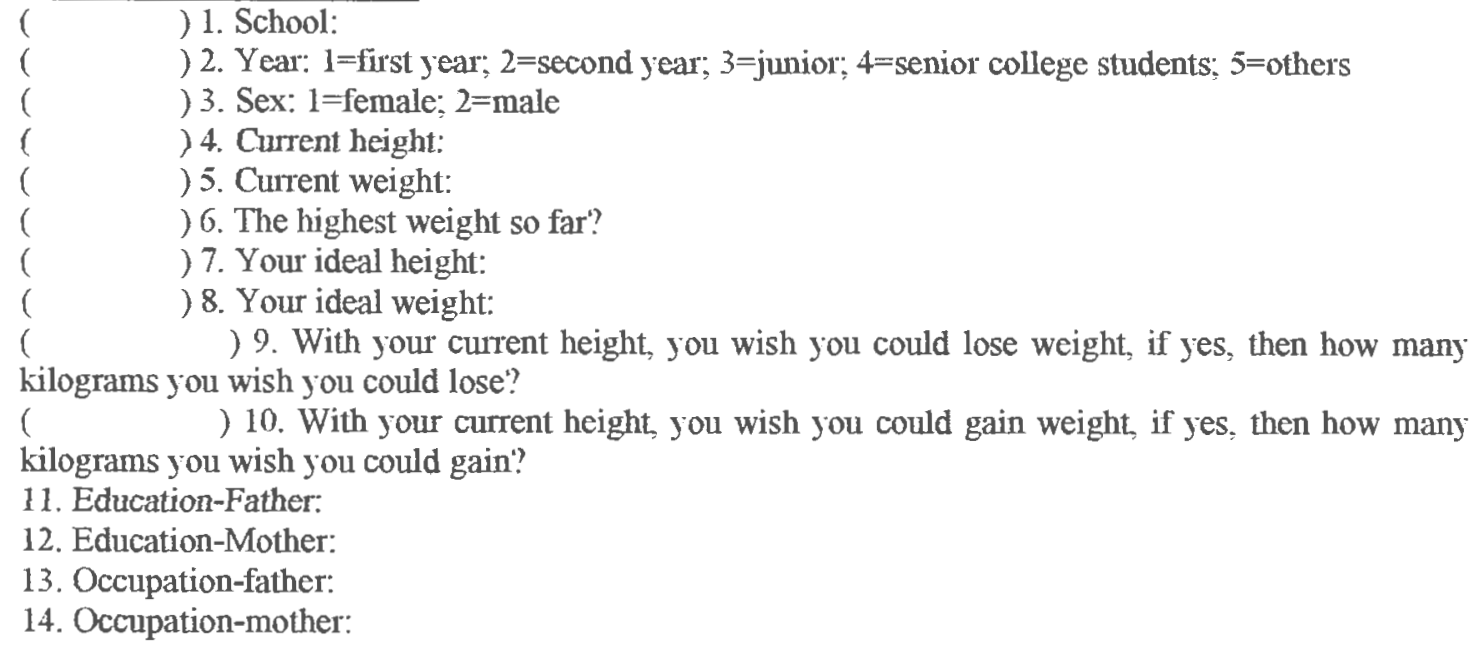

\section{weight management}

People trying to lose weight typically try a number of different methods. The most successful strategies include:

- Exercising more

- Eating smaller amounts of food

- Eating less junk food (e.g., soda, French fries, candy, chips, donuts, cookies, etc.)

- Eating more fruits and vegetables

( ) 15. Are you doing all of these things to lose weight?

$1=$ no, and I do NOT plan to start in the next 6 months.

$2=$ no, but I am seriously thinking about starting in the next 6 months.

$3=$ no, but I am planning to start in the next 30 days.

$4=\mathrm{es}$, I have been, but for less than 6 months.

5=yes, I have been for MORE then 6 months.

\section{Weight management}

How often in the last 30 days has your family done the following:

- $1=$ never

- $2=$ rarely

- $3=$ sometimes

- $4=$ often

- $\quad 5=a l m o s t$ always

( ) 16. Encourage each other to try to maintain a health weight.

( ) 17 Discuss how being overweight is unhealthy:

( ) 18. Remind each other to be more physically active.

( ) 19 Share ideas on how to eat less and exercise more.

How often in the last 30 days have your friends done the following:

- $1=$ never

- $2=$ rarely

- $3=$ sometimes

- $4=$ often

- $5=$ =almost always

( ) 20. Encourage each other to try to maintain a health weight.

( 21. Discuss how being overweight is unhealthy.

( ) 22. Remind each other to be more physically active.

( 23. Share ideas on how to eat less and exercise more. 
)24. How do you feel about your current weight?

$1=$ I would like to lose a lot of weight.

$2=$ I would like to lose a little weight.

$3=I$ would like to stay the same weight.

4=I would like to gain a little weight.

$5=$ I would like to gain a lot of weight.

\section{Exercise}

1. Regular exercise is any planned physical activity (e.g., brisk walking, jogging, bicycling, swimming, basketball, tennis, etc.) performed to increase physical fitness. Such activity should be performed 3 or more times per week for 30 minutes or more each time at a level that increases your breathing rate or causes you to break into a sweat.

( ) 25 .According to the definition above, are you currently engaging in regular exercise?

$1=$ no, and I do NOT plan to start in the next 6 months.

$2=$ no, but $I$ am seriously thinking about starting in the next 6 months.

$3=$ no, but I am planning to start in the next 30 days.

$4=$ yes, I have been, but for less than 6 months.

$5=$ yes, I have been for MORE then 6 months.

26. Over the past 30 days, on how many days did you participate in regular vigorous exercise for a total of 30 minutes per day?

Number of days (if none, put " $00 "$ )

\section{How important?}

Each statement represents a thought that might occur to a person who is deciding whether or not to lose weight. Please indicate how IMPORTANT each of these statements might be to you if you were considering a decision to lose weight. There are FIVE possible responses to each of the items that reflect your answer to the question "How important would this be to you?" Please circle the number that best describes how important each statement would be to you if you were deciding whether or not to lose weight.

\section{1}

not important at all

\section{2}

slightly

important

\section{3} moderately important
4

moderately

important
5 extremely important

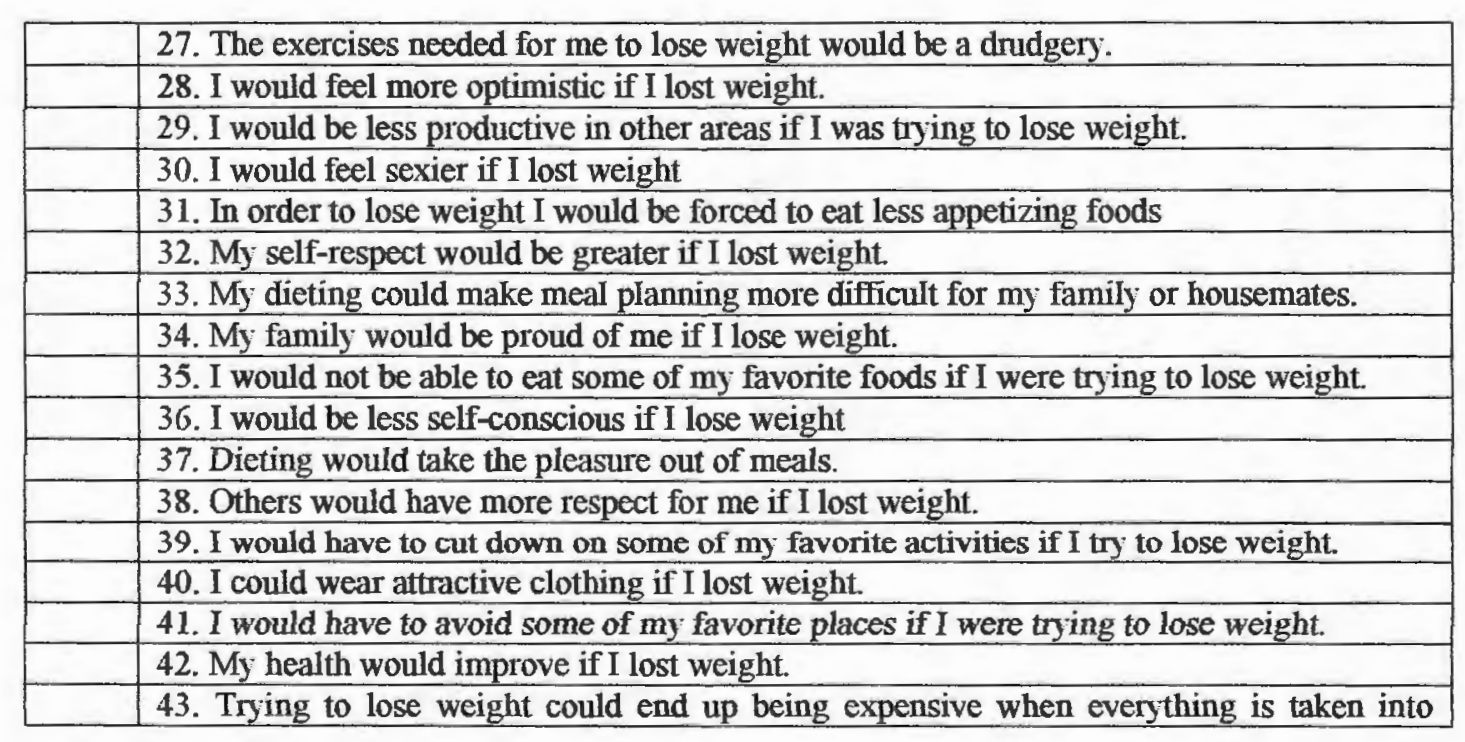




\begin{tabular}{|l|l|}
\hline & account. \\
\hline & 44. I would feel more energetic if I lost weight. \\
\hline & 45. I would have to cut down my favorite snacks while I was dieting. \\
\hline & 46. I would be able to accomplish more if I carried fewer pounds. \\
\hline
\end{tabular}

\section{Confidence}

This form describes some typical eating situations. Everyone has situations which make it very hard for them to keep their weight down. The following are a number of situations relating to eating patterns and attitudes. This form will help you to identify the eating situations which you find the hardest to manage.

Read each situation listed below and decide how confident (or certain) you are that you will be able to resist eating in each of the difficult situations. In other words, pretend that you are in the eating situation right now. On a scale from 1 (not confident) to 5 (extremely confident), choose ONE number that reflects how confident you feel now about being able to successfully resist the desire to eat. Write this number down next to each item.

$1=$ Not confident at all that you can resist the desire to eat

$2=$ slightly confident that you can resist the desire to eat

$3=$ moderately confident that you can resist the desire to eat

$4=$ very confident that you can resist the desire to eat

$5=$ extremely confident that you can resist the desire to eat

I AM CONFIDENT THAT:

\begin{tabular}{|l|l|}
\hline & 47. I can resist eating when I am anxious (nervous). \\
\hline & 48. I can control my eating on the weekends. \\
\hline 49. I can resist eating even when I have to say "no" to others. \\
\hline 50. I can resist eating when I feel physically run down. \\
\hline 51. I can resist eating when I am watching TV. \\
\hline 52. I can resist eating when I am depressed (or down). \\
\hline 53. I can resist eating when there are many different kinds of food available. \\
\hline 54. I can resist eating even when I feel it is impolite to refuse a second helping. \\
\hline 55. I can resist eating even when I have a headache. \\
\hline 56. I can resist eating when I am reading. \\
\hline 57. I can resist eating when I am angry (or irritable). \\
\hline 58. I can resist eating even when I am at a party \\
\hline 59. I can resist eating even when others are pressuring me to eat. \\
\hline 60. I can resist eating when I am in pain. \\
\hline 61. I can resist eating just before going to bed. \\
\hline 62. I can resist eating when I have experienced failure. \\
\hline 63. I can resist eating even when high-calorie foods are available. \\
\hline 64. I can resist eating even when I think others will be upset if I don't eat. \\
\hline 65. I can resist eating when I feel uncomfortable. \\
\hline 66. I can resist eating when I am happy. \\
\hline
\end{tabular}




\section{Appendix D: Survey battery Chinese version}

\section{二、基本資料}

1. 學校：

( )2.年級 : (1) =高一; (2) =高二； (3)=高三

4.目前的身高：

)3.性别：(11 = 男性； (2)=大性

5.目前的體重 : 公分

6.到目前爲止最重的體重：

7.理想的身高： 公斤

8 .理想的體重 : 公分 公斤

9.對於目前的體重，你希望能隇重? 如果是的話，你希望能減重多少公斤： 公厅

10.對於目的前體重, 你希望能增重? 如果是的話, 你希望能增加多少公斤： 公厅 11.父親教育程度：(請打勾、)

\begin{tabular}{|c|c|c|c|c|c|c|}
\hline 父親 & & & & & \\
\hline 教育程度 & 不識字 & 小學 & $\begin{array}{c}\text { 國中 } \\
\text { 初中 }\end{array}$ & $\begin{array}{c}\text { 高中 } \\
\text { 高職 }\end{array}$ & $\begin{array}{c}\text { 專科學校 } \\
\text { 大學 }\end{array}$ & $\begin{array}{c}\text { 硼究所 } \\
\text { 碩士或博士 }\end{array}$ \\
\hline
\end{tabular}

12.母親教育程度：(請打勾、)

\begin{tabular}{|c|c|c|c|c|c|c|}
\hline 母親 & & & & & & \\
\hline 教育程度 & 不識字 & 小學 & $\begin{array}{c}\text { 國中 } \\
\text { 初中 }\end{array}$ & $\begin{array}{c}\text { 高中 } \\
\text { 高職 }\end{array}$ & $\begin{array}{c}\text { 專科學校 } \\
\text { 大學 }\end{array}$ & $\begin{array}{c}\text { 㸴究所 } \\
\text { 碩士或博士 }\end{array}$ \\
\hline
\end{tabular}


13-14 父母職業：(請參考表格在適當的闌位上打勾、, 若無適合的選項, 請在「其他」處說明)

\begin{tabular}{|c|c|c|c|c|c|c|c|}
\hline 13.父親 & & & & & & & \\
\hline 14.母親 & & & & & & & \\
\hline $\begin{array}{l}\text { 職 } \\
\text { 業 } \\
\text { 類 } \\
\text { 別 }\end{array}$ & \begin{tabular}{|l|} 
大專校長 \\
大專教師 \\
大法官 \\
簡任以上公 \\
務員 \\
立法委員 \\
監察委員 \\
考試委員 \\
董事長 \\
總經理 \\
將級軍官 \\
醫師 \\
科學家
\end{tabular} & 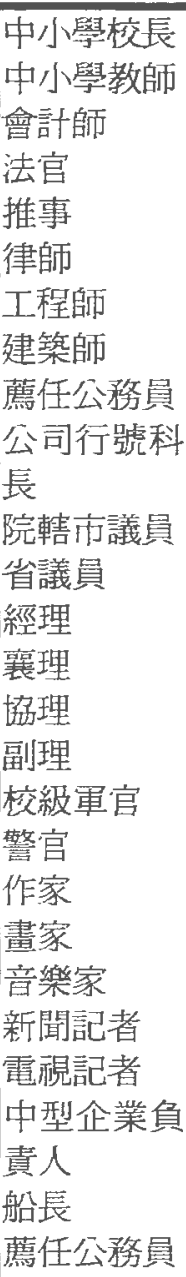 & 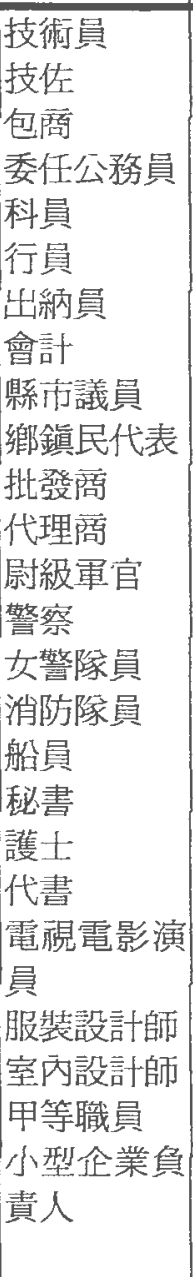 & \begin{tabular}{|l} 
技工 \\
水電匠 \\
店員 \\
商店老板 \\
零售員 \\
推銷員 \\
郵差 \\
乙等職員 \\
自抟農 \\
理髮師 \\
美容師 \\
廚師 \\
領班 \\
監工 \\
裁縫 \\
士官 \\
司機 \\
園藝業者 \\
打字員 \\
小店主 \\
領班 \\
監工
\end{tabular} & \begin{tabular}{|l|} 
工廠工人 \\
學徒 \\
小販 \\
農民 \\
漁民 \\
清橴工 \\
雜工 \\
臨時工 \\
工友 \\
建築物看管 \\
員 \\
門房 \\
僱工 \\
友傏 \\
服務生 \\
舞女
\end{tabular} & $\begin{array}{l}\text { 家庭主婦 } \\
\text { 無業 } \\
\text { 退休 }\end{array}$ & 其他 \\
\hline
\end{tabular}


三、減肥策略

（）15. 一般來說，嘗試減肥的人會使用許多不同種的隇肥方法。最成功的幾種策略包括：

*多做運動

*減少進食量

*少吃垃圾食物（如, 可樂, 炸著條, 糖果, 薯片, 甜甜圈, 餅乾等)

*多攝食水果與蔬荣

妳/你正在使用以上所有的方式來減肥嗎?

(1)=沒有。而且在接下來的六個月裡，我也不打算開始做。

(2)=沒有。但是我正在好好的考慮我在接下來的六個月裡要開始用以上的方法來減肥。

(3) =沒有。但是我計畫要在 30 天內開始減肥。

(4)二是的。我正在使用這些方法來減肥，但是實施起來還不到六個月

(5)=是的。我使用這些方法來減肥，而且已經超過六個月了。

16-19 在過去的 30 天中, 妳的家人有多常做下列的行䍃：

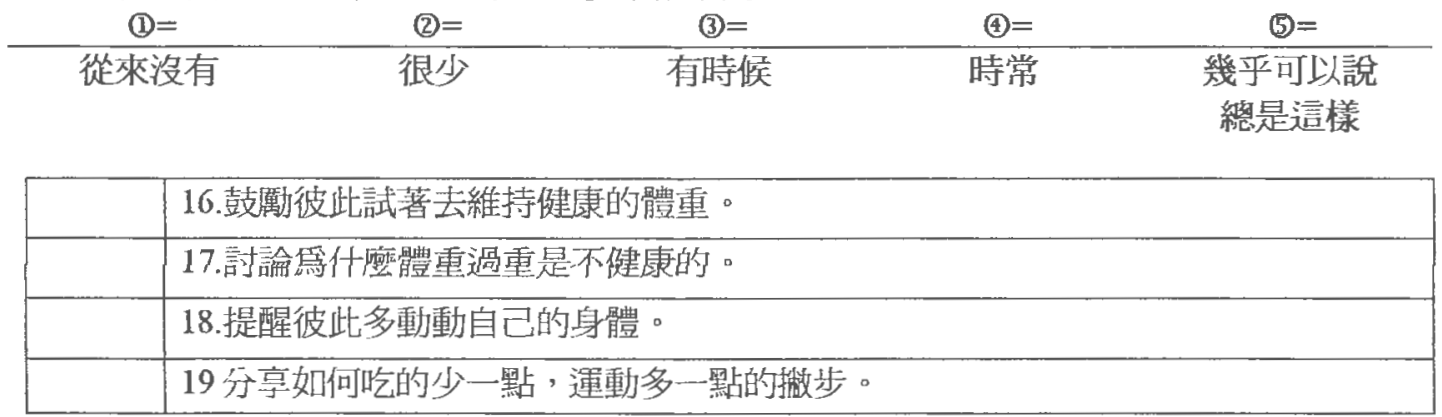

20-23 在過去的 30 天中, 妳的朋友有多常做下列的行鷂：

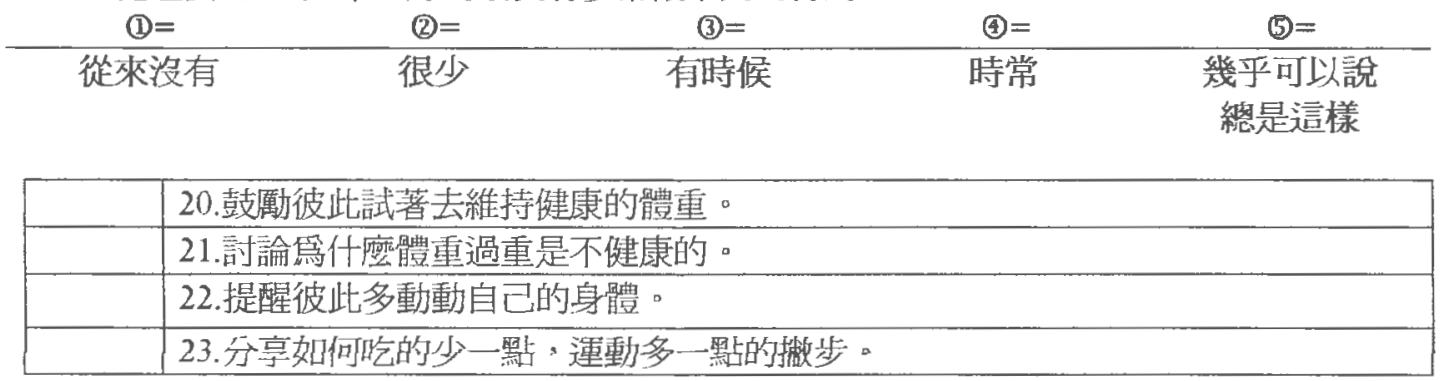

（）24.妳覺得妳現在的體重如何?

(1) =如果可能的話, 我想要隇輕很多。

(2)=如果可能的話, 我想要诚輕一些。

(3)二我想要保持與現在相同的體重。

(4)二如果可能的話, 我想要增加一些體重

(5)二如果可能的話, 我想要增加很多體重。 


\section{三、運動策略}

規律運動指的是任何一種有計畫的肢體活動（如快走, 慢跑, 騎腳踏車, 游泳, 打籃球, 打網 球等), 鹞的是要管淮身體健康。這樣的運動需要每週至少做 3 次, 每次至少 30 分鐘, 而且澾 到呼吸頻率睤加或是出汗的程度。

（）25.根據以上的定義, 妳現在有做規律運動嗎?（學校體育課除外）

(1)=沒有。而且在接下來的六個月裡, 我也不打算開始做。

(2)=沒有．但是我正在好好的考慮我在接下來的六個月裡要開始做規律運動

(3)=沒有・但是我計畫要在 30 天內開始做規律運動。

()=是的・我正在做規律運動, 但是實施起來還不到六個月。

(5) 是的。我正在做規律運動, 而且已經超過六個月了。

26. 在過去的 30 天中, 妳你有多少天每日運動總和澾 30 分鐘以上?（學校體育課除外）。 天數 (如果沒有, 請填“ $00^{-\prime}$ )

\section{四、決策權衡}

以下每一個敘述代表正在決定是否要減重的人可能有的想法。如果你曾考慮是否要減重, 請指 出每一個想法對你而言是多重要。關於每一個決定你打算是否要減重的想法有五種不同程度的 重要性。

針對每一個想法, 選出「這對你有多重要? 的程度, 請選出最適當的答案。

(1) $=$

一點也不重要
(2) $=$

有點重要
(3) $=$

中等程度地重要
(4)=

非常重要
(5)=

極爲重要

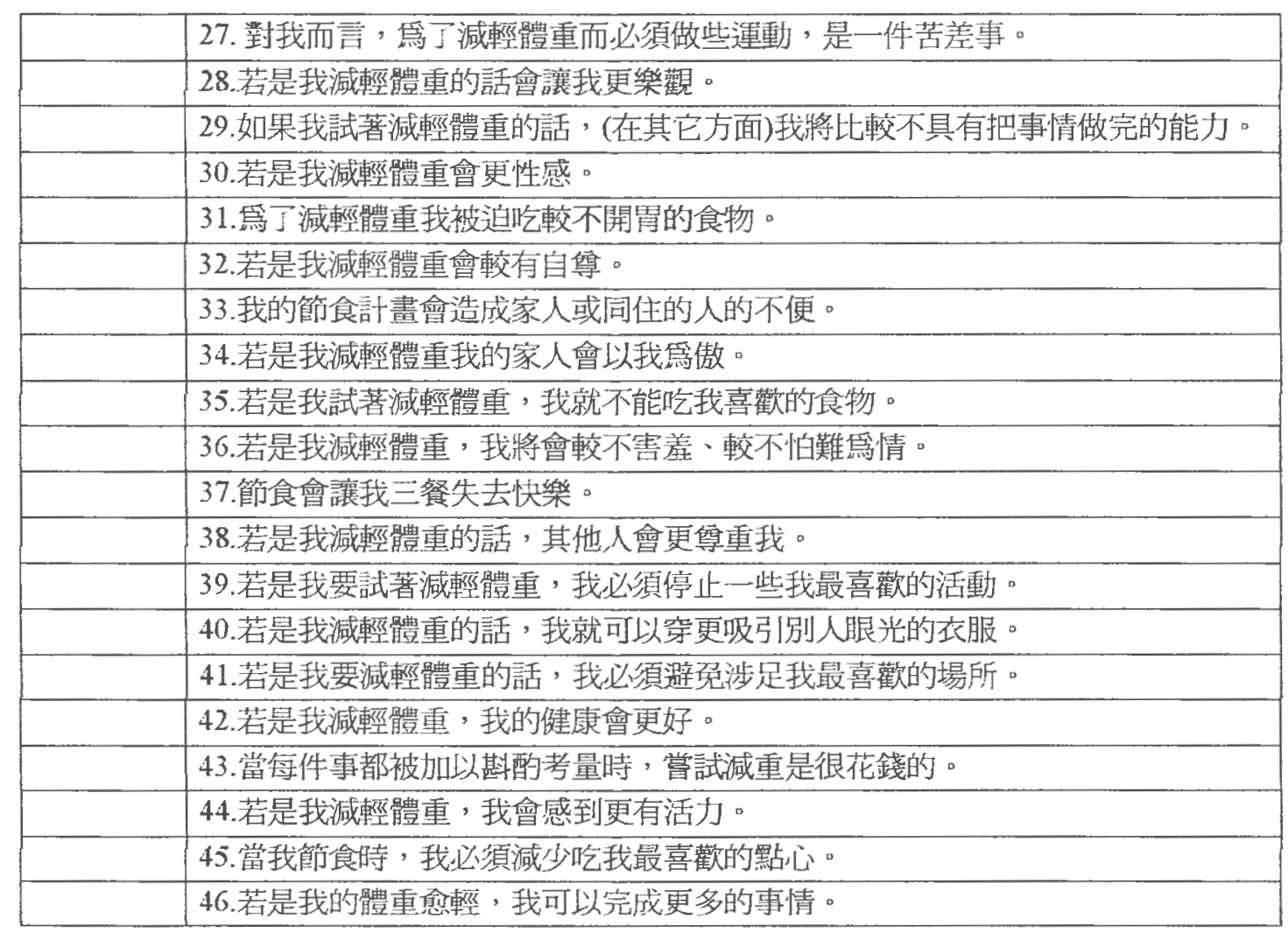




\section{五、飲食控制自我效能量表}

這你量表描述一些典型的飲食情境。每個人都有讓他難以維持體重的狀況。以下有許多關於欴 食習慣和態度的情境, 这你問卷能夠幫助你指出你很難控制飲食的情境。

閱讀以下的情境, 決定你在各種不同的情境下, 你能夠克制飲食的把握程度。換句話說, 假設 你現在正在飲食情境下, 從(1) (一點也沒把握)到(5)(極有把握), 選出「你能夠成功的克制想吃東 西的慾望，的把握程度

$$
\begin{aligned}
& \text { (1) =一點也沒把握你可以克制吃東西的慾望 } \\
& \text { (2)=有一點把握你可以克制吃東西的唂望 } \\
& \text { (3)=中等程度有把握你可以克制吃東西的慾望 } \\
& \text { (๑)=非常有把握你可以克制吃東西的愁望 } \\
& \text { (5)=極有把握你可以克制吃東西的慾望 }
\end{aligned}
$$

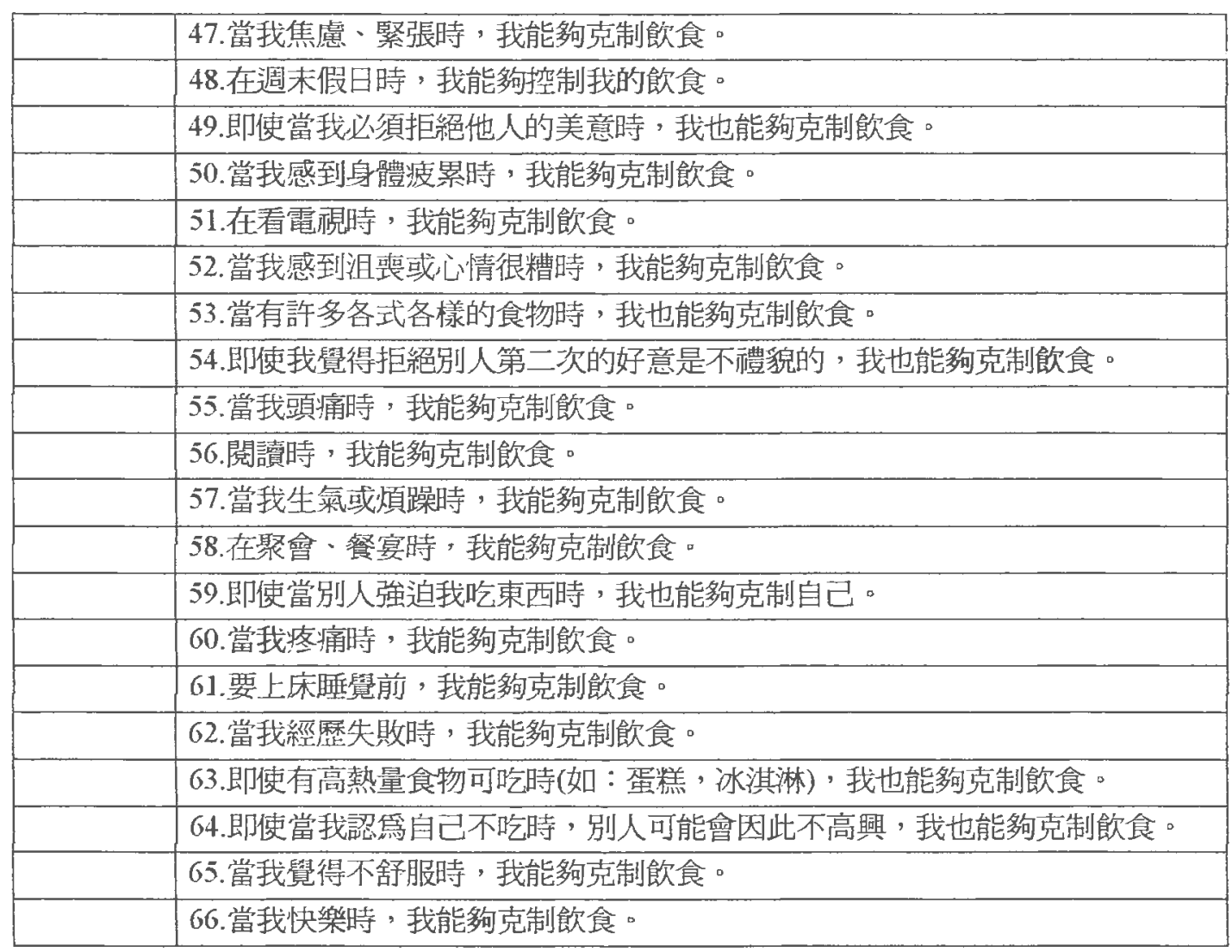




\section{Bibliography}

Abbott, R.D., Wilson, P.W., Kannel, W.B., \& Castelli, W.P. (1988). High density cholesterol, total cholesterol, screening and myocardial infarction. The Framingham Study. Atherosclerosis, 8, 207217.

Akamatsu, R., Otake, K., \& Shimai, S. (2003), Development of Japanese Decision Balance Index (DBI) and stage of behavioral change. Japanese Journal of Health Psychology, 16, 1-9.

Alexander, M.A., Sherman, J.B. \& Clark, L. (1991). Obesity in Mexican-American preschool childrena population group at risk. Public Health Nursing, 8, 53-58.

Allison, D.B., \& Saunders, S.E. (2000). Obesity in North America: an overview. The Medical Clinics of North America, 84, 305-332.

Allison, D.B., Fontaine, K.R., Manson, J.E., Stevens, J., \& VanItallie, T.B. (1999). Annual deaths attributable to obesity in the United States. Journal of the American Medical Association, 282, $1530-1538$.

Alwin, D. F. \& Jackson, D. J. (1981). Applications of simultaneous factor analysis to issues of factorial invariance. In D. D. Jackson \& E. P. Borgotta (Eds.) Factor analysis and measurement in sociological research: A multidimensional perspective. Beverly Hills, CA: Sage

Bandura, A. (1997). Self-efficacy: The exercise of control. New York: W.H. Freeman.

Barrett-Connor, E.L. (1985). Obesity, atherosclerosis and coronary artery disease. Annuals of Internal Medicine, 103, 1010-1019.

Bollen, K. A. (1989). Structural equations with latent variables. NY: Wiley: A leading, readable text on structural modeling.

Bray; G.A.(1985). Complications of obesity: Annuals of Internal Medicine, 103, 1052-1062.

Brislin, R. (1993). Understanding culture's influence on behovior. New York: Harcourt Brace.

Brownell, K.D. (1991) Dieting and the search for the perfect body: where physiology and culture collide Behoviour Therapy, 22, 1-12.

Brugman, E, Meulmeester, J.F., Spee-van der Wekke, A, Beuker, R.J., Zaadstra, B.M., Radder, J.J., \& Verloove-Vanhorick, P.S. (1997). Dieting, weight and health in adolescents in the Netherlands International Journal of Obesity, 21, 54-70. 
Byrne, B.N. (2001). Structural Equation Modeling with AMOS. Rahwah, NJ: Lawrence Erlbaum Associates.

Chang, C-J., Wu, C-H., Chang, C-S., Yao, W-J., Yang, Y-C., Wu, J-S., \& Lu, F-H, (2003). Low body mass index but high percent body fat in Taiwanese subjects: implications of obesity cutoffs. International journal of Obesity, 27, 253-259.

Cheung, G.W., \& Rensvold, R. B. (2002). Evaluating goodness-of-fit indexes for testing measurement invariance. Structural Equation Modeling, 9, 233-255.

Chu NF.(2001). Prevalence and trends of obesity among school children in Taiwan-the Taipei Children Heart Study: International Journal of Obesity, 25, 170-176.

Clark, M.M., Abrams, D.B., Niaura, R.S., Eaton, C.A., \& Rossi, J.S. (1991). Self-efficacy in weight management. Journal of Consulting and Clinical Psychology, 59, 739-744.

Criqui, M.H., Barrett-Connor, E., Holdbrook, M.J., Austin, M., \& Turner, J.D. (1980). Clustering of cardiovascular disease risk factors. Preventive Medicine, 9, 525-533.

Deurenberg-Yap, M, Schmidt, G., van Staveren, W.A., \& Deurenberg, P. (2000). The paradox of low body mass index and high body fat percentage among Chinese, Malays and Indians in Singapore. International Journal of Obesity, 24, 1011-1017.

Deurenberg, P., Deurenberg-Yap, M., Guricci, S. (2002). “Asians are different from Caucasian and from each other in their body mass index/ body fat per cent." Obesity Reviews, 3, 141-146.

Deurenberg-Yap, M., Tan, B.Y., Chew, S.K., Deurenberg, P., \& van Staveren, W.A. (1999). Manifestation of cardiovascular risk factors at low levels of body mass index and waist-hip ratio in Singaporearr-Chinese. Asia Pacific Journal of Clinical Nutrition, 8, 177-183.

Deurenberg, P., Yap, M., van Staveren, W.A. (1998). Body mass index and percent body fat: a metaanalysis among different ethnic groups. International Journal of Obesity, 22, 1164-1171.

DiClemente, C.C., Prochaska, J.O., Fairhurst, S.K., Velicer, W.F., Velasquez, M.M., \& Rossi, I.S. (1991). The process of smoking cessation: An analysis of precontemplation, contemplation and preparation stages of change. Journal of Consulting and Clinical Psychology, 59, 295-304. 
Dietz, W.H. (2002). Medical consequences of obesity in children and adolescents. In: Fairburn, C.G. Brownell, K.D.(eds). Eating Disorders and Obesity: A comprehensive Handbook. Guilford Press: New York, 2002, pp 473-476.

Ebbeling, C.B., Pawlak, D.B., \& Ludwig, D.S. (2002). Childhood obesity: public health crisis, common sense cure. Lancet, 360, 473-482.

Emmons, K.M., Marcus, B.H., Linnan, L., Rossi, J.S., \& Abrams, D.B. (1994). Mechanisms in multiple risk factor interventions: Smoking, physical activity; and dietary fat intake among manufacturing workers. Preventive Medicine, 23, 481-489.

Feinleib, M. (1985). Epidemiology of obesity in relation to health hazards. Annuals of Internal Medicine, 103, 1019-1024.

Gidding, S.S. (1995). A perspective on obesity. The American Journal of the Meducal Sciences, 310 , S68-71.

Greene, G.W., Fey-Yensan, N., Padula, C., Rossi, S., Rossi, J.S., \& Clark, P.G. (in press). Differences in psychosocial variables by stage of change for fruits and vegetables in older adults. Journal of the American Dietetic Association.

Greene, G., \& Rossi, S., (1998). Stages of change for dietary fat reduction over 18 months. Journal of the American Dietetic Association, 98, 529-534.

Greene, G.W., Rossi, S.R., Rossi, J.S., Velicer, W.F., Fava, J.L., \& Prochaska, J.O. (1999). Dietary applications of the stages of change model. Journal of the American Dietetic Association, 99, 673678.

Guillaume, M. \& Lissau, I. Epidemiology. In: Burniat W, Cole T, Lissau I, Poskitt EME (eds). Child and Adolescent Obesity: Causes and Consequences, Prevention and Management. Cambridge University Press: Cambridge, 2002, 28-49.

Guricci, S., Hartriyanti, Y., Hautvast, JGAJ, Deurenberg, P. (1998). Relationship between body fat and body mass index: differences between Indonesians and Dutch Caucasians. Europe Journal of Clinical Nutrition, 52, 779-783.

Hargreaves, M.K., Schlundt, D.G., Buchowski, M.S., Hardy; R.E., Rossi, S.R., \& Rossi, J.S. (1999). Stages of change and the intake of dietary fat in African-American women: Improving stage 
assignment using the Eating Styles Questionnaire. Journal of the American Dietetic Association, $99,1392-1399$.

Hoffmans MDAF, Kromhout D, de Lezenne Coulander C. (1988). The impact of body mass index of 78,612 18-year old Dutch men on 32-year mortality from all causes. Journal of Clinical Epidemiology, 41, 749-756.

Horn, J. L. (1965). A rationale and test for the number of factors in factor analysis. Psychometrika, 32, 179-185.

Huang. Y.C., Wu, J.Y., \& Yang, MJ. (2003)Weight-for-height reference and the prevalence of obesity for school children and adolescents in Taiwan and Fuchien Areas. Journal of Chinese Medical Association, 66, 599-606.

Hubert, H. B. (1986). The importance of obesity in the development of coronary risk factors and disease: the epidemiologic evidence. Annul Review Public Health, 7, 493-502.

Inue S. Criteria for obesity in Japan and Asia Oceania and causes of obesity in Japan. ILSI Symposium and Workshop on Forging Effective Strategies for Prevention and Management of Overweight and Obesity in Asia. Singapore: 22-24 April 2002.

Janis, I. \& L. Mann, L. (1977). Decision Making: A Psychological Analysis of Conflict, Choice and Commitment. New York: Free Press.

Jöreskog, K.G. \& Sörbom, D. (1989). LISREL 7 (2nd ed.). A Guide to the Program and Applications. Chicago: SPSS.

Kaneko, K., Kiriike, N., Ikenaga, K., Miyawaki, D., \& Yamagami, S (1999). Weight and shape concerns and dieting behaviours among pre-adolescents and adolescents in Japan Psychiatry and Clinical Neurosciences. Psychiatry and Clinical Neurosciences, 53, 365.

Kannel, W.B. \& Wilson PWF (1995). An update on coronary risk factors. The Medical Clinics of North America, 79, 951-971.

Kissebah, A.H., Freedman, D.S., \& Peiris, A.N. (1989). Health risks of obesity. The Medical Clinics of North America, 73, 111-138

Lai, S.W., Ng, K.C., Lin, H.F., \& Chen, H.L. (2001). Association between obesity and hyperlipidemia among children. Yale Journal of Biological Medicine, 74, 205-210. 
Lobstein, T, James, W.P.T., \& Cole. T. (2003). Increasing levels of excess weight among children in England. International Journal of Obesity, 27, 1136-1138.

Long, J. Scott. (1983). Covariance Structure Models: An Introduction to LISREL. Beverly Hills: Sage Publications. ISBN: 0-8039-2045-8 (pbk.).

Lowry, R., Galuska, D.A., Fulton, J.E., Wechsler, H., \& Kann, L. (2002). Weight management goals and practices among US high school students: Associations with physical activity, diet, and smoking. Journal of Adolescent Health, 31, 133-144.

Lu, F.H., Yang, Y.C., Wu,J.S., Wu,C.H., \& Chang, C.J.(1998). A population-based study of the prevalence and associated factors of diabetes mellitus in southern Taiwan. Diabetic Medicine: a Journal of the British Diabetic Assaciation, 15, 564-572.

Manson, J., Willett, W.C., Stampfer; M.J., et al. (1995). Body weight and mortality among women. New England Journal of Medicine, 333, 677-685.

Marcus, B.H., Rossi, J.S., Selby, V.C., Niaura, R.S., \& Abrams, D.B. (1992). The stages and processes of exercise adoption and maintenance in a worksite sample. Health Psychology, 11, 386-395.

Mokdad, A.H., Ford, E.S., Bowman, B.A., Dietz, W.H., Vinicor, F., Bales, V.S., \& Marks, J. (2003). Prevalence of obesity, diabetes, and obesity-related health risk factors, 2001. Journal of American Medical Association, 289, 76-79.

Moreno, L.A., Sarría. A., \& Popkin, B.M. (2002).The nutrition transition in Spain: a European Mediterranean country. Europe Journal of Clinical Nutrition, 56, 1-12.

Neumark-Sztainer, D., Rock, C.L., Thornquist, M.D., Cheskin, L.J., Neuhouser, M.L., \& Barnett, M.J.(2000). Weight-Control Behaviors among Adults and Adolescents: Associations with Dietary Intake. Preventive Medicine, 30, 301-391.

Nowak, M., Speare, R., \& Crawford, D.(1996), Gender differences in adolescent weight and shaperelated beliefs and behaviour. Journal of Pediatrics and Child Health, 32, 148-152.

O'Connell, D., \& Velicer, W. F. (1988). A decisional balance measure and the stages of change model for weight loss. International Journal of the Addictions, 23, 729-750.

Okazaki, S., \& Sue, S. (1995). Methodological issues in assessment research with ethnic minorities. Psychological Assessment, 7, 367-375. 
Pan, W.H., Flegal, K.M., Chang, H.Y., Yeh, W.T., Yeh, C.J., \& Lee, W.C. (2004). Body mass index and obesity-related metabolic disorders in Taiwanese and US whites and blacks: implications for definitions of overweight and obesity for Asians. American Journal of Clinical Nutrition, 79, 31 39.

Paquette, M.C. \& Raine, K. (2004). Sociocultural context of women's body image. Social Science \& Medicine, 59, 1047-1058.

Pi-Sunyer, F.X. (1991). Health implications of obesity. American Journal Clinical Nutrition, 53, 1595S-1603S.

Plummer, B.A., Velicer, W.F., Redding, C.A., Prochaska, J.O., Rossi, J.S., Pallonen, U.E., \& Meier; K.S. (2001). Stage of change, decisional balance, and temptations for smoking. Measurement and validation in a large, school-based population of adolescents. Addictive Behaviors, 26, 551-571

Prochaska, J.O. (1994). Strong and weak principles for progressing from precontemplation to action on the basis of twelve problem behaviors. Health Psychology, 13, 47-51.

Prochaska, J.O., DiClemente, C.C., \& Norcross, J.C. (1992). In Search of how people change, American Psychologist, 1102-1114.

Prochaska, J.O., Norcross, J.C., Fowler, J.L., Follick, M.J., \& Abrams, D.B. (1992). Attendance and outcome in a work site weight control program: Processes and stages of change as process and predictor variables. Addictive Behaviors, $17,35-45$.

Prochaska, J.O., Velicer, W.F., Guadagnoli, E., Rossi, J.S., \& DiClemente, C.C. (1991). Patterns of change: Dynamic typology applied to smoking cessation. Multivariate Behovioral Research, 26, 83-107.

Prochaska, J.O., Velicer, W.F., Rossi, J.S., Goldstein, M.G., Marcus, B.H., Rakowski, W., Fiore, C., Harlow, L.L., Redding, C.A., Rosenbloom, D., \& Rossi, S.R. (1994). Stages of change and decisional balance for 12 problem behaviors. Health Psychology, 13, 39-46.

Prochaska, J.O., Velicer, W.F., DiClemente, C.C., \& Fava, J. (1988). Measuring processes of change: applications to the cessation of smoking. Journal of Consulting and Clinical Psychology, 56, 520528. 
Rocchini, A.P., Katch, V., Schork, A., \& Kelch, R.P (1987). Insulin and blood pressure during weight loss in obese adolescents. Hypertension, 10,267-273.

Rodin, J.(1993).Cultural and psychosocial determinants of weight concerns. Annals of Internal Medjcine, 119, 643-645.

Rossi, J.S. (1995). Why do people fail to maintain weight loss? In D.B. Allison \& F.X. Pi-Sunyer (Eds.), Obesity treatment: Establishing goals, improving outcomes, and reviewing the research agenda (pp. 97-102). New York: Plenum.

Rossi, S.R., \& Rossi, J.S. (1999). Concepts and theoretical models. In N. Jairath (Ed.), Coronary heart disease and risk factor management: A nursing perspective (pp. 47-69). Orlando, FL: W.B. Saunders.

Rossi, J.S., Rossi, S.R., Velicer, W.F., \& Prochaska, J.O. (1995). Motivational readiness to control weight. In D.B. Allison (Ed.), Handbook of assessment methods for eating behaviors and weightrelated problems: Measures, theory, and research (pp. 387-430). Thousand Oaks, CA: Sage.

Rossi, S.R., Rossi, J.S., Rossi-DelPrete, L.M., Prochaska, J.O., Banspach, S.W., \& Carleton. R.A. (1994). A processes of change model for weight control for participants in community-based weight loss programs. International Journal of the Addictions, 29, 161-177.

Rössner, S. (2002). Obesity: the disease of the twenty-first century. International Journal of Obesity, $26, \mathrm{~S} 2-\mathrm{S} 4$.

Simopolous, A.P. \& Van Itallie, T.B. (1984). Body weight, health and longevity. Annuals of Internal Medicine, 100, 285-295.

Srinivasan, S.R., Bao, W., Wattigney, W.A., \& Berenson, G.S. (1996). Adolescent overweight is associated with adult overweight and related multiple cardiovascular risk factors: the Bogalusa Heart Study. Metabolism, 45, 235-240.

Strauss, R. S. (1999). Childhood obesity. Current Problems in Pediatrics, 29, 1-29.

Steen, S.N., Wadden, T.A., Foster, G.D., \& Andersen, R.E. (1996). Are obese adolescent boys ignoring an important health risk? The International Journal of Eating Disorders, 20, 281-286.

Troiano, R.P., Flegal, K.M., Kuczmarski, R.J., Campbell, S.M., \& Johnson, C.L. (1995). Overweight prevalence and trends for children and adolescents. The National Health and Nutrition' 
Examination Surveys, 1963 to 1991. Archives of Pediatrics \& Adolescent Medicine, 149, 10851091.

Vallis, M., Ruggiero, L., Greene, G., Jones, H., Zinman, B., Rossi, S., Edwards, L., Rossi, J.S., \& Prochaska, J.O. (2003). Stages of change for healthy eating in diabetes: Relation to demographic, eating-related, health care utilization, and psychosocial factors. Diabetes Care, 26, 1468-1474.

Velicer, W. F. (1976). Determining the number of components from the matrix of partial correlations. Psychometrika, 41, 321-327.

Wang, J., Thomton, J.C., Russell, M., Burastero, S., Shen, J., Tanenbaum, S., Heymsfield, S., \& Pierson, R. N.(1996). Comparison for BMT and body fat percent among Puerto Ricans, Blacks, Whites and Asians living in the New York City area. Obesity Research, 4, 377-384.

Wang, Y., Monteiro, C., \& Popkin, B.M. (2002). Trends of obesity and underweight in older children and adolescents in the United States, Brazil, China, and Russia. American Journal of Clinical Nutrition, $75,971-977$.

World Health Organization. Obesity: preventing and managing the global epidemic. Report of a WHO consultation on obesity; Geneva, 3-5 June, 1997. WHO: Geneva, 1998.

World Health Organization. Obesity: Preventing and Managing the Global Epidemic: WHO Obesity Technical Report Series no. 894. WHO: Geneva, 2000.

Wu, Y.F. The appropriate cutoff points of BMI and waist circumference for identifying obesity and overweight in Chinese adults: a pooling analysis of a cross-sectional sample of 240,000 adults and a follow-up cohort of 76,227 adults. ILSI Symposium and Workshop on Forging Effective Strategies for Prevention and Management of Overweight and Obesity in Asia. Singapore: 22-24 April 2002. 